NBER WORKING PAPER SERIES

\title{
CARBON POLICY AND THE EMISSIONS IMPLICATIONS OF ELECTRIC VEHICLES
}

\author{
Kenneth Gillingham \\ Marten Ovaere \\ Stephanie M. Weber \\ Working Paper 28620 \\ http://www.nber.org/papers/w28620
NATIONAL BUREAU OF ECONOMIC RESEARCH
1050 Massachusetts Avenue
Cambridge, MA 02138
March 2021

We are grateful for conversations and comments from numerous colleagues, including Pei Huang and Brian Reed, and from seminar participants at Yale, London School of Economics, Triangle Resource and Environmental Economics Seminar, Ghent University, Michigan State, UC Dublin, Harvard, and the AERE Summer meetings. This work was developed under Assistance Agreement No. RD835871 awarded by the U.S. Environmental Protection Agency (EPA) to Yale University. It has not been formally reviewed by EPA. The views expressed in this document are solely those of the authors and do not necessarily reflect those of the Agency. The views expressed herein are those of the authors and do not necessarily reflect the views of the National Bureau of Economic Research.

NBER working papers are circulated for discussion and comment purposes. They have not been peer-reviewed or been subject to the review by the NBER Board of Directors that accompanies official NBER publications.

(C) 2021 by Kenneth Gillingham, Marten Ovaere, and Stephanie M. Weber. All rights reserved. Short sections of text, not to exceed two paragraphs, may be quoted without explicit permission provided that full credit, including $(\subset$ notice, is given to the source. 
Carbon Policy and the Emissions Implications of Electric Vehicles

Kenneth Gillingham, Marten Ovaere, and Stephanie M. Weber

NBER Working Paper No. 28620

March 2021

JEL No. H23,Q48,Q53,Q54,Q58,R48

\author{
$\underline{\text { ABSTRACT }}$ \\ reverses. \\ Kenneth Gillingham \\ School of the Environment \\ Yale University \\ 195 Prospect Street \\ New Haven, CT 06511 \\ and NBER \\ kenneth.gillingham@yale.edu \\ Marten Ovaere \\ Ghent University \\ Sint-Pietersplein 6 \\ 9000 Gent \\ Belgium \\ and Yale University \\ marten.ovaere@ugent.be \\ Stephanie M. Weber \\ Yale University \\ 195 Prospect Street \\ New Haven, CT 06511 \\ stephanie.weber@yale.edu
}

Will a carbon tax improve the welfare consequences of policies to promote electric vehicles? This paper examines when a complementarity could exist between carbon pricing and high electric vehicle adoption. We analyze electricity generation in recent years to show that in several regions, carbon pricing interacts with electric vehicle adoption. Under moderate carbon prices like those in effect today, additional electric vehicles will be more likely to be charged with coalfired generation than without carbon pricing. We confirm this finding using a detailed dynamic model that includes the transportation and power sectors. At much higher carbon prices, the effect 


\section{Introduction}

In most countries around the world, environmental policy consists of a patchwork of regulations and incentives. Economists recognize that multiple policy instruments may be needed when there are multiple externalities, such as carbon pricing to internalize damages from greenhouse gases and investments in innovation to address spillovers in the innovation of new green technologies (Jaffe et al. 2005, Popp et al. 2010, Acemoglu et al. 2012, Gillingham \& Stock 2018, Stiglitz 2019). However, it is often the case that environmental regulations interact with each other. For example, emissions leakage is a major argument against the implementation of state-level fuel economy standards at the same time as a federal standard (Goulder et al. 2011) and was also a potential concern in the design of the Obama Administration Clean Power Plan that allowed neighboring states to use different policy instruments (Bushnell et al. 2017).

Interactions between policies may not always be negative though. Consider a policy to promote electric vehicles. Such a policy might be expected to be complementary with carbon pricing, in that it will be more effective at reducing greenhouse gas emissions and improving social welfare if there is also policy in place to decarbonize electricity (Holland et al. 2021). Indeed, many countries around the world are considering or already implementing policies to promote electric vehicles along with more general carbon pricing policies. ${ }^{1}$ In the United States, California has a zero-emission vehicle mandate at the same time as a cap-and-trade system for greenhouse gases. Such a pairing of policy instruments has the potential to improve economic efficiency by helping to address multiple market failures but may lead to consequential interactions between the policies.

This paper demonstrates important interactions between electric vehicle policies and carbon pricing in both an empirical analysis using data from recent years and a prospective analysis. We show that the two policies may not always be complementary and the emissions benefits of electric vehicle policies may actually be reduced in the presence of carbon pricing over a very relevant range of moderate carbon prices. The intuition for this finding is that carbon pricing can reorder the dispatch of electricity generation, pushing coal generation to the margin more often, and increase the demand for electricity, slowing the retirements of coal plants. We empirically document that these effects have been occurring in several regions of the United States in recent years by exploiting variation in the ratio of coal to natural gas prices, which can be mapped to implicit carbon prices as in Cullen \& Mansur

\footnotetext{
${ }^{1}$ For example, China has heavily promoted electric vehicles and has implemented a national carbon capand-trade system as of February 1, 2021. Ireland, the Netherlands, Sweden, and Slovenia plan to ban sales of internal combustion engine cars after 2030 at the same time as the European Trading System ratchets down the number of permits available.
} 
(2017). Yet electric vehicles were less than $2 \%$ of new vehicle sales in 2020, while many electric vehicle offerings are planned in upcoming years. ${ }^{2}$ We thus use a detailed dynamic model including the power and transportation sectors to show how these policy interactions can occur in the upcoming decades, potentially eroding the benefits of vehicle electrification.

Our findings provide a cautionary tale for policymakers. They show how electric vehicle policies can be less effective at reducing long-run emissions under moderate carbon pricing than under no carbon pricing or under much higher carbon pricing, and thus would be less likely to be social welfare-improving. To be clear, carbon pricing alone can be highly effective at reducing emissions, regardless of whether or not it is in concert with an electric vehicle policy. And electric vehicles remain a potential long-run pathway to decarbonization. But the combination of the two policies can lead to the same or even lower emission reductions than the carbon price alone. This can happen under realistic conditions, such as carbon prices similar to those in cap-and-trade systems in California and the Northeast, as well as the carbon prices implicit in the Obama Administration's Clean Power Plan and some proposed Clean Energy Standards in Congress.

We show that this interaction is most likely to happen in regions with coal-fired generation that currently is usually inframarginal but not far from being uneconomic. In such a setting, a moderate carbon price path-in line with many prices in effect or proposed-can push coalfired generation to the margin more often. It is least likely to happen in regions with minimal coal-fired generation, at extremely low or much higher carbon price paths, or when there are extraordinarily inexpensive renewables. These results provide guidance to policymakers deliberating on where it might be most effective to focus electric vehicle policies and whether to bear the political cost of higher carbon prices, such as those that more closely match recent estimates of the social cost of carbon. Further, the results directly influence calculations of the benefits and costs of electric vehicle policies, by highlighting that policy interactions are important to consider.

This study contributes to several growing areas in the economic literature. It relates closely to work on interactions between policy instruments. There is a deep literature on interactions in the tax system in second-best settings. For example, environmental taxes can interact with other, distortionary taxes, such as income taxes, leading to optimal environmental taxes below the Pigouvian tax rate (Bovenberg \& Goulder 1996). More broadly, economists have emphasized that the combination of quantity and price policy instruments can reduce or eliminate the effectiveness of one of the instruments. For example, a carbon tax

\footnotetext{
${ }^{2}$ See https://insideevs.com/news/489525/us-electric-car-market-share-record-2020/ for IHS Markit's estimate of the all-electric market share in 2020. For a list of over 45 expected offerings in model years 2021-2023, see https://www.caranddriver.com/news/g29994375/ future-electric-cars-trucks/.
} 
can render a renewable portfolio standard for electricity generation non-binding or a royalty surcharge on federal coal leasing (a price instrument) can render the Obama-era proposed Clean Power Plan non-binding in some cases when states choose to use quantity instruments to comply with the plan (Gerarden et al. 2020). Similarly, overlapping jurisdictions can also negatively impact the effectiveness of a policy (Goulder \& Stavins 2011). For instance, a state-level fuel economy standard may not reduce emissions on net when there is a binding federal standard (Goulder et al. 2011). In contrast, two policies using price instruments (e.g., a federal carbon tax and a state-level carbon tax) are widely considered to be additive in terms of emission reductions, and indeed desirable to address multiple externalities (Fischer et al. 2017).

Our work shows an important context where two price instruments-such as incentives for electric vehicles and a carbon tax-are not necessarily additive in providing emission reductions, and in fact the effect of the combined policies may be worse than the carbon tax alone. $^{3}$ A key feature that leads to this result is that the interaction in our study occurs across sectors, rather than across jurisdictional borders. This feature of our study is likely to hold in many other policy-relevant settings as well. There has been a substantial policy effort to switch from fossil fuels to electricity in many sectors. There are bans on natural gas in new homes in over a dozen cities across the United States to encourage all-electric construction. ${ }^{4}$ The United Kingdom is currently in the process of banning natural gas boilers for central heat, leaving heat pump and electric options available. ${ }^{5}$ Marine ships at berth are in the process of being electrified in many locations (Gillingham \& Huang 2020). And there is work underway to shift industrial processes, such as steel-making, to electricity or "green hydrogen" produced with excess electricity from renewables or from nuclear plants. ${ }^{6}$ Our findings of unexpected interactions between policies may become more important over time should these transitions gather speed faster than the electricity is decarbonized.

A transition to electric vehicles also may be underway. Our paper contributes to the economic literature on the emissions implications of electric vehicles. Graff Zivin et al. (2014) find considerable heterogeneity in the carbon dioxide emissions from electric vehicles across regions of the United States, resulting in higher emissions from using an electric

\footnotetext{
${ }^{3}$ Conceptually, our work also certainly applies to quantity instruments as well, such as a zero-emission vehicle standard and a carbon cap-and-trade. However, there may be differences in how the forces play out. For instance, the combination of incentives for electric vehicles and a binding economy-wide cap-and-trade can never lead to more emissions than the cap, but our results suggest that the incentives for electric vehicles may raise the cost of the cap-and-trade system.

${ }^{4}$ See https : //www . cbsnews.com/news/cities-are-banning-natural-gas-in-new-homes-because-of-climate-char

${ }^{5}$ See https : //www .express.co.uk/news/uk/1372691/gas-boilers-uk-government-energy-savings-install-gas-b

${ }^{6}$ See https : //www . forbes.com/sites/scottcarpenter/2020/08/31/swedish-steelmaker-uses-hydrogen-instead$? \mathrm{sh}=1 \mathrm{a} 856 \mathrm{~b} 2 \mathrm{e} 2 \mathrm{c} 8 \mathrm{~b}$
} 
vehicle than a gasoline one in many regions. Holland et al. (2016) follow on this line of research by incorporating additional pollutants and found even greater regional variation, but a similar result. ${ }^{7}$ Holland et al. (2020) account for the massive decline in emissions from electricity from 2010 to 2017 to find that, as of 2017, electric vehicles became cleaner than gasoline vehicles on average. Holland et al. (2021) use a dynamic model calibrated to the U.S. market to analyze the welfare effects of bans on fossil fuel-powered vehicles. They show that a much higher substitutability between gasoline vehicles and electric vehicles than is observed today would be needed for a gasoline vehicle production ban to be welfare-improving. A distinguishing characteristic of our work is the focus on how the marginal emissions from electric vehicles would differ with a carbon pricing policy in both an empirical analysis using data from today's electricity grid and a prospective analysis using a detailed dynamic model to simulate tomorrow's electricity grid.

Our research also connects to the broader economic literature on electric vehicles. There is a growing literature on electric vehicle charging infrastructure and network effects in the two-sided electric vehicle market (Springel 2021, Li et al. 2017, Zhou \& Li 2018, Li 2021). This body of literature suggests the existence of indirect network effects that support policy to build out the charging network and/or increase demand for electric vehicles. Other recent work on electric vehicles examines the effects of electric vehicle policies (Clinton \& Steinberg 2019, Muehlegger \& Rapson 2021), determining what electric vehicle buyers would have bought otherwise to assess the effects of electric vehicle incentive policies (Xing et al. 2021, Muehlegger \& Rapson 2020), and estimating how much electric vehicles are driven to inform analyses of electric vehicle policies (Burlig et al. 2021). Our study points out the implications of policies to increase the uptake of electric vehicles when implemented in concert with carbon pricing.

Our quantitative analysis follows a long line of literature in using dynamic simulation models with forward-looking agents to shed light on policy questions. For example, the prospective analysis in our paper has some methodological similarities to Gerarden et al. (2020), although with an entirely different research question and different dynamic model. For the quantitative estimates in our prospective analysis, we use the National Energy Modeling System run on a Yale server. The National Energy Modeling System is a detailed dynamic structural model developed over many years by the U.S. Energy Information Administration (EIA) for use in policy analysis by the U.S. government. We adopt this model due to its granular detail in both the electricity and transportation sectors. The model has a large team of dedicated personnel continually developing it and projections from the model

\footnotetext{
${ }^{7}$ Archsmith et al. (2015) find that considering regional differences in temperature can further reinforce this result because batteries perform poorly in the cold.
} 
are widely used by governments and industry. It has also been used in many peer-reviewed publications and other economic analyses over the years (e.g., Goulder 2010, Morrow et al. 2010, Auffhammer \& Sanstad 2011, Small 2012, Gillingham \& Huang 2019, 2020). By adopting a model commonly used by policymakers, our quantitative estimates have direct relevance to policy discussions in the U.S. government about electric vehicle policy and carbon pricing.

The remainder of this paper is organized as follows. Section 2 provides a conceptual framework to illustrate how carbon pricing can in certain cases reduce the benefits of electric vehicle policy. Section 3 provides empirical evidence showing that these cases are not hypothetical, but are occurring in the current U.S. electricity system. Section 4 outlines the research design of our prospective analysis and presents results indicating that our empirical findings are likely to hold over a range of carbon prices over time. Section 5 concludes.

\section{Conceptual Framework}

The emission reductions from policies to promote electric vehicles will depend on the carbon intensity of driving the electric vehicle versus the alternative, as well as the number of miles driven by each type of vehicle, as has been explored in the previous literature discussed above. The key insight of this paper is that the carbon intensity of driving an electric vehicle will change when there is carbon pricing.

In this section, we present a simple conceptual framework to fix ideas about how this change might occur. We focus on electric vehicles because of the current policy interest, but this framework would also apply to electrifying many other end-uses. The framework is intentionally stylized to quickly provide intuition. It sets aside a set of complicating issues, including the dynamics of power plant operation (e.g., ramping costs), elastic demand (as might be possible with time-varying pricing or demand response programs), market power, transmission constraints, forward contracts, and unplanned outages and other electricity markets outside of the wholesale market. Adding these features should not affect the basic high-level intuition we are aiming to impart.

Our stylized framework begins with a common setting in the United States, where the short-run aggregate supply curve for electricity (often called the 'generation stack') in a particular region is as follows. First, there is the must-take generation (nuclear and renewables, $R$ ) that produce electricity at zero or very low marginal cost. Then, with low prices of natural gas, comes high-efficiency natural gas combined cycle $(N G C C)$ generation. This is followed by coal $(C)$ generation and then by less-efficient natural gas peaker plants $(N G)$, 
which produce at a high cost. $^{8}$ While of course in reality there is going to be some heterogeneity in each of these categories (e.g., inefficient NGCC that is more expensive than coal generation or natural gas peaker plants that are lower cost than coal generation), this stylized presentation of the supply curve is useful for cleanly presenting how carbon pricing will affect the marginal generator.

Panel (a) in Figure 1 shows this illustrative generation stack for an example time period, with the $\mathrm{y}$-axis showing the price in dollars per megawatt (MW) and the $\mathrm{x}$-axis showing the quantity in MW. The dotted line shows a perfectly inelastic demand. One can think of the location of the vertical demand curve in the figure as a fairly typical "average" load on the system and can imagine demand shifting to the left and right throughout the day and over the seasons, depending on the region and types of loads being served.

In Panel (a), additional load due to more electric vehicles being charged on the grid will be powered by natural gas peaker plants in this typical time period. Thus, the emissions implications of electric vehicles are likely to be preferable to gasoline-powered vehicles, due to the much lower emission intensity of natural gas (although line losses and differences in supply chain emissions would have to be taken into account). In Panel (b), we see a shift upwards in the supply curve due to the imposition of a very low carbon price (e.g., a carbon tax close to zero). The shift upwards is greater for coal generation than natural gas generation due to the higher carbon intensity of coal generation. But, the carbon price is so small that there is no substantial change in the order of dispatch. Again, electric vehicles would be powered by natural gas peaker plants in this typical time period.

In Panel (c) of Figure 1, a moderate carbon price is imposed. This carbon price is sufficiently high for coal generation to be pushed up the supply curve and become the marginal generation in this typical time period. Operators try hard to avoid ramping coal plants up and down due to high ramping costs, so our stylized representation may in practice mean that the length of time that a coal plant is "on" is lengthened due to additional demand from electric vehicles, but it could also mean some ramping of already-on coal plants is occurring to meet the marginal demand. The core insight is that adding electric vehicles under a moderate carbon price can lead to more coal generation being used to power the electric vehicles. This erodes the emission reduction benefits from electric vehicles. Of course, the moderate carbon price leads to less coal generation overall-but the key point is that coal generation is more likely to be on the margin in this scenario.

Panel (d) of Figure 1 shows a case where the carbon price is much larger. Here the carbon price raises the cost of coal generation so much relative to natural gas generation that coal generation becomes supramarginal and is not turned on at all. In practice, this

\footnotetext{
${ }^{8}$ We assume away imports and oil-fired generation, as including these would add little to the intuition.
} 
means that many coal plants will run only rarely, at times of very high load. It also implies that additional electric vehicles will likely to be charged by natural gas in most time periods. This is similar to the situation in Panel (b).

Appendix A develops an analytical model based on the conceptual framework to further explore when carbon pricing is most likely to lead to electric vehicles being charged with coal generation. The modeling indicates that for a given demand, when the carbon price reaches a threshold determined by the relative marginal costs and relative carbon intensities of coal and natural gas peaker plants, coal plants will be pushed to the margin. Similarly, for a given demand, when the carbon price reaches a threshold determined by the same factors, coal plants will become supramarginal.

Thus far, this discussion has focused on the short-run implications of adding electric vehicles. However, similar logic might apply in the long run as well. In the long run, the timing of coal plant retirements is crucial. If the carbon price is very low and coal generation remains inframarginal most of the time, then adding electric vehicle load would be unlikely to affect the timing of coal plant retirements. If we have a moderate carbon price that is sufficiently high that coal generation is pushed to the margin more often, then adding electric vehicle load can raise the wholesale price of electricity and help keep those coal plants economic longer. This would delay coal plant retirements and decrease the economic incentive to build new, cleaner plants. In contrast, if we have a much higher carbon price so that coal generation becomes supramarginal most of the time, the coal plants will already be uneconomic and will be retired anyway. Separately, it is also true that in the long run prices may be passed on to consumers and demand may be more responsive. Carbon pricing may also lead to more renewables being built, making it more likely that coal becomes supramarginal on the long run.

\section{Empirical Analysis}

In this section we use recent historical data to assess whether there have been short-run shifts in electricity dispatch consistent with changes suggested by our conceptual framework.

\subsection{Research Strategy}

Our conceptual framework explains why there might be a range of carbon prices that lead coal generation to be on the margin more often due to changes in the relative prices of coal and natural gas generation. To examine this empirically, we would ideally leverage exogenous variation in carbon prices. However, there is very limited variation in carbon prices in the 
United States. Moreover, the carbon prices that do exist tend to be in regions that rely little on coal generation, such as California or states in the Northeast under the Regional Greenhouse Gas Initiative. The linchpin of the conceptual framework is that carbon pricing can lead coal plants to replace gas-fired generation on the margin, which could increase the carbon intensity of marginal electricity generation. Without coal plants, carbon prices would not raise the emission intensity on the margin. Thus, our empirical research strategy focuses on variation in the relative prices of natural gas and coal generation, rather than variation in carbon prices, and focuses on regions with sufficient coal generation.

Our research strategy draws from insights in Cullen \& Mansur (2017), which is focused on inferring short-run carbon abatement costs in the electricity sector. Cullen \& Mansur (2017) rely on exogenous shocks in natural gas prices primarily coming from technological advances in hydraulic fracturing (i.e., 'fracking') to provide variation in the relative prices of natural gas and coal. They then infer how dispatch, and thus emissions, change when natural gas generators become more competitive with coal plants. Our approach also leverages recent variation in natural gas prices from the continued technological advances in fracking and the build out of pipelines in different regions to serve new natural gas drilling. In addition, similar to Cullen \& Mansur (2017), we are also interested in how the relative prices of natural gas and coal influence dispatch of coal and natural gas generation. However, our focus is on how changes in the relative prices of natural gas and coal affect the likelihood of coal plants being on the margin, rather than inferring carbon abatement costs.

The mapping from the relative prices of natural gas and coal to the carbon price does not hold under all conditions. Cullen \& Mansur (2017) provide a detailed discussion of when the price ratio of coal to natural gas can be used as a sufficient statistic for carbon prices in the context of analyzing electricity dispatch and emissions. A first condition is that marginal costs alone determine generation decisions, which should be the case in a competitive market. If marginal costs determine generation decisions, then the ordering of generators by marginal costs will not change regardless of the level of the fuel costs. Another condition is that shortrun dynamic considerations do not heavily influence fuel switching between coal and natural gas. For example, coal plants are expensive to ramp up and down, which can lead them to stay on during short windows with low prices to avoid ramping. However, evidence suggests that these considerations are a secondary factor affecting fuel switching (Cullen 2015). A third condition is that firms must also respond to shocks in marginal costs due to fuel inputs in the same way as shocks in marginal costs due to carbon taxation. Fabra \& Reguant (2014) provide evidence from the Spanish market that firms respond similarly, suggesting that this condition is likely to hold.

Another condition that is important for the interpretation of any results using this strat- 
egy is that demand is perfectly inelastic. This is a standard assumption for analyzing shortrun questions in electricity markets, but is not likely to hold in the long run. Responsive demand could lead to lower overall electricity load at higher carbon prices and the marginal generator may not need to be dispatched.

A final condition is that long-run investment decisions have a negligible effect on shortrun fuel switching. For instance, carbon prices will likely lead to investment in renewable generation over a longer time horizon. This would shift the entire aggregate supply curve for electricity to the right and lead to an imperfect mapping between carbon prices and the price ratio. Thus, Cullen \& Mansur (2017) emphasize that their results are valid for understanding short-run fuel switching between coal and natural gas but not long-run dispatch decisions. Similarly, our research design here has only a short-run interpretation.

We focus our research on four regions where there is substantial coal and natural gas generation. These four regions cover much of the middle of the country and are served by four very large independent system operators: Electric Reliability Council of Texas (ERCOT), Midcontinent Independent System Operator (MISO), PJM Interconnection, and Southwest Power Pool (SPP). See Figure 2 for a map of the independent system operator regions in the United States. Fuel switching between coal and natural gas is likely to be small or minimal along the West Coast and in the Northeast due to very little reliance on coal, but fuel switching may occur in many other regions, including the four regions we study.

Our research question in this section asks how changes in the relative prices of coal and natural gas influence whether coal or natural gas is being used to serve additional load on the system. To examine this, we segment our sample based on the ratio of coal to natural gas prices. By segmenting the data, we can clearly observe whether the fuel source of the generator that is on the margin adjusts when the ratio exhibits large changes. For example, when the ratio is high, coal is relatively more expensive than natural gas, as might happen with high carbon prices.

Thus, for each subsample based on the coal-gas ratio, each region, and for both coal and natural gas, we estimate the following model of generation of fuel type $f$ at hour-in-thesample $t$ :

$$
q_{f t}=\sum_{p \in\{\text { peak,offpeak }\}} \beta_{p} 1(\text { peak })_{p} l_{\text {oad }}+\gamma_{S} q_{\text {solar }, t}+\gamma_{W} q_{\text {wind }, t}+\delta_{h m y}+\epsilon_{f t} .
$$

We use $q_{f t}$ to denote the quantity of electricity generated by fuel type $f$ in hour $t$. $1(\text { peak })_{p}$ is an indicator variable for the period $p$ being a peak period of the day, where the peak period is defined as any hour between 7 am and $10 \mathrm{pm}$ on weekdays. We estimate a 
separate coefficient for peak and off-peak to shed light on how the results may be different depending on when electric vehicle owners charge their vehicles. load $_{t}$ refers to the average electricity demand on the system at time $t$. Our coefficients of greatest interest are $\beta_{\text {peak }}$ and $\beta_{\text {offpeak }}$ for coal generation as they quantify the effect of additional load on coal generation, such as from electric vehicles. ${ }^{9}$

Because intermittent renewable generation can affect the need for conventional generation, we control for hourly solar output $q_{\text {solar }, t}$ and hourly wind output $q_{\text {wind, } t}$ (Fell \& Kaffine 2018). We also include fixed effects $\delta_{h m y}$ for each hour-of-the-day interacted with the monthof-the-sample to flexibly account for seasonality and daily patterns in load and fossil generation throughout our sample. $\epsilon_{f t}$ is the error term.

Our model is similar to the specification in Holland et al. (2016). One difference is the addition of the controls for intermittent renewables to account for greater renewables market share in recent years (the Holland et al. (2016) sample ends in 2012). Another is that we focus on peak versus off-peak hours instead of hour of the day for our primary results. A third difference is that we segment the sample based on the coal to natural gas ratio. Identification in both our setting and in Holland et al. (2016) is based on shocks to electricity load after controlling for a rich set of fixed effects. For example, one source of variation is that several more people may happen to be home in a particular hour of a particular month than the average, leading to a positive shock for electricity load. These shocks should be plausibly random with respect to operator decisions at coal and natural gas power plants.

\subsection{Data}

We bring together a rich data set from several public sources that covers from January 2014 to December 2019. Hourly load and net generation by energy source (e.g., coal, natural gas, nuclear, hydro, solar, wind, import, other) are obtained from the independent system operators. We use EIA Form 923 for plant-level monthly data of coal and natural gas fuel expenditures, electricity generation, and fuel consumption. These also include data on each generation plant's heat rate, which is an inverse measure of fossil fuel power plant efficiency in units of million Btus (MMBtu) burned per megawatt-hour (MWh).

For every plant, we calculate the variable fuel cost per MWh for every month as the product of the plant's heat rate and fuel cost (in units of $\$ / \mathrm{MMBtu}$ ) for transactions with a maximum contract duration of one year. We combine these data with EIA Form 860M to match plants to the four regions. We then calculate a generation-weighted monthly gas and

\footnotetext{
${ }^{9}$ Note that in the presence of congestion in the transmission grid, the marginal plant charging an electric vehicle might differ between locations.
} 
coal price per MWh for every region. ${ }^{10}$

Table 1 reports the mean and standard deviation for the main variables of interest for each region. Panel A shows the summary statistics for the hourly electricity demand in the region and hourly generation by fuel type. PJM is the largest market, with over three times the load in SPP. In MISO and SPP, the coal-fired generation is almost double gas-fired generation, but the two fuel sources generate about the same amount in PJM. In ERCOT, there is less coal generation than natural gas generation. In each of the regions, there is a sizable amount of wind generation, while solar generation is still fairly limited.

Panel B shows the summary statistics for heat rates and emission rates. The heat rates are similar across regions, especially for coal generation. SPP has the highest heat rate for natural gas, indicating it has the least-efficient natural gas plants on average. ${ }^{11}$ Combining this with hourly generation, the average carbon dioxide emission rate is highest in MISO and SPP. The average rate is lowest in PJM, where nuclear plants produce more than a third of all electricity, and is almost equal to the emission rate of gas-fired generation.

Panel C presents coal and natural gas prices. We observe that the price of coal is relatively stable across the regions, with little variation. In contrast, the price of natural gas has considerable variation, so we have substantial variation in the gas-to-coal price ratio. Coal prices are on average below natural gas prices, such that the mean coal-to-gas ratio is below one in every region. The ratio is lowest in SPP and highest in PJM.

The substantial variation over time in the coal-to-gas price ratio can be seen in Panel (a) of Figure 3. ${ }^{12}$ The coal-to-gas price ratio is the lowest early in the sample in 2014. There is a slight trend upwards, as more natural gas drilling occurs and more pipelines open. There are a few shocks due to periods of especially cold weather and/or pipeline constraints. For example, January 2018 included a period of prolonged cold weather that affected much of the eastern United States, leading to much higher natural gas demand for building heating and thus higher prices in the unseasonably coldest areas. ${ }^{13}$ Thus, PJM shows a strong spike in the gas-to-coal ratio, while SPP shows little difference.

\footnotetext{
${ }^{10}$ Appendix B provides more detail on the calculation and presents the time series of coal and natural gas prices in all four regions. Our approach largely follows Cullen \& Mansur (2017) and we find that additional refinements, such as incorporating the effect of sulfur, ash, and Btu content make little difference to our findings.

${ }^{11}$ Note that the average heat rate of gas-fired plants is going to be the weighted average of natural gas combustion turbines (11.5-12.5 MMBtu/MWh) and combined-cycle natural gas plants (7.4-8.1 MMBtu/MWh).

${ }^{12}$ This figure presents the ratio in terms of the cost of coal-fired and gas-fired generation, which combines the heat rate with the fuel prices to provide the ratio that is relevant for fuel-switching decisions. In Appendix B, we show that the figure looks very similar if we plot the ratio of the fuel prices themselves. We ran robustness checks and our findings would not change if we used the fuel prices rather than the generation costs to determine the thresholds to segment our sample.

${ }^{13}$ See https://www.pjm.com/-/media/library/reports-notices/weather-related/ 20180226-january-2018-cold-weather-event-report.ashx.
} 
Panel (b) of Figure 3 maps the coal-to-gas price ratios to implicit carbon prices. We refer to these as 'implicit' carbon prices because the mapping holds under the conditions discussed above, and most importantly would be unlikely to hold in the long run. ${ }^{14}$ Panels (a) and (b) of Figure 3 align in the sense that high values in the coal-gas ratio, as in the spring of 2017 or 2019, match high implicit carbon prices. A key observation from Panel (b) is that the variation in the coal-to-gas ratio is sufficiently large that it maps to swings in implicit carbon prices ranging from near zero to as high as $\$ 160 /$ ton $\mathrm{CO}_{2}$.

\subsection{Estimation Results}

\subsubsection{Empirical evidence of coal generation pushed to the margin}

Our coefficients of greatest interest are $\beta_{\text {peak }}$ and $\beta_{\text {offpeak }}$, and we run the regression in (1) separately for different levels of gas-to-coal price ratios. Thus, due to the large number of coefficients, we plot the coefficients in figures to show how the share of marginal generation that is powered by coal-fired power plants changes with higher gas-to-coal price ratios. We use five quantiles of evenly sized subsamples, where the quantiles in terms of gas-to-coal price ratios map roughly to implicit carbon prices of around $\$ 8, \$ 27, \$ 35, \$ 40, \$ 50$, and $\$ 120$ per ton of $\mathrm{CO}_{2}$ respectively.

Figure 4 presents the results. Each panel represents a different region. We plot the coefficients of each of the five quantiles of implicit carbon prices and connect them with lines. The solid line represents off-peak hours, while the dashed line represents peak hours. For example, in Panel (a), the point on the solid line at the first implicit carbon price quantile indicates that just over $50 \%$ of marginal generation during off-peak hours will be powered by coal in MISO when there is a minimal carbon price. The point on the solid line at the fifth implicit carbon price quantile shows that with much higher implicit carbon prices nearly $60 \%$ of marginal generation during off-peak hours will be powered by coal in MISO. These results are significantly different from each other. ${ }^{15}$

The findings in Figure 4 are striking. For MISO and SPP, the share of marginal generation powered by coal generally increases with the carbon price. In the peak hours the share of marginal generation from coal is much lower than the off-peak hours, but with higher carbon prices, the share for the peak and off-peak begins to converge. This is consistent with coal plants being pushed up the aggregate supply curve as cheaper natural gas becomes

\footnotetext{
${ }^{14}$ To perform this mapping, we have to normalize the level of the prices to some value, and we use the average 2014 value throughout the sample to provide a clean illustration of the variation in implicit carbon prices. For expositional purposes, we also added a constant intercept in all four regions sufficient to ensure that the lowest value (PJM in January 2014) is positive.

${ }^{15} \mathrm{In}$ a two-sided t-test for differences in means, we find a p-value of 0.000 .
} 
inframarginal. The logic for this follows from our conceptual framework: marginal demand during peak periods was previously being mostly met with natural gas, but the higher implicit carbon prices mean that coal generation becomes more expensive and is used to serve marginal demand more often in the peak hours. In short, the upward slope of the curve for MISO and SPP, and the convergence of peak and off-peak, indicate that the carbon price is pushing coal plants to the margin. Recall that MISO and SPP have much more coal generation than natural gas generation during our time frame (Table 1). ERCOT shows a similar pattern for peak hours, but in the off-peak hours coal on the margin begins to very slightly decline with higher carbon prices, although the overall trend is upward. This is again consistent with coal plants being pushed up the aggregate supply curve and becoming more marginal during peak hours.

PJM differs from the other three regions. At a low implicit carbon price, the share of marginal generation powered by coal is higher than any of the other regions. But more importantly, we also observe that the share of marginal generation that is powered by coal generally decreases with higher carbon prices, in contrast to all of the other regions (where it is constant or slightly increasing at higher levels of implicit carbon prices). One possible explanation for the inverse relationship between the share of coal-fired marginal generation and implicit carbon prices is that coal is being pushed to the margin and then becoming supramarginal and (eventually) uneconomic. We will explore this possible explanation below.

\subsection{2 $\mathrm{CO}_{2}$ emissions from marginal generation}

But first we turn to what these findings imply for emissions from marginal generation, which is highly relevant for electric vehicle policy. We perform the same estimations as those that created Figure 4, only focusing on using natural gas generation as the dependent variable. The results are the inverse of those in Figure 4 because in all of the regions, coal and natural gas comprise over $90 \%$ of marginal generation. In fact, in MISO, SPP, and ERCOT, coal and natural gas generation make up almost $100 \%$ of marginal generation. In PJM, marginal demand is also met by imports, dual-fuel generation, and oil generation, at $5 \%, 3 \%$, and $2 \%$,

respectively. The results showing marginal generation by natural gas in each region over the different carbon prices are included in Appendix Figure C.1.

We obtain the average $\mathrm{CO}_{2}$ emission rate from marginal generation by multiplying the shares of gas and coal in marginal generation with their respective carbon emission intensity. We calculate the monthly carbon emission intensity per region from EIA Form 923 data. Figure 5 presents the emission rates for marginal generation in each region over the five 
quantiles of implicit gas-to-coal prices. ${ }^{16}$ Due to the increased coal generation on the margin at higher carbon prices for MISO, SPP, and ERCOT, we find that the average emission rate is increasing with the level of the implicit carbon price. The increase in emission rate with the implicit carbon price is even stronger for peak hours, but the emission rate during off-peak hours always remains higher. Importantly, the difference between the emission rate in the peak and off-peak becomes smaller with higher carbon prices, consistent with the convergence we saw for MISO, SPP, and ERCOT in Figure 4.

Figure 5 also presents the average $\mathrm{CO}_{2}$ emission rate from marginal generation for two electric vehicle weekday charging profiles from the Electric Power Research Institute (EPRI). ${ }^{17}$ The "uncontrolled charging profile" assumes that electric vehicles start charging as soon as they arrive at home, such that the bulk of additional electricity demand is between $4 \mathrm{pm}$ and $11 \mathrm{pm}$. Thus, most of the electricity for charging will be drawn during peak hours. The "maximum delay" charging profile assumes that electric vehicles start charging at the latest possible time to be fully charged just before being used in the morning, such that the bulk of additional electricity demand is between 4 am and 10 am (mostly off-peak hours). To develop these emission rate estimates, we estimate equation (1) for each hour of the day rather than peak and off-peak periods (see Appendix $\mathrm{C}$ for details). ${ }^{18}$ The emission rate results for the two charging profiles for MISO, SPP, and ERCOT mirror the results for the peak and off-peak in each region. The uncontrolled charging profile has a similar emission rate for marginal generation as the rate for the peak hours and the maximum delay charging profile has a similar emission rate as the rate for the off-peak hours. These charging profiles are useful for bringing empirical data to bear on when the marginal electric vehicle owners might actually be charging.

The results in Figure 5 for PJM largely match those for PJM in Figure 4. In contrast to the other three regions, the emission rate in PJM is slightly decreasing with higher implicit carbon prices. In addition, the gap in the emission rate between the peak and off-peak grows with higher implicit carbon prices because the peak emission rate drops more. Again, this may be because the coal plants that are on the margin during peak hours become supramarginal and uneconomic with higher implicit carbon prices.

These results suggest that for large swaths of the United States, coal plants can be pushed to the margin and be more likely to power new loads with higher implicit carbon prices,

\footnotetext{
${ }^{16}$ The emission rate for marginal generation may be slightly underestimated because marginal plants are likely less efficient than the average plant, and thus the $\mathrm{CO}_{2}$ emission intensity of marginal plants is likely higher than the average.

${ }^{17}$ Appendix Figure C.2 shows these charging profiles.

${ }^{18}$ Appendix Figures C.3 to C.5 present the resulting coefficients of marginal coal, gas, and emissions for every hour of the day and for three quantiles of the implicit carbon price.
} 
implying that higher carbon prices can reduce the emissions benefits of electric vehicles. It is important to note that the average share of coal generation is still declining with higher implicit carbon prices (see Appendix Figure C.6). So a higher carbon price will still reduce total $\mathrm{CO}_{2}$ emissions, even if it means that in some regions additional electric vehicles may be more likely to be charged with coal.

\subsubsection{When is coal likely to be pushed to the margin?}

Our empirical results display some heterogeneity across regions, with PJM being quite different than the other three regions. All four regions have sizable market shares of coal generation, which allows for coal to gas switching with the imposition of a carbon price. This raises the question of why PJM is different and has less of the marginal generation provided by coal when there are higher implicit carbon prices.

Table 2 presents a set of statistics that help clarify why PJM is so different than the other regions. The first three columns show the capacity factor for coal at three different quantiles of implicit carbon prices. ${ }^{19}$ The capacity factor is defined as the ratio of the average output of a plant to the maximum possible output. The capacity factor provides a sense of how often existing plants are running and how much of their capacity they are using when they are running. In the other three regions, the capacity factor is declining with higher implicit carbon prices. However, in PJM, the capacity factor does not decline.

Why would we not see a decline in the the coal capacity factor in PJM when the implicit carbon price is much higher? The main reason is that there was a much larger retirement of coal capacity in PJM than the other regions during our sample period, as is shown in Column (4) of Table 2 . This again suggests that coal plants in PJM are becoming supramarginal more often, as some of these plants became entirely uneconomic and end up retiring entirely.

Column (5) of Table 2 helps explain why so much coal is being retired. A striking 23 GW of natural gas capacity was added in PJM over our sample period, which far exceeds the additions in the other regions. The additional natural gas capacity (which comes in at low cost), provides a force similar to the effect of increasing coal-to-gas ratios and can push coal even further up the aggregate supply curve to be supramarginal more often.

Columns (6) and (7) indicate that change in the overall average annual load and the growth of renewables during our sample period was not appreciably different in PJM than the other regions. ${ }^{20}$ These findings paint a picture of the different dynamics that have been

\footnotetext{
${ }^{19}$ We calculate the installed coal and gas generation capacity per region per month using EIA Form $860 \mathrm{~m}$. We use the nameplate capacity - which might be $5 \%$ to $10 \%$ higher than the actual capacity available for generation - including backup plants that do not run very often.

${ }^{20}$ In the Appendix we have a set of figures to provide more details on how PJM differs from the other regions: Appendix Figure C.7 for capacity factors, Appendix Figure C.8 showing natural gas capacity over
} 
occurring in PJM and help explain why PJM is different than the other regions during our sample period in the marginal generation from coal. They also suggest that for coal plants to be pushed to the margin by carbon pricing, there must not only be a sufficient amount of coal capacity that is near the margin, but that the coal plants must be economic enough that they do not become supramarginal and pushed towards retirement.

\section{Dynamic Simulation}

Thus far, we have empirically demonstrated that increases in the ratio of coal to gas prices, as would occur with carbon pricing, can shift coal generation to the margin in the short run. This implies that in the short run, electric vehicle policies may not reduce emissions as much when implemented in concert with carbon pricing because they will be charged more often using coal-fired power.

In the long run, this effect may not hold. A rapidly increasing market share for electric vehicles may increase electricity demand much beyond the margin. There may be retirements of old coal power plants and builds of new renewable generation. This may be especially important if renewable energy technologies, such as wind and solar, continue to drop in cost. This motivates our decision to use a dynamic model to develop projections into the future to provide insight into whether our empirical finding of coal being pushed to the margin in the short run is also relevant in the long run. The National Energy Modeling System is well-suited to develop quantitative estimates of the effects of electric vehicle policies with and without carbon pricing.

\subsection{The National Energy Modeling System}

The National Energy Modeling System is a disaggregated dynamic equilibrium model of the U.S. energy system. It includes a detailed representation of all major energy markets, including transportation and the electric power sector. In the electric power sector, retirement, new construction, and retrofit decisions are based on maximizing the net present value with perfect foresight of future prices. The model equilibrates supply and demand in all markets, iterating until convergence to endogenously solve for equilibrium prices in each year. ${ }^{21}$ The model includes the full supply chain, beginning from imports and extraction of unprocessed fuels to final end uses. For each primary, intermediate, or final energy market, there are calibrated supply curves based on geologic constraints and engineering data, as well as demand

time, and Appendix Figure C.9 showing coal capacity over time.

${ }^{21}$ Oil prices are the one exception; they are exogenously set. 
curves based on econometric analysis by the Energy Information Administration.

The model contains 13 modules covering different sectors and produces detailed quantitative estimates of energy consumption and emissions through 2050 at the national and regional level. The regional disaggregation varies depending on the sector, but most sectors, including the transportation sector, are based on the nine Census divisions. The electricity sector is an exception and has 22 regions based on boundaries drawn by the North American Electric Reliability Corporation. ${ }^{22}$ The model includes all major environmental and energy regulations that currently exist. Many regulations have an expiration date, and the model assumes these regulations sunset, and thus become non-binding, upon expiration.

The transportation sector covers all primary modes of transportation, including air travel, freight transport, and miscellaneous transportation energy demand (EIA 2016). New light duty vehicle sales are modeled with a nested logit framework, calibrated to match current sales. New sales adjust over time based on projections of future incomes, demand for owning a vehicle, fuel prices, and cost declines of different technologies. ${ }^{23}$ The nested logit framework includes fuel economy, price, vehicle range, fuel availability, battery replacement cost, performance, home refueling capability, maintenance costs, luggage space, and make and model diversity within vehicle class. The types of vehicles in the model include conventional (gasoline, diesel, flex-fuel ethanol, bi-fuels, CNG/LNG, LPG), hybrid-electric, dedicated alternative-fuel (CNG/LNG and LPG), fuel cell (gasoline, methanol, hydrogen), and electric (100- and 200-mile). Cars and light trucks each have six size classes: minicompact, subcompact, compact, midsize, large, and 2-seater for cars, and light trucks are available as commercial or large pickups, vans, and utility vehicles. Existing vehicles are exogenously scrapped as they age using vehicle survival curves. The model uses exogenous charging profiles for electric vehicles.

Automakers add new technologies to vehicles as the technologies become less expensive. They are also subject to the constraints of Corporate Average Fuel Economy standards and state-level zero-emission vehicle standards. The model includes an iterative process to meet the fuel economy standards. If an automaker is in violation of the standards, it can add technologies, change the vehicles they produce, or reduce attributes such as horsepower or weight. Once these decisions are made for all automakers, the vehicle choice model will then provide the new market shares, and compliance will be assessed. This process continues until all automakers are in compliance. The model insures compliance with zero-emission vehicle

\footnotetext{
${ }^{22}$ See Figure D.1 in Appendix D for maps of the regional disaggregation for the transportation and electricity sectors. Note that the very latest version of the model, as of 2021, has increased the number of electricity sector regions to 25 .

${ }^{23}$ New vehicle technologies follow a learning curve calibrated to existing technology costs. Thus, greater adoption of the technology lowers the cost of adding the technology to a vehicle.
} 
(ZEV) standards in a similar way in the relevant regions: solving for the unconstrained ZEV sales and adjusting for compliance. It iterates over both regulations.

The electricity market module makes capacity planning and generating decisions for the 22 regions based on forecasted electricity demand from other sectors, fuel prices, technology costs, emissions policies, and macroeconomic parameters, such as capital costs. The model includes a range of fossil fuel, nuclear, and renewable technologies, including not-currentlyeconomic technologies like advanced nuclear that may become cheaper exogenously over time and through learning-by-doing. ${ }^{24}$ Electricity demand is incorporated into representative load curves across seasons, times of day, and regions, and engineering constraints in generation are incorporated. Trading is permitted across markets subject to transmission constraints.

Based on expected demand, the model makes decisions about new construction of generating facilities, possible retirement of existing plants, and the adoption of emissions mitigation technology. These capacity expansion decisions are made to minimize expected costs, where costs include capital, operations and maintenance, and fuel costs, subject to environmental regulations (e.g., those covering local air pollutants and $\mathrm{CO}_{2}$ at the state, regional, or federal level). Electricity dispatch is determined simultaneously across regions using a least-cost optimization of plants based on operating and transmission costs, with constraints based on emissions limits, engineering characteristics, and required maintenance. Electricity plants are price takers. The electricity market module ultimately outputs electricity prices, fuel consumption, and emissions.

Our study uses the National Energy Modeling System run on a Yale server, and thus at EIA's request, we refer to it hereafter as "Yale-NEMS." We compile the code given to us by EIA, and make only very minor modifications to the code to allow it to run on our server and to output additional results. We are able to replicate EIA's Annual Energy Outlook reference case results (to a rounding error). Our baseline in this study is the 2017 Annual Energy Outlook, but we run robustness checks with scenarios that more closely align with the results in the 2020 Annual Energy Outlook to ensure that changes over the past few years do not appreciably change our results. ${ }^{25}$

The model we are using is a complex structural model with numerous relationships and parameters. A natural question thus arises as to whether the projections from the model are credible and useful for policy analysis. There are several reasons to believe that the model is

\footnotetext{
${ }^{24}$ The full list of electricity generating technologies includes existing coal without flue gas desulfurization (FGD), existing coal with FGD, new pulverized coal with FGD, advanced clean coal technology, advanced clean coal technology with sequestration, gas/oil steam, conventional gas/oil combined cycle, advanced combined cycle, advanced combined cycle (with sequestration), conventional combustion turbine, advanced combustion turbine, fuel cells, distributed generation, conventional nuclear, advanced nuclear, conventional hydropower, geothermal, solar-thermal, solar-photovoltaic, wind, wood, and municipal solid waste.

${ }^{25}$ We use the Annual Energy Outlook reference case without the Clean Power Plan.
} 
capturing relevant policy dynamics. There is an entire team at EIA developing the model for use by the U.S. Congress and executive branch. ${ }^{26}$ It is also widely used for analysis by consulting firms such as the Rhodium Group and OnLocation, and the Annual Energy Outlook projections from the model are used for corporate decision-making by numerous companies in the energy industry. The academic literature using the model is also extensive, and includes analyses of policies covering nearly all major energy sectors, including transportation and electricity (Goulder 2010, Morrow et al. 2010, Auffhammer \& Sanstad 2011, Cullenward et al. 2016, Mignone et al. 2017, Gillingham \& Huang 2019, 2020). The projections from the model have been critiqued as being slow to adjust to changes in the market (O'Neill \& Desai 2005, Auffhammer 2007, Wilkerson et al. 2013). Hence, we run sensitivity analysis, including scenarios with much more optimistic renewables costs, to see what happens if the energy transition is more rapid than EIA's analysts expect.

\subsection{Policy Scenarios}

We develop a set of scenarios to illustrate the interactions when electric vehicle policies are implemented along with carbon pricing. These are then compared to the Annual Energy Outlook reference case.

\subsubsection{High Electric Vehicle Market Share}

There are many possible ways for policymakers to incentivize electric vehicles. Direct subsidies, zero-emission vehicle standards, public funding of charging infrastructure, research and development tax credits, and direct public research into new technologies are among many of the possible approaches that governments could use to foster long-run uptake of electric vehicles. Yet, the fundamental concepts discussed in our conceptual framework should apply regardless of what the exact policy design is, as long as it leads to additional electric vehicles charging on the grid. Thus, we focus on a scenario with a high level of electric vehicles and are agnostic as to the exact policy that leads to this outcome. This approach allows for greater generalizability of our results to many possible policies that could lead to a high market share for electric vehicles.

There are numerous industry projections that show electric vehicles reaching a much higher market share in the upcoming decades. One of the most prominent of these projections is the annual Bloomberg New Energy Finance (BNEF) Electric Vehicle Outlook. In the 2020 BNEF Outlook, electric vehicles are projected to increase from less than $2 \%$ market share

\footnotetext{
${ }^{26}$ The model is extensively documented: see https://www.eia.gov/outlooks/aeo/nems/ documentation/.
} 
in 2020 to nearly $60 \%$ market share in 2040 in the United States (Bloomberg New Energy Finance 2020). This is a massive transformation of the market, but it is largely consistent with projections by the International Energy Agency (IEA 2020) and others in the industry. BNEF explicitly expects continued policy measures to encourage electric vehicles, including continued subsidies and public funding towards charging infrastructure. BNEF also projects battery prices to continue the precipitous decline observed over the past decade.

We develop a scenario intended to roughly match with the BNEF projections for electric vehicle market share over time, which is substantially larger than the market share included in the Annual Energy Outlook reference case. The difference between our scenario and the reference case is more than a marginal change and is useful for allowing us to clearly see the effects of adding many more electric vehicles charging. Appendix Figure D.3 shows the share of new light-duty vehicle sales that are electric vehicles by year in this scenario and the reference case. The vehicle stock transitions more slowly. In this scenario, electric vehicles account for approximately $46 \%$ of light duty vehicles and $64 \%$ of passenger cars on the road in 2050. ${ }^{27}$ By 2040, there are 23 million electric vehicles or plug-in hybrid electric light-duty vehicles (20 million cars) in the reference case and 93 million light-duty vehicles (60 million cars) in this scenario.

We make the following changes to implement this scenario: (1) we assume battery costs decline to roughly reach the price of $\$ 40 / \mathrm{kWh}$ by 2030 , (2) we increase the rate at which the make and model diversity for electric vehicles converges toward that of conventional vehicles, and (3) we adjust the technology-specific constant for all plug-in electric vehicle coefficients in the logit random utility model to ensure that we match the BNEF scenario with the battery cost decline we assume. Appendix D includes the details of each of these changes. After reducing battery costs as discussed above, we allow the model to set overall vehicle prices. Appendix Figure D.2 shows the decline of average electric vehicle prices over time in this scenario and the reference case (for compact cars, but the relative price changes are similar for other classes). The vehicle price declines, while perhaps optimistic, are still slower than projections made by Elon Musk, CEO of Tesla, who promised a $\$ 25,000$ electric vehicle within three years. ${ }^{28}$ Volkswagen has also claimed dramatic electric vehicle cost declines. ${ }^{29}$

\footnotetext{
${ }^{27}$ The more broadly defined category of battery electric and plug-in hybrid electric vehicles account for around $53 \%$ of light-duty vehicles and $71 \%$ of passenger cars on the road.

${ }^{28}$ See https://www.nytimes.com/2020/09/22/business/tesla-elon-musk-battery-day.html.

${ }^{29}$ See https : / www. theverge.com/2021/3/15/22325813/vw-volkswagen-power-day-battery-electric-car-announc mc_cid=982fee4e91\&mc_eid=b1fa5041a3.
} 


\subsubsection{Carbon Pricing}

We model the implementation of a range of carbon pricing policies that gradually increase over time. In practice, these policies could either be carbon taxes or tradeable permit systems with an allowance price equal to the carbon tax. All of the scenarios begin in 2020 with a price of $\$ 2 /$ ton $\mathrm{CO}_{2}$ (2016 dollars) that increases over time until 2040, after which the carbon price remains constant. It is difficult to choose a central case scenario because a wide range of different carbon prices may be politically possible. ${ }^{30}$ For the sake of illustration, we choose a central case with a carbon price that increases linearly to reach $\$ 30 /$ ton in $2040 .{ }^{31}$ We also consider a lower tax that reaches $\$ 5.30 /$ ton, a higher tax that reaches around $\$ 49 /$ ton, and an even higher tax that reaches $\$ 70 /$ ton (all in $2016 \$$. Most of these price paths are well below the path of the social cost of carbon (SCC) in the Obama Administration's estimates, which begins around $\$ 49 /$ ton in 2020 (2016\$, or approximately $\$ 54 /$ ton in $2020 \$$ )(IWG 2016), and thus represent a partial internalization of the externality.

In our carbon pricing scenarios, we do not cycle the revenues back into the economy, which could lead to some increased economic activity and emissions. The reason for this is that it is difficult to know how the revenues would be allocated and analyzing the effects of different approaches to revenue allocation is outside the scope of this paper (see Goulder (1995) for one of the early works in a long line of literature on this topic).

We also combine carbon pricing with our high electric vehicle market share scenario to examine the interactions between these policies.

\subsection{Dynamic Simulation Results}

In this section we summarize the results from running the scenarios in Yale-NEMS, focusing on the effects on electricity generation and air pollutant emissions.

\subsubsection{Electricity generation}

We begin by examining the fuel sources that are used to generate the electricity for the additional electric vehicles in the high electric vehicle scenario. Specifically, we calculate the difference in electricity generation from coal, natural gas, and renewables between the high electric vehicle scenario and the reference case. We calculate this difference both with and

\footnotetext{
${ }^{30}$ For example, the allowance price in California's cap-and-trade system is $\$ 17.98$ in March 2021 (https : //www.theice.com/marketdata/reports/142) and the price in the Northeast Regional Greenhouse Gas Initiative was $\$ 7.41$ in Q4 2020 (https://www.rggi.org/auctions/auction-results/prices-volumes). But there are discussions about substantially tightening these caps, which would lead to higher prices.

$31 \$ 30 /$ ton translates to an increase in the gasoline tax of roughly $\$ 0.27 /$ gallon.
} 
without carbon pricing for each year. For the ease of presentation, we sum up the total generation over the full period from 2020 to 2050.

Panel (a) in Figure 6 presents these differences in generation between the high electric vehicle scenario and the reference scenario. The first three bars represent the change in total generation for coal, natural gas, and renewables under the reference scenario. The second three represent the change in generation for our central case carbon pricing scenario. The third shows the difference in the additional generation required by the electric vehicle scenario between the carbon pricing and the reference case.

In Panel (a), we observe that under the reference case, the additional generation required by electric vehicles is provided entirely by natural gas and renewables. This is consistent with projected continued low natural gas prices and declining costs of renewables. Despite the additional load, coal generation essentially stays flat and even very slightly decreases. The slight decrease is due to new lower-cost natural gas and renewables capacity coming online leading to older coal plants becoming uneconomic more often.

In contrast, under moderate carbon pricing, all three fuels are used to meet the additional load from electric vehicles. Natural gas and renewables are still used more than coal, but there is a sizable increase in coal generation to power the additional load on the system from electric vehicles. The differences in the third set of bars highlight how much more coal is being used to power electric vehicles under the carbon pricing scenario. These results show an important interaction effect that aligns with the short-run empirical findings.

This interaction effect can also be seen in Panel (b) Figure 6, which presents total generation for coal by year out to 2050. The high electric vehicle demand scenario is nearly the same as the reference case (a decline of 14.5 billion $\mathrm{kWh} /$ year). The carbon price leads to substantial reductions in coal generation relative to the reference case. However, when the high electric vehicle demand is combined with the carbon pricing, coal generation is used more than without the electric vehicle demand (by 112.4 billion $\mathrm{kWh} / \mathrm{year}$ ).

There are two fundamental reasons for the additional coal generation from electric vehicle charging. The most important is a dynamic effect: the additional demand from the electric vehicles leads to coal plants being retired later. Carbon pricing serves to make many coal plants uneconomic over time, but the additional demand from electric vehicles raises wholesale prices for electricity, rendering some of these coal plants economic for longer. A secondary reason is that in some years coal is dispatched more often to help serve the additional electric vehicle demand (i.e., coal is on the margin). Appendix Figure D.4 shows coal generation's capacity factor and total capacity over time, decomposing the interaction effect on coal generation. Without a dynamic model of new plant builds, it would be difficult to develop this insight. 
We have focused thus far on coal, but it is worth discussing renewables as well. Our findings for renewables are the inverse of those for coal. The total capacity of renewables is higher whenever there is a carbon price in place. In addition, the total capacity of renewables is higher with many more electric vehicles charging. But the amount of additional renewable capacity brought online to serve the electric vehicles is lower when there is a carbon price (see Appendix Figure D.5). An explanation for this finding is that the marginal cost of building renewables is increasing in the amount built both cumulatively and in each year. Thus, with greater capacity of renewables being built anyway under a carbon price, it is less profitable to build more renewables to power the electric vehicles. Instead, more coal plants are kept running longer before retirement to power the electric vehicles.

\subsection{Emissions}

Electric vehicle policies are usually justified based on the emissions savings made possible by switching from gasoline or diesel to electricity (both in the short run and in the long run). A policy leading to a high electric vehicle market share would be expected to reduce emissions from transportation, but increase emissions from electricity unless electricity is fully decarbonized. Thus, we examine emissions from vehicles and the electricity sector. ${ }^{32}$ Our emissions analysis assumes a fixed carbon price in each year, but it is important to note that with an economy-wide cap-and-trade system, our results on emissions would be different if the carbon price is allowed to vary to guarantee that the cap is met. Yet the forces at work here would remain.

For each scenario, we examine emissions of $\mathrm{CO}_{2}$ and several common air pollutants: nitrogen oxides $\left(\mathrm{NO}_{\mathrm{x}}\right)$, particulate matter with a diameter less than 2.5 micrometers (PM2.5), sulfur dioxide $\left(\mathrm{SO}_{2}\right)$, and volatile organic compounds (VOCs). For the electricity sector, Yale-NEMS calculates emissions of $\mathrm{CO}_{2}, \mathrm{NO}_{\mathrm{x}}$, and $\mathrm{SO}_{2}$. We calculate emissions for the remaining pollutants by estimating implicit emissions factors at the NERC-region level using 2014 National Emissions Inventory Data and then applying those emission factors to power sector fuel consumption outputs. ${ }^{33}$ Similarly, Yale-NEMS calculates $\mathrm{CO}_{2}$ emissions from vehicles, but not the other pollutants. We calculate these emissions using emission factors from the U.S. Environmental Protection Agency, which are delineated by vehicle type, fuel, and vintage and are measured on a gram/mi basis (Lenox et al. 2013). ${ }^{34}$

\footnotetext{
${ }^{32}$ We focus on highway vehicles, which would exclude ATVs, agricultural vehicles, construction vehicles, etc. There are modest changes in emissions in other sectors from re-equilibration of prices, but these are second-order effects that do not change the insights presented here.

${ }^{33} \mathrm{~A}$ caveat of this approach is that these emission factors do not evolve over time, but we could not find suitable projections of emission factors for these pollutants from the power sector.

${ }^{34}$ Vehicle non- $\mathrm{CO}_{2}$ emissions are calculated by multiplying Yale-NEMS estimates for annual vehicle-miles-
} 
Figure 7 presents the net emissions associated with vehicles and the electricity sector. Several takeaways are apparent in Figure 7. First, high electric vehicle demand reduces $\mathrm{CO}_{2}$ emissions from the reference case, but carbon pricing alone reduces $\mathrm{CO}_{2}$ emissions just as much as carbon pricing combined with high electric vehicle demand. In other words, when combined with our central case carbon pricing scenario, policies to greatly increase the market share of electric vehicles do not appreciably reduce $\mathrm{CO}_{2}$ emissions further. This is an important result and we will explore whether this holds with other carbon price paths shortly.

A second finding is that the impacts of each scenario on the emissions of other common air pollutants are generally similar to the effects on $\mathrm{CO}_{2}$ emissions. One difference is that the increase in PM2.5 and $\mathrm{SO}_{2}$ emissions from electric vehicles is larger under carbon pricing than the reference case, due to greater use of coal plants. Another difference is that electric vehicles reduce VOC emissions even under the carbon pricing scenario, most likely because the VOC emissions from electricity generation are very small. Another observation from Figure 7 is that carbon pricing leads to notably lower emissions of all pollutants, as would be expected. Despite the perverse interaction with high electric vehicle demand, carbon pricing still remains an efficient and effective approach to reduce emissions.

We next monetize the changes in pollution between each of the scenarios and the reference case. We use values of marginal damages for each of the air pollutants from the widelyused AP3 model, ${ }^{35}$ and the central case estimate of the social cost of carbon from the Obama Administration's Interagency Working Group (IWG 2016). We calculate the avoided pollution damages for each year out to 2050 and then present the results by calculating a net present value using a $3 \%$ discount rate.

We present the net present value of the avoided pollution damages in Table $3 .{ }^{36}$ This table includes the full set of our carbon pricing policies, allowing us to examine whether our findings above hold at different levels of carbon pricing. Recall that our central case carbon price reaches $\$ 30 /$ ton by 2040 (shown in column (2)). All three scenarios result in avoided pollution damages relative to the reference case. The first row shows that our high electric vehicles demand scenario leads to $\$ 3.16$ billion/year in avoided pollution damages. The second row shows that this is dwarfed by the avoided pollution damages in all of the carbon pricing scenarios except the lowest path in column (1). The third row combines the high electric vehicle demand scenario with carbon pricing.

When comparing the combined scenario to carbon pricing alone, we observe that high

traveled by the emission factors, and then summing over all vehicle types and years. These emission factors evolve over time based on the U.S. Environmental Protection Agency's estimates.

${ }^{35}$ See https://public.tepper.cmu.edu/nmuller/APModel . aspx.

${ }^{36} \mathrm{~A}$ graphical breakdown of these damages by scenario and pollutant can be found in figure D.6. 
electric vehicle demand does not always lead to additional avoided damages on average. Indeed, in our central case estimate, the combined policy leads to lower avoided damages than carbon pricing alone. This is primarily the result of the emissions from the increased coal generation used to power the electric vehicles (as seen in Figure 6) dominating the emission reductions from vehicle electrification.

However, at lower carbon pricing paths and higher carbon pricing paths, the emission reductions from vehicle electrification dominate, so there will be avoided pollution damages. This aligns with the basic intuition in our conceptual framework and empirical results. At low carbon prices, coal generation generally remains inframarginal (and not being retired), so the additional electric vehicles are powered to a greater degree by natural gas and renewables. At much higher carbon prices, coal plants are pushed to being supramarginal and are retired earlier, leading the additional electric vehicle demand to again be powered to a greater degree by natural gas and renewables.

In the last row of Table 3, we calculate what we call 'net complementarity.' This metric compares the avoided damages from the combined policy to the sum of the avoided damages from each policy separately. A positive value suggests a complementarity between the two policies in that the sum is greater than the parts. A negative value suggests the opposite. In the last row, we see that the value is negative for all carbon prices that we simulated. This may be surprising because a common intuition is that electric vehicles will reduce emissions more with a decarbonized electricity system and carbon pricing would facilitate such a decarbonized electricity system. Our quantitative results indicate that another force dominates: added electric vehicles are powered from generation on the margin and carbon pricing increases the emission intensity of the marginal generation. This effect will eventually dissipate at much higher carbon prices.

\subsubsection{Emissions by region}

One finding that emerged strongly from our empirical analysis is that there are substantial regional differences. For example, regions that have minimal coal generation are not going to observe an effect in dispatch or retirements of coal plants. Our quantitative simulation results thus far suggest that the regions that do have sufficient coal generation can drive the results for the entire country. We now turn to exploring heterogeneity across regions. YaleNEMS endogenously chooses where in the United States the electric vehicles are purchased, following existing patterns. ${ }^{37}$

\footnotetext{
${ }^{37}$ In the reference case, the Pacific region (Alaska, California, Hawaii, Oregon, and Washington) accounts for $28 \%$ of all electric vehicles sold, followed by the South Atlantic region (Delaware, Florida, Georgia, Maryland, North Carolina, South Carolina, Virginia, and West Virginia), which is responsible for 18\% of
} 
In Figure 8 we illustrate how the avoided pollution from adding electric vehicles can be quite different across regions. ${ }^{38}$ There are two bars for each of the nine Census regions. The first bar calculates the difference in the discounted avoided pollution damages between the reference case and the high electric vehicle scenario. The second bar calculates the difference in the discounted avoided pollution damages between our central carbon price scenario and the combined high electric vehicle plus carbon pricing scenario. We again use a $3 \%$ discount rate for both and include avoided pollution benefits out to 2050.

Figure 8 shows that all of the regions benefit from avoided pollution damages due to adding electric vehicles in the reference case. But when there is a moderate carbon price in place, five of the nine regions show increases in pollution damages. Notably, these are all regions with a higher market share of coal generation (see Appendix Figure D.1 for a map of the Census regions). Indeed, regions that have minimal coal generation, such as New England and the Pacific region, show avoided pollution damages.

These results align reasonably closely with those that would be expected from the empirical analysis, although they should not be expected to align perfectly because avoided pollution damages are a function of many factors. Appendix Figure D.8 shows the additional generation from coal, natural gas, and renewables used to charge the electric vehicles in the high electric vehicles scenario by region. In all of the regions, coal generation increases more when there is the carbon price in place than when there is not. However, in some regions, the increase in coal generation is small and is offset by larger increases in natural gas or renewables generation, contributing to the overall avoided pollution damages in those regions. ${ }^{39}$

new electric vehicle sales (see Appendix Table D.1 for electric vehicle sales by region in 2030 and 2040). Under the increased electric vehicle demand scenario, the regions that gain the most new electric vehicles are the South Atlantic, followed by the Pacific, the West South Central region (Arkansas, Louisiana, Oklahoma, and Texas) and the East North Central region (Illinois, Indiana, Michigan, Ohio, and Wisconsin).

${ }^{38}$ Appendix Figure D.7 shows maps of the avoided damages per year by region for each of the scenarios to further illustrate the heterogeneity.

${ }^{39}$ In the previous section, the carbon intensity of marginal generation in ERCOT increased with carbon pricing, but here, the West South Central region (which includes ERCOT, along with parts of SERC and SPP) is one of the regions where the carbon tax actually increases avoided pollution benefits from electric vehicles. This difference is due to price effects in the non-ERCOT subregions that are present in the West South Central region. Specifically, in the SERC Reliability Corporation/Delta, electric vehicle charging in the presence of a carbon tax raises prices by $20 \%$ more than it does in the absence of the carbon tax (the fourth highest increase of the 22 NERC subregions). This price increase reduces electricity demand and, therefore, generation in the SERC Reliability Corporation/Delta subregion, and in West South Central overall. Thus, in Figure D.8, the sum of the bars under 'price' is lower than the sum of the bars under 'reference' (this is particularly apparent in the 'price - reference' bars, where the magnitude of the decrease in natural gas generation is clearly larger than the magnitude of the increase in both coal and renewables). 


\subsection{Sensitivity Analysis}

In Table 3 above, we included several carbon price paths, illuminating that our quantitative modeling results accord with our conceptual framework in showing that for a range of moderate carbon prices, electric vehicle policies may reduce emissions less than in the absence of carbon pricing-and may not even reduce emissions at all. With much higher carbon prices or much lower carbon prices, this is not a concern. However, the moderate carbon price path is in the range that may be politically feasible. Here we explore other assumptions that may influence when the negative interaction between carbon pricing and electric vehicle policy is likely to be present. ${ }^{40}$ For each we present a representative scenario to help clarify when we would and would not expect our results to hold.

\subsubsection{Low-cost renewables}

One possible circumstance that could affect whether moderate carbon prices negatively affect the emission reductions from electric vehicle policies is a case where the cost of renewables drops very rapidly. Because renewables are must-take generation, massive builds of renewables could push coal generation up the supply curve to be supramarginal and eventually uneconomic. Renewables are also intermittent, so dispatchable natural gas generation is more likely to benefit than coal generation, which is more expensive to ramp up and down. Yale-NEMS accounts for these issues.

We model a low-cost renewables scenario based on AEO 2020's high renewables case. These changes lead to an increase in capacity of more than 300 additional gigawatts by 2050, relative to the reference case in the same year. By 2050, then, renewables make up approximately $39 \%$ of total electricity sector generation, compared to $23 \%$ in the reference.

Results for this scenario are in Table 4; we find that electric vehicles now reduce emissions in the presence of a carbon tax, but we still do not observe net complementarity. Even with much lower renewables costs, it is less expensive to keep coal plants online and run existing coal plants slightly more than to build new facilities. Appendix Figure D.10 reveals that this outcome is a function of both mechanisms: coal retirements are avoided and coal capacity factors increase in the latter half of the simulated time frame.

With much more optimistic renewables costs-well beyond the historical improvements we have seen-eventually coal plants will be pushed up the aggregate supply curve and electric vehicles will be charged with renewables and natural gas.

\footnotetext{
${ }^{40}$ We also explore a robustness run where the reference case is matched to be somewhat close to AEO2020, and find that the interaction between electric vehicle policy and carbon pricing remains (e.g., see Appendix Figure D.9 showing coal generation).
} 


\subsubsection{Earlier electric vehicle adoption}

A major uncertainty is just how quickly electric vehicles will be adopted. Thus, we adjust the BNEF electric vehicle adoption projection to allow for even faster adoption of electric vehicles. We accomplish this by adjusting the consumer preferences for electric vehicles in the logit model, and leave battery prices consistent with the other scenarios. We show electric vehicle adoption over time in this early adoption scenario in Appendix Figure D.3.

Our key finding is that if electric vehicle adoption occurs earlier, then there are more coal plants online, and thus more that can be moved to the margin and retired later. Accordingly, our interaction between electric vehicle policies and carbon pricing is exacerbated, as seen in Column (2) of Table 4. If electric vehicle adoption occurs later, there will be less expensive renewables and more coal plants will have been retired anyway. So the interaction effect tends to be dampened.

\section{Conclusion}

Using both an empirical analysis of historical data from recent years and a detailed dynamic model, we demonstrate an important interaction between electric vehicle policy and carbon pricing policy that plays out over a range of moderate carbon prices that very likely fall within the range of politically feasible prices. The key intuition for our results is that carbon pricing will push coal generation up the aggregate supply curve to the margin and eventually to retirement. Thus, within a range of carbon prices, additional electric vehicles are more likely to be powered by coal, and the additional demand for electricity can slow coal retirements.

These results do not indicate that carbon pricing is ineffective at reducing emissions. In fact, we show that carbon pricing can be quite effective at all levels, and the perverse interaction can be reversed with sufficiently high carbon prices that push coal generation to be uneconomic. Further, our results do not controvert electric vehicles as a pathway to decarbonizing transportation in the long run. But the United States still relies on coal for nearly a quarter of its electricity, and in some regions the coal share is much higher. Thus, this work should be viewed as a cautionary tale about how two policies in different sectors can interact to reduce the effectiveness of the policies combined-even if they are both price policies.

Electric vehicle policy is particularly germane in policy discussions today. Our results highlight that higher carbon prices (or no carbon price) would allow electric vehicle policy to be much more effective at reducing emissions than than the carbon prices observed in the 
recent past in the United States. Holding the cost of electric vehicle policy constant, this also implies that the welfare benefits of such policy will be greater under no carbon price or higher carbon prices. And from an overall social welfare perspective, higher carbon prices closer to the social cost of carbon would provide larger welfare benefits than no carbon price at all. Stepping back, our findings reinforce the simple point that the benefits of electric vehicles will be much greater if they are sequenced after coal plants are retired, allowing for a complementarity.

Our results show that emissions could even increase by adding electric vehicle policy to a moderate carbon policy. Under an economy-wide cap-and-trade system, total emissions are capped, so they would not increase. However, the coal-fired electricity dispatch and retirement effects we show in this paper with moderate carbon prices could still occur, only they would raise the allowance price, implying that the cost of meeting the cap is higher. This could possibly lead to less tightening of the cap in the future. In a cap-and-trade system that covers the electricity sector but not the transportation sector, like the Chinese national carbon trading scheme, a shift to electric vehicles will unambiguously decrease total emissions.

There is ample room for further work on this topic. With new technologies and regulations, electric vehicle owners can be encouraged to charge at the most economically-efficient times of day, which could change the charging patterns and thus marginal emissions from electric vehicle policies. Further, vehicle-to-grid technology could mean that electric vehicles could be used to dispatch to the grid during peak times, increasing their monetary and emissions benefits. Exploring these in future research could provide additional insight to policymakers on the design of electric vehicle policy in concert with carbon pricing.

\section{References}

Acemoglu, D., Aghion, P., Bursztyn, L. \& Hemous, D. (2012), 'The environment and directed technical change', American Economic Review 102(1), 131-166.

Archsmith, J., Kendall, A. \& Rapson, D. (2015), 'From Cradle to Junkyard: Assessing the Life Cycle Greenhouse Gas Benefits of Electric Vehicles', Research in Transportation Economics 52, 72-90.

Auffhammer, M. (2007), 'The Rationality of EIA Forecasts Under Symmetric and Asymmetric Loss', Resource and Energy Economics 29(2), 102-121. 
Auffhammer, M. \& Sanstad, A. H. (2011), Energy Efficiency in the Residential and Commercial Sectors.

Bernow, S. \& Duckworth, M. (1998), 'An Evaluation of Integrated Climate Protection Policies for the United States', Energy Policy 26(5), 357-374.

Bloomberg New Energy Finance (2020), New Energy Outlook 2020, Technical report.

Bordoff, J. \& Houser, T. (2014), American Gas to the Rescue? The Impact of US LNG Exports on European Security and Russian Foreign Policy.

Bovenberg, A. \& Goulder, L. (1996), 'Optimal environmental taxation in the presence of other taxes: General-equilibrium analyses', American Economic Review 86(4), 985-1000.

Brown, M. A., Cox, M. \& Baer, P. (2013), 'Reviving manufacturing with a federal cogeneration policy', Energy Policy 52, 264-276.

Brown, M. A., Jackson, R., Cox, M., Cortes, R., Deitchman, B. \& Lapsa, M. V. (2011), Making Industry Part of the Climate Solution: Policy Options to Promote Energy Efficiency, Technical report, Oak Ridge National Laboratory, Oak Ridge, TN.

Brown, M. A., Levine, M. D., Short, W. \& Koomey, J. G. (2001), 'Scenarios for a clean energy future', Energy Policy 29(2001), 1179-1196.

Brown, S. P. A. \& Krupnick, A. J. (2010), Abundant Shale Gas Resources: Long-Term Implications for U.S. Natural Gas Markets.

Brown, S. P. A., Krupnick, A. J. \& Walls, M. A. (2009), Natural Gas: Is It a Bridge to a Low Carbon Future?

Burlig, F., Bushnell, J., Rapson, D. \& Wolfram, C. (2021), 'Low energy: Estimating electric vehicle electricity use', AEA Papers and Proceedings forthcoming.

Bushnell, J., Holland, S., Hughes, J. \& Knittel, C. (2017), 'Strategic policy choice in statelevel regulation', American Economic Journal: Economic Policy 9(2), 57-90.

Chandel, M. K., Pratson, L. F. \& Jackson, R. B. (2011), 'The potential impacts of climate-change policy on freshwater use in thermoelectric power generation', Energy Policy 39(10), 6234-6242.

Clinton, B. \& Steinberg, D. (2019), 'Providing the spark: Impact of financial incentives on battery electric vehicle adoption', Journal of Environmental Economics and Management 98. 
Cullen, J. (2015), 'Dynamic responses to environmental regulation in the electricity industry', American Economic Journal: Economic Policy 5(4), 107-133.

Cullen, J. A. \& Mansur, E. T. (2017), 'Inferring carbon abatement costs in electricity markets: A revealed preference approach using the shale revolution', American Economic Journal: Economic Policy 9(3), 106-133.

Cullenward, D., Wilkerson, J., Wara, M. \& Weyant, J. P. (2016), 'Dynamically Estimating the Distributional Impacts of U.S. Climate Policy with NEMS: A Case Study of the Climate Protection Act of 2013', Energy Economics 55, 303-318.

EIA (2015), Analysis of the Impacts of the Clean Power Plan, Technical report, Washington, D.C.

EIA (2016), Transportation Demand Module of the National Energy Modeling System : Model Documentation, Technical Report July.

Fabra, N. \& Reguant, M. (2014), 'Pass-through of emissions costs in electricity markets', American Economic Review 104(9), 2872-2899.

Fell, H. \& Kaffine, D. (2018), 'The fall of coal: Joint impacts of fuel prices and renewables on generation and emissions', American Economic Journal: Economic Policy 10(2), 90-116.

Fischer, C., Preonas, L. \& Newell, R. (2017), 'Environmental and technology policy options in the electricity sector: Are we deploying too many?', Journal of the Association of Environmental and Resource Economists 4(4), 959-984.

Gallagher, K. S. \& Collantes, G. (2008), Analysis of Policies to Reduce Oil Consumption and Greenhouse- Gas Emissions from the U.S. Transportation Sector.

Geller, H., Bernow, S. \& Dougherty, W. (1999), Meeting America's Kyoto Protocol Target: Policies and Impacts.

Gerarden, T., Reeder, W. \& Stock, J. (2020), 'Federal coal program reform, the clean power plan, and the interaction of upstream and downstream climate policies', American Economic Journal: Economic Policy 12(1), 167-199.

Gillingham, K. (2013), The Economics of Fuel Economy Standards versus Feebates.

Gillingham, K. \& Huang, P. (2019), 'Is natural gas a bridge to a low-carbon future or a dead-end?', Energy Journal 40(2), 75-100. 
Gillingham, K. \& Huang, P. (2020), 'Long-run environmental and economic impacts of electrifying shipping in the united states', Environmental Science and Technology 54(16), 9824-9833.

Gillingham, K. \& Stock, J. (2018), 'The cost of reducing greenhouse gas emissions', Journal of Economic Perspectives 32(4), 1-20.

Goulder, L. (2010), Using Cap and Trade to Reduce Greenhouse Gas Emissions.

Goulder, L. H. (1995), 'Environmental taxation and the double dividend: A reader's guide', International Tax and Public Finance 2(2), 157-183.

Goulder, L. H., Jacobsen, M. R. \& Van Benthem, A. A. (2011), 'Unintended consequences from nested state and federal regulations : The case of the Pavley greenhouse-gas-per-mile limits', Journal of Environmental Economics and Management 63, 187-207.

Goulder, L. H. \& Stavins, R. N. (2011), 'Challenges from state-federal interactions in US climate change policy', American Economic Review: Papers $\&$ Proceedings 101(3), 253257.

Graff Zivin, J. S., Kotchen, M. J. \& Mansur, E. T. (2014), 'Spatial and temporal heterogeneity of marginal emissions: Implications for electric cars and other electricity-shifting policies', Journal of Economic Behavior and Organization 107, 248-268.

Holland, S., Mansur, E., Muller, N. \& Yates, A. (2020), 'Decompositions and policy consequences of an extraordinary decline in air pollution from electricity generation', American Economic Journal: Economic Policy 12(4), 244-274.

Holland, S., Mansur, E. \& Yates, A. (2021), 'The electric vehicle transition and the economics of banning gasoline vehicles', American Economic Journal: Economic Policy forthcoming.

Holland, S. P., Mansur, E. T., Muller, N. Z. \& Yates, A. J. (2016), 'Are There Environmental Benefits from Driving Electric Vehicles ? The Importance of Local Factors', American Economic Review 106(12), 3700-3729.

Houser, T., Larsen, J., Melton, M., Ketchum, W. \& Mohan, S. (2015), Commodity Market Impacts of EPA's Clean Power Plan.

Houser, T. \& Mohan, S. (2013), American Energy Productivity: The Economic, Environmental, and Security Benefits of Unlocking Energy Efficiency. 
IEA (2020), Global EV Outlook 2020, Technical report.

IWG (2016), Technical Support Document: Technical Update of the Social Cost of Carbon for Regulatory Impact Analysis Under Executive Order 12866, Technical report.

Jaffe, A., Newell, R. \& Stavins, R. (2005), 'A tale of two market failures: Technology and environmental policy', Ecological Economics 54, 164-174.

Koomey, J. G., Webber, C. A., Atkinson, C. S. \& Nicholls, A. (2001), 'Addressing energyrelated challenges for the US buildings sector: Results from the clean energy futures study', Energy Policy 29(14), 1209-1221.

Larsen, J., Ladislaw, S. O., Melton, M. \& Herndon, W. (2016), Assessing the Final Clean Power Plan Emissions Outcomes.

Lenox, C., Dodder, R., Gage, C., Loughlin, D., Kaplan, O. \& Yelverton, W. (2013), 'Epa u.s. nine-region markal database, database documentation.'.

Li, J. (2021), 'Compatibility and investment in the u.s. electric vehicle market', MIT Working Paper .

Li, S., Tong, L., Xing, J. \& Zhou, Y. (2017), 'The market for electric vehicles: Indirect network effects and policy design', Journal of the Association of Environmental and Resource Economists 4(1), 89-133.

Mignone, B. K., Showalter, S., Wood, F., McJeon, H. \& Steinberg, D. (2017), 'Sensitivity of natural gas deployment in the US power sector to future carbon policy expectations', Energy Policy 110(June), 518-524.

Morrow, W. R., Gallagher, K. S., Collantes, G. \& Lee, H. (2010), 'Analysis of Policies to Reduce Oil Consumption and Greenhouse-Gas Emissions from the US Transportation Sector', Energy Policy 38(3), 1305-1320.

Muehlegger, E. \& Rapson, D. (2020), 'Correcting estimates of electric vehicle emissions abatement: Implications for climate policy', NBER Working Paper 27197.

Muehlegger, E. \& Rapson, D. (2021), 'Subsidizing low- and middle-income adoption of electric vehicles: Quasi-experimental evidence from california', UC Davis Working Paper .

O'Neill, B. C. \& Desai, M. (2005), 'Accuracy of past projections of US energy consumption', Energy Policy 33(8), 979-993. 
Palmer, K., Sweeney, R. \& Allaire, M. (2010), Modeling Policies to Promote Renewable and Low-Carbon Sources of Electricity.

Popp, D., Newell, R. \& Jaffe, A. (2010), Energy, the Environment, and Technological Change, in B. Hall \& N. Rosenberg, eds, 'Handbook of the Economics of Innovation', Vol. 2, Elsevier.

Scott, M. J., Dirks, J. A. \& Cort, K. A. (2007), 'The value of energy efficiency programs for US residential and commercial buildings in a warmer world', Mitigation and Adaptation Strategies for Global Change 13(4), 307-339.

Small, K. A. (2010), Energy Policies for Automobile Transportation: A Comparison Using the National Energy Modeling System.

Small, K. A. (2012), 'Energy policies for passenger motor vehicles', Transportation Research Part A-Policy and Practice 46(6), 874-889.

Springel, K. (2021), 'Network externalities and subsidy structure in two-sided markets: Evidence from electric vehicle incentives', American Economic Journal: Economic Policy conditionally accepted.

Stiglitz, J. (2019), 'Addressing climate change through price and non-price interventions', European Economic Review 119, 594-612.

US Drive (n.d.), 'Grid Integration Tech Team and Summary Report on EVs at Scale and the U. S. Electric Power System', (November 2019).

Wilkerson, J. T., Cullenward, D., Davidian, D. \& Weyant, J. P. (2013), 'End use technology choice in the national energy modeling system (NEMS): An analysis of the residential and commercial building sectors', Energy Economics 40, 773-784.

Xing, J., Leard, B. \& Li, S. (2021), 'What does an electric vehicle replace?', Journal of Environmental Economics and Management forthcoming.

Zhou, Y. \& Li, S. (2018), 'Technology adoption and critical mass', Journal of Industrial Economics 66.

\section{Tables}


Table 1: Summary Statistics for Empirical Analysis

\begin{tabular}{|c|c|c|c|c|c|}
\hline Variable & Units & MISO & SPP & ERCOT & PJM \\
\hline \multicolumn{6}{|c|}{ Panel A. Hourly electricity generation and load } \\
\hline Load & MWh & $\begin{array}{c}77,421 \\
(12,047)\end{array}$ & $\begin{array}{l}29,056 \\
(5,558)\end{array}$ & $\begin{array}{l}41,008 \\
(9,509)\end{array}$ & $\begin{array}{c}90,327 \\
(16,629)\end{array}$ \\
\hline Coal generation & MWh & $\begin{array}{l}35,129 \\
(8,740)\end{array}$ & $\begin{array}{l}13,853 \\
(3,853)\end{array}$ & $\begin{array}{l}11,553 \\
(3,654)\end{array}$ & $\begin{array}{l}27,296 \\
(8,359)\end{array}$ \\
\hline Gas generation & MWh & $\begin{array}{l}17,557 \\
(6,714)\end{array}$ & $\begin{array}{c}6,503 \\
(3,202)\end{array}$ & $\begin{array}{l}18,047 \\
(7,876)\end{array}$ & $\begin{array}{l}27,161 \\
(9,635)\end{array}$ \\
\hline Solar generation & MWh & N.R. & $\begin{array}{c}38 \\
(60)\end{array}$ & $\begin{array}{c}218 \\
(199)\end{array}$ & $\begin{array}{c}162 \\
(259)\end{array}$ \\
\hline Wind generation & MWh & $\begin{array}{c}4,748 \\
(2,691)\end{array}$ & $\begin{array}{c}5,773 \\
(3,643)\end{array}$ & $\begin{array}{c}6,443 \\
(3,996)\end{array}$ & $\begin{array}{c}2,358 \\
(1,645)\end{array}$ \\
\hline \multicolumn{6}{|c|}{ Panel $B$. Heat rate and emission rate } \\
\hline Heat rate coal & MMBtu/MWh & $\begin{array}{l}10.60 \\
(0.09)\end{array}$ & $\begin{array}{l}10.46 \\
(0.18)\end{array}$ & $\begin{array}{l}10.71 \\
(0.20)\end{array}$ & $\begin{array}{l}10.16 \\
(0.20)\end{array}$ \\
\hline Heat rate natural gas & MMBtu/MWh & $\begin{array}{c}8.33 \\
(0.58)\end{array}$ & $\begin{array}{c}8.83 \\
(1.19)\end{array}$ & $\begin{array}{c}7.73 \\
(0.25)\end{array}$ & $\begin{array}{c}7.73 \\
(0.56)\end{array}$ \\
\hline Emissions rate coal & $\mathrm{tCO}_{2} / \mathrm{MWh}$ & $\begin{array}{c}1.01 \\
(0.01)\end{array}$ & $\begin{array}{c}1.00 \\
(0.02)\end{array}$ & $\begin{array}{c}1.02 \\
(0.02)\end{array}$ & $\begin{array}{c}0.97 \\
(0.02)\end{array}$ \\
\hline Emissions rate natural gas & $\mathrm{tCO}_{2} / \mathrm{MWh}$ & $\begin{array}{c}0.44 \\
(0.03)\end{array}$ & $\begin{array}{c}0.47 \\
(0.06)\end{array}$ & $\begin{array}{c}0.41 \\
(0.01)\end{array}$ & $\begin{array}{c}0.41 \\
(0.03)\end{array}$ \\
\hline Average emissions rate & $\mathrm{tCO}_{2} / \mathrm{MWh}$ & $\begin{array}{c}0.55 \\
(0.07)\end{array}$ & $\begin{array}{c}0.57 \\
(0.11)\end{array}$ & $\begin{array}{c}0.46 \\
(0.08)\end{array}$ & $\begin{array}{c}0.41 \\
(0.05)\end{array}$ \\
\hline \multicolumn{6}{|c|}{ Panel C. Coal and natural gas prices } \\
\hline Coal price & $\$ / \mathrm{MMBtu}$ & $\begin{array}{c}2.19 \\
(0.14)\end{array}$ & $\begin{array}{c}1.67 \\
(0.06)\end{array}$ & $\begin{array}{c}1.94 \\
(0.18)\end{array}$ & $\begin{array}{c}2.42 \\
(0.14)\end{array}$ \\
\hline & $\$ / M W h$ & $\begin{array}{l}23.46 \\
(1.91)\end{array}$ & $\begin{array}{l}17.57 \\
(0.63)\end{array}$ & $\begin{array}{l}20.44 \\
(1.77)\end{array}$ & $\begin{array}{l}24.76 \\
(1.35)\end{array}$ \\
\hline Natural gas price & $\$ / M M B t u$ & $\begin{array}{c}3.34 \\
(0.94)\end{array}$ & $\begin{array}{c}3.22 \\
(1.01)\end{array}$ & $\begin{array}{c}3.27 \\
(0.92)\end{array}$ & $\begin{array}{c}3.74 \\
(2.12)\end{array}$ \\
\hline & $\$ / M W h$ & $\begin{array}{l}28.09 \\
(9.10)\end{array}$ & $\begin{array}{l}28.49 \\
(9.21)\end{array}$ & $\begin{array}{l}24.85 \\
(6.40)\end{array}$ & $\begin{array}{c}28.84 \\
(13.92)\end{array}$ \\
\hline Coal-gas ratio MWh & / & $\begin{array}{c}0.90 \\
(0.23) \\
\end{array}$ & $\begin{array}{c}0.67 \\
(0.20) \\
\end{array}$ & $\begin{array}{c}0.87 \\
(0.19) \\
\end{array}$ & $\begin{array}{c}0.96 \\
(0.25) \\
\end{array}$ \\
\hline
\end{tabular}

Notes: The electricity generation and load data include 52,584 hourly observations from January 2014 to December 31, 2019. The coal and natural gas transactions data include 69,291 plant-month transactions for 273 plants from January 2014 to December 31, 2019. The heat rate of coal and gas is calculated as the monthly generation-weighted average ratio of energy use and electricity generation. The emissions rate of coal and natural gas is calculated by multiplying the heat rate by the carbon content of coal (210 lbs/MMBtu) and natural gas (117 lbs/MMBtu). The average emission rate is defined as the ratio of total $\mathrm{CO}_{2}$ emissions to load. The region-level coal and gas price is the monthly generation-weighted average product of plant-level heat rate (MMBtu/MWh) and fuel expenditure data (\$/MMBtu). $\mathrm{tCO}_{2}$ refers to metric tons of carbon dioxide. "N.R." refers to data that is not reported. 
Table 2: Key Electricity System Metrics of the Four Regions Showing How PJM is Different

\begin{tabular}{lccccccc}
\hline & $\begin{array}{c}(1) \\
\text { Capacity factor } \\
\text { at carbon price: }\end{array}$ & $\begin{array}{c}\text { Net coal capacity } \\
\text { retirement } \\
(\mathrm{GW})\end{array}$ & $\begin{array}{c}(5) \\
\text { Net gas capacity } \\
\text { addition } \\
(\mathrm{GW})\end{array}$ & $\begin{array}{c}(6) \\
\text { Growth of } \\
\text { average load } \\
(\mathrm{GWh})\end{array}$ & $\begin{array}{c}(7) \\
\text { Growth of average } \\
\text { renewable generation } \\
(\mathrm{GWh})\end{array}$ \\
\hline MISO & $83 \%$ & $77 \%$ & $68 \%$ & 7.89 & -2.49 & -0.93 & 1.37 \\
SPP & $68 \%$ & $65 \%$ & $54 \%$ & 2.56 & 0.60 & 4.14 & 5.35 \\
ERCOT & $70 \%$ & $67 \%$ & $52 \%$ & 4.87 & 5.02 & 4.99 & 5.10 \\
PJM & $58 \%$ & $54 \%$ & $58 \%$ & 16.79 & 22.77 & -1.17 & 1.05 \\
\hline
\end{tabular}

Notes: The capacity factor is the average value in three equal subsamples with a low, medium, and high carbon price. Net natural gas capacity additions and net coal capacity retirements are between January 2014 and December 2019. The growth of average hourly load and average renewable generation are calculated between the average for 2014 and for 2019 (except for PJM, where renewable generation data is only available as of 2016).

Table 3: Discounted Avoided Pollution Damages to 2050

\begin{tabular}{lllll}
\hline & $(1)$ & $(2)$ & $(3)$ & $(4)$ \\
& \multicolumn{4}{c}{ Carbon price in 2040} \\
& $\$ 5.30 /$ ton & $\$ 30 /$ ton & $\$ 48.70 /$ ton & $\$ 70 /$ ton \\
\hline Electric Vehicles & 3.16 & 3.16 & 3.16 & 3.16 \\
Carbon Price & 3.68 & 30.84 & 48.86 & 61.82 \\
Electric Vehicles + Carbon Price & 6.76 & 29.60 & 50.02 & 63.01 \\
\hline Benefit Adding EVs to Carbon Price & 3.08 & -1.24 & 1.16 & 1.19 \\
Net Complementarity & -0.08 & -4.40 & -2.00 & -1.96 \\
\hline
\end{tabular}

Notes: Units are billions of $2016 \$$ year and all values are changes relative to the reference case. The discount rate is 3\%. 'Electric Vehicles' refers to our high electric vehicle demand scenario. 'Benefit Adding EVs to Carbon Price' shows the added discounted avoided damages from adding high electric vehicle demand to an existing carbon pricing policy. 'Net Complementarity' is calculated as the avoided damages from the 'Electric Vehicles + Carbon Price' policy minus the sum of the avoided damages from each of the electric vehicle and carbon pricing policies.

Table 4: Discounted Avoided Pollution Damages to 2050, Sensitivity Cases

\begin{tabular}{llll}
\hline & $(1)$ & $(2)$ & $(3)$ \\
& & \multicolumn{2}{c}{ Sensitivity Case } \\
& Baseline & EV Timing & High Renewables \\
\hline Electric Vehicles & 3.16 & 3.14 & 2.68 \\
Carbon Price & 30.84 & 30.84 & 36.06 \\
Electric Vehicles + Carbon Price & 29.60 & 28.54 & 36.46 \\
\hline Benefit Adding EVs to Carbon Price & -1.24 & -2.30 & 0.41 \\
Net Complementarity & -4.40 & -5.44 & -2.27 \\
\hline
\end{tabular}

Notes: Units are billions of $2016 \$$ year and all values are changes relative to the reference case. The discount rate is $3 \%$. 'Electric Vehicles' refers to our high electric vehicle demand scenario. 'Benefit Adding EVs to Carbon Price' shows the added discounted avoided damages from adding high electric vehicle demand to an existing carbon pricing policy. 'Net Complementarity' is calculated as the avoided damages from the 'Electric Vehicles + Carbon Price' policy minus the sum of the avoided damages from each of the electric vehicle and carbon pricing policies. 


\section{Figures}

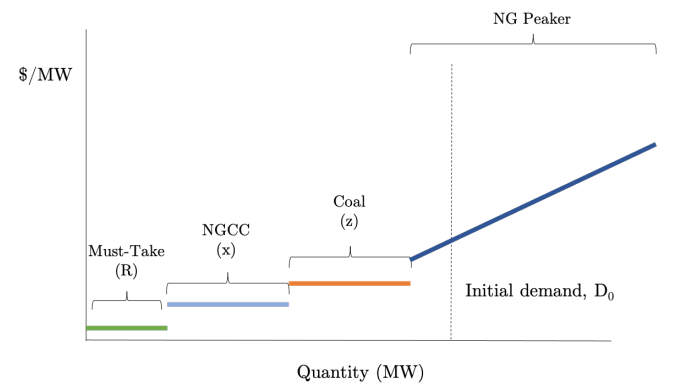

(a) Short-run aggregate supply of electricity.

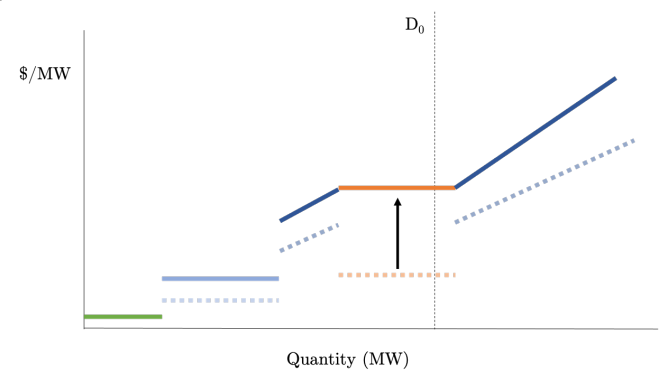

(c) Reordering with moderate carbon price.

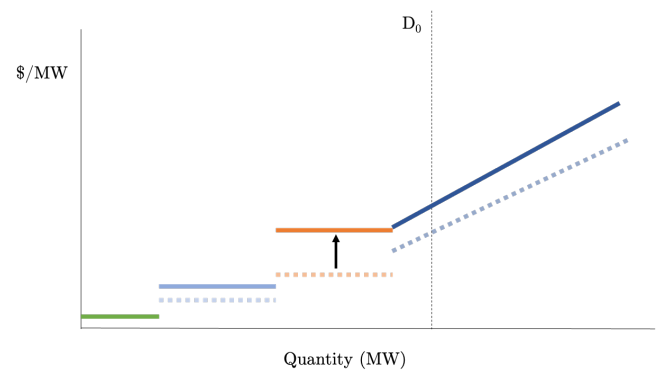

(b) Reordering with low carbon price.

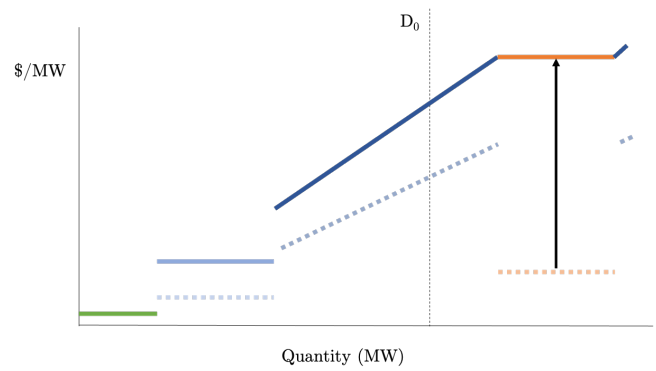

(d) Reordering with high carbon price.

Figure 1: This stylized framework illustrates how electric vehicles may be powered by coal generation under a moderate carbon price, but not a higher or lower carbon price. Each bar represents one type of plant, in ascending order of marginal cost. In figures (b) - (d), the solid line represents the post-tax marginal cost and the dashed line represents the original marginal cost depicted in (a). The arrow shows how the post-tax marginal cost for coal rises substantially more than the post-tax marginal cost for natural gas. 


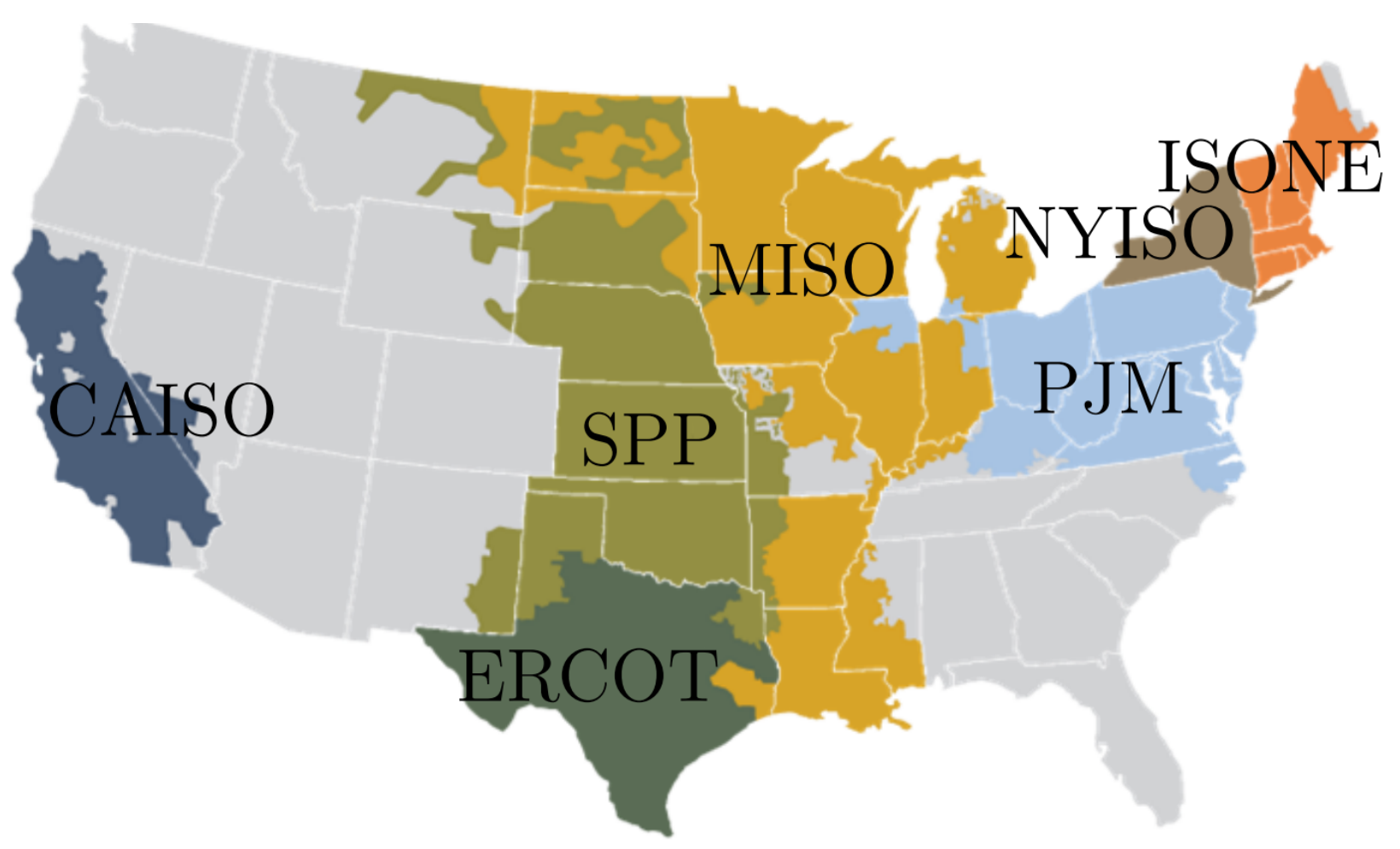

Figure 2: Independent system operators in the United States. 


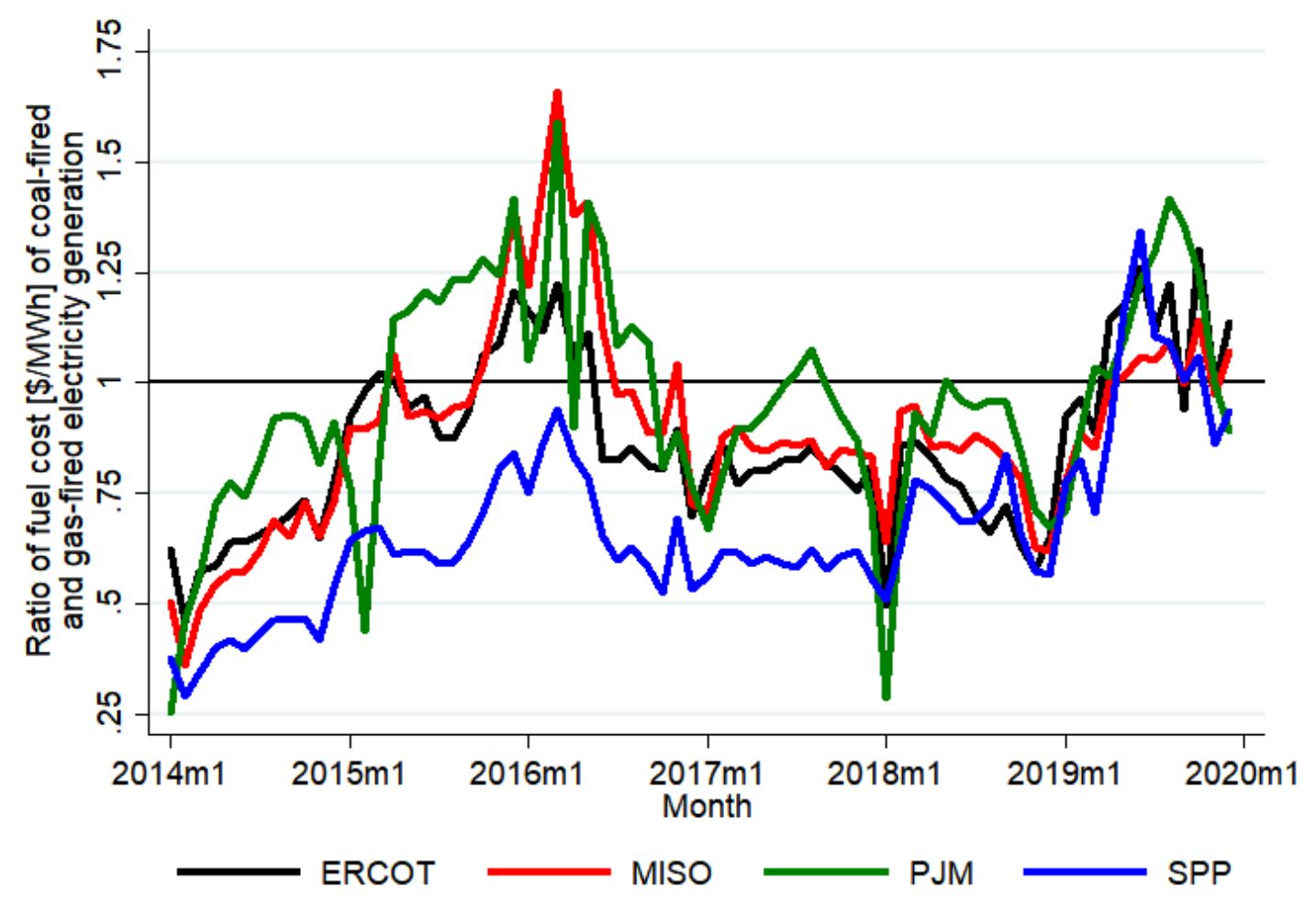

(a) Ratio of the variable fuel cost of coal-fired to gas-fired electricity generation by month.

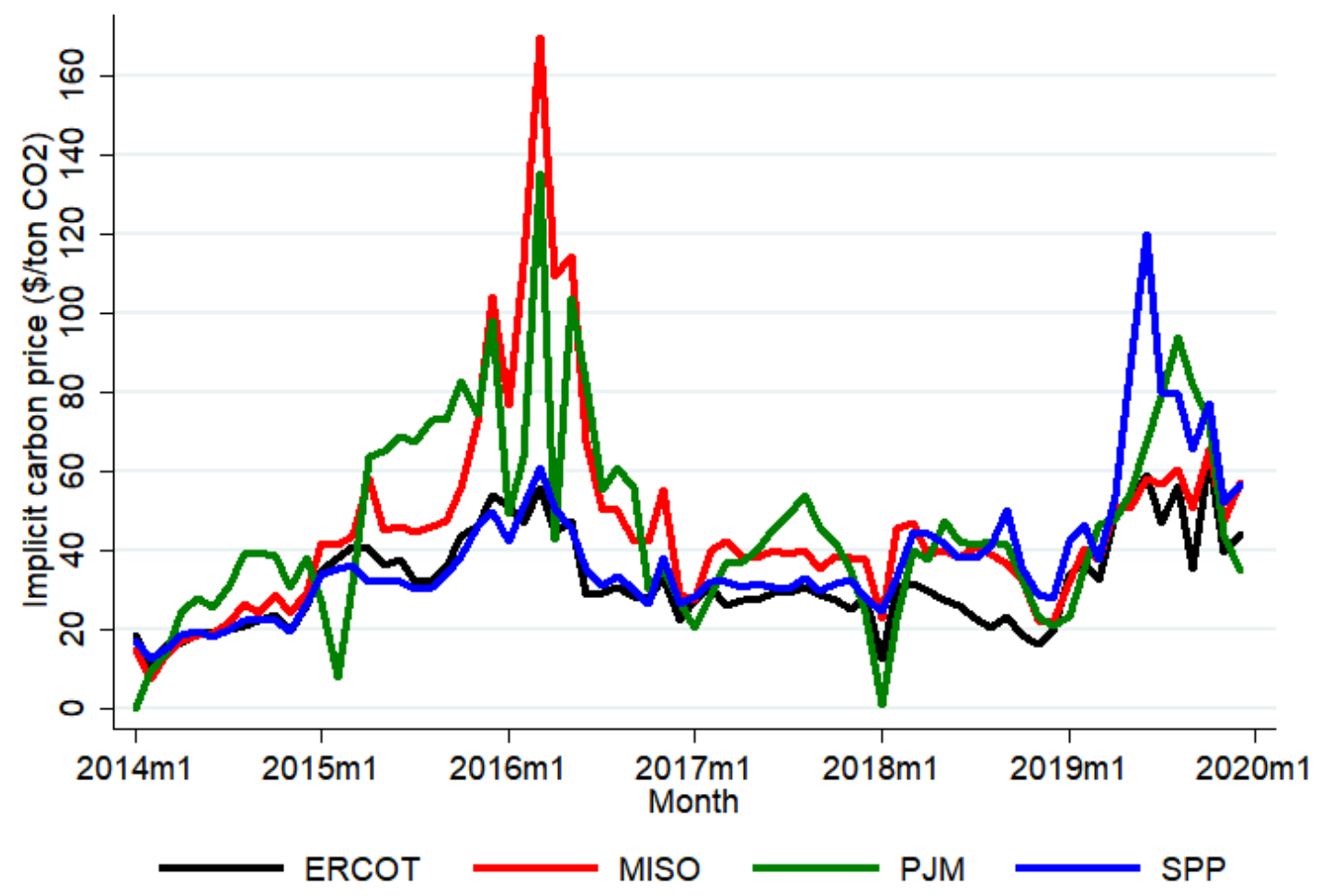

(b) Implicit carbon price corresponding to the gas-coal ratio.

Figure 3 


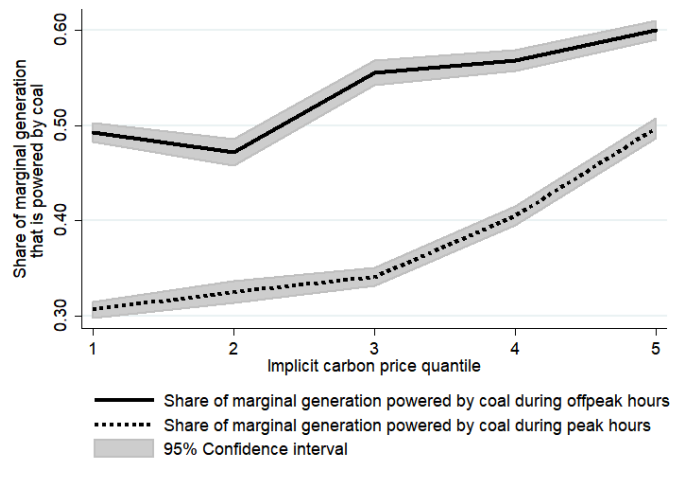

(a) MISO

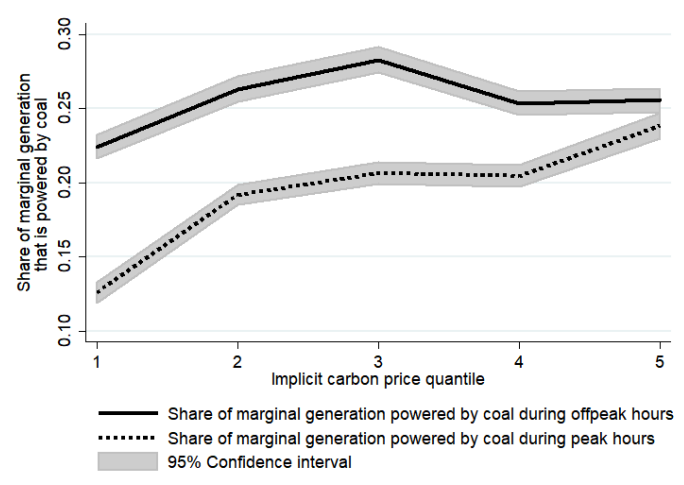

(c) ERCOT

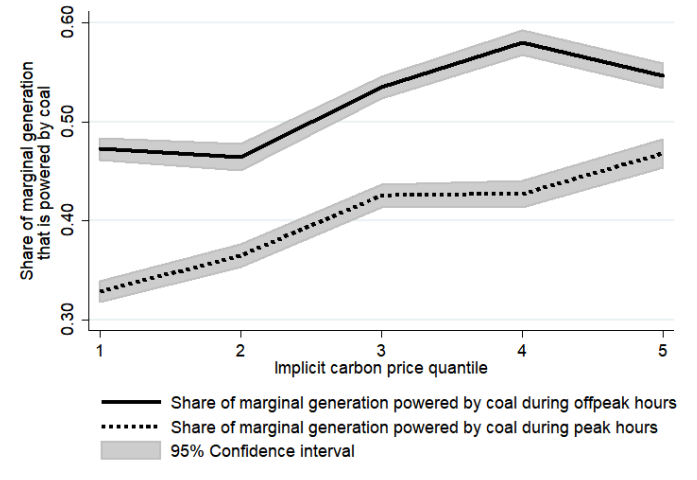

(b) SPP

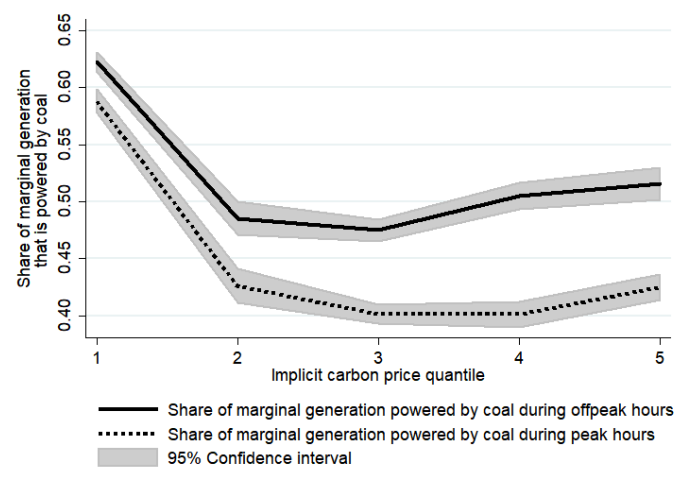

(d) PJM

Figure 4: Share of marginal generation that is coal-fired for different levels of the implicit carbon price in ERCOT, MISO, PJM, and SPP. Error bars represent the $95 \%$ confidence interval. 


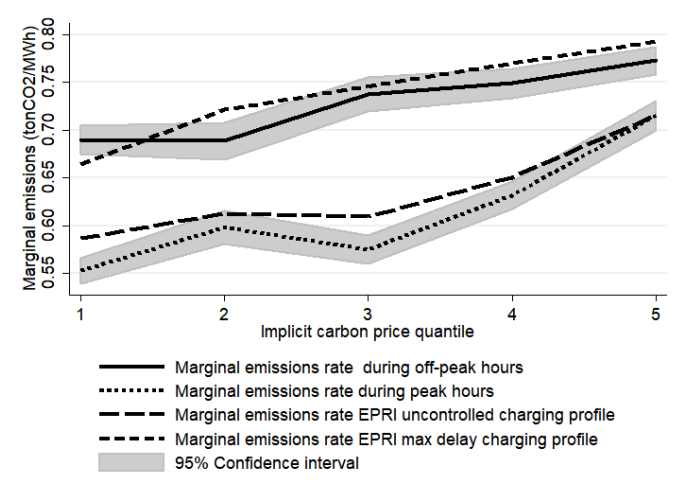

(a) MISO

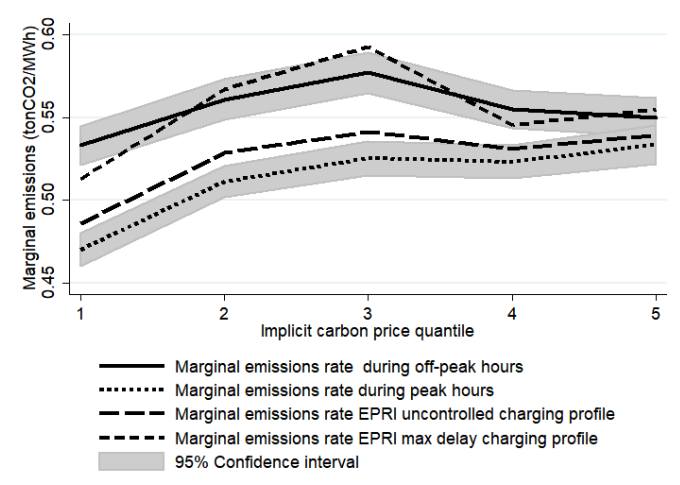

(c) ERCOT

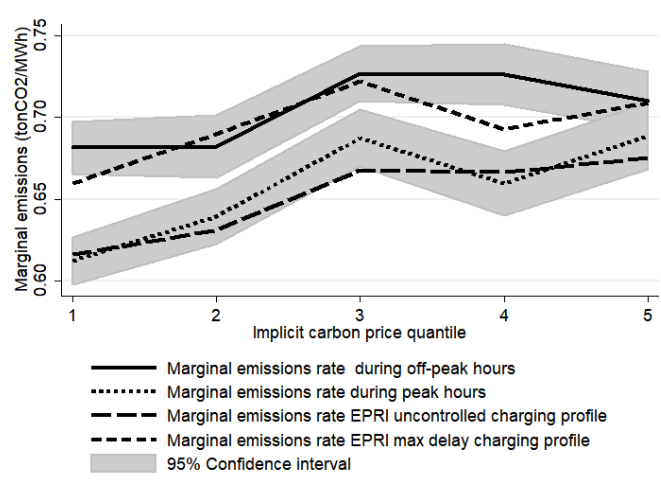

(b) SPP

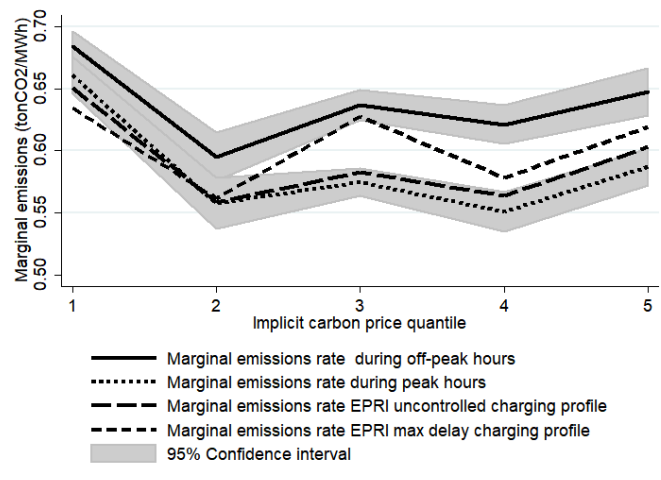

(d) PJM

Figure 5: $\mathrm{CO}_{2}$ emission rate for marginal generation for different quantiles of the implicit carbon price in ERCOT, MISO, PJM, and SPP. Error bars represent the $95 \%$ confidence interval. 


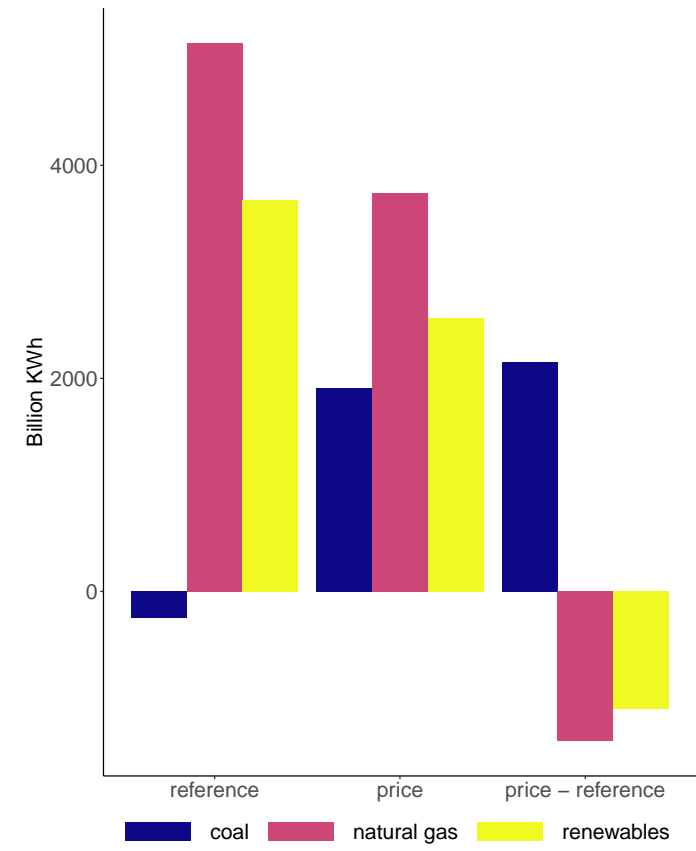

(a) Additional generation from EVs

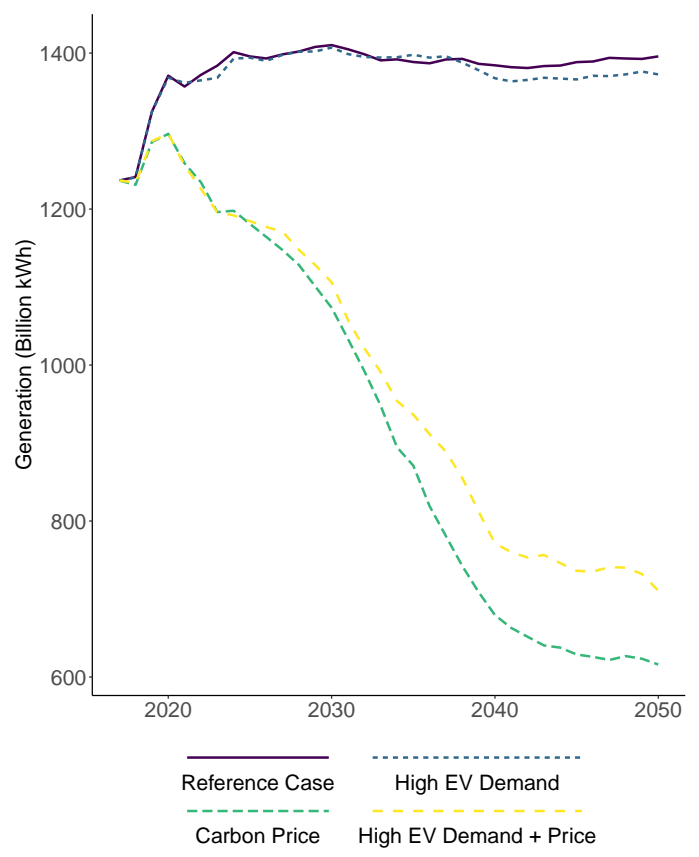

(b) Coal-fired generation

Figure 6: Panel (a) shows additional generation between 2020 and 2050 associated with the added electric vehicles between the reference and high electric vehicle case. 'Price' refers to our central case carbon price scenario. The rightmost set of three bars shows the difference between the effects with and without the carbon price. Panel (b) shows total coal-fired generation over time under different scenarios. 


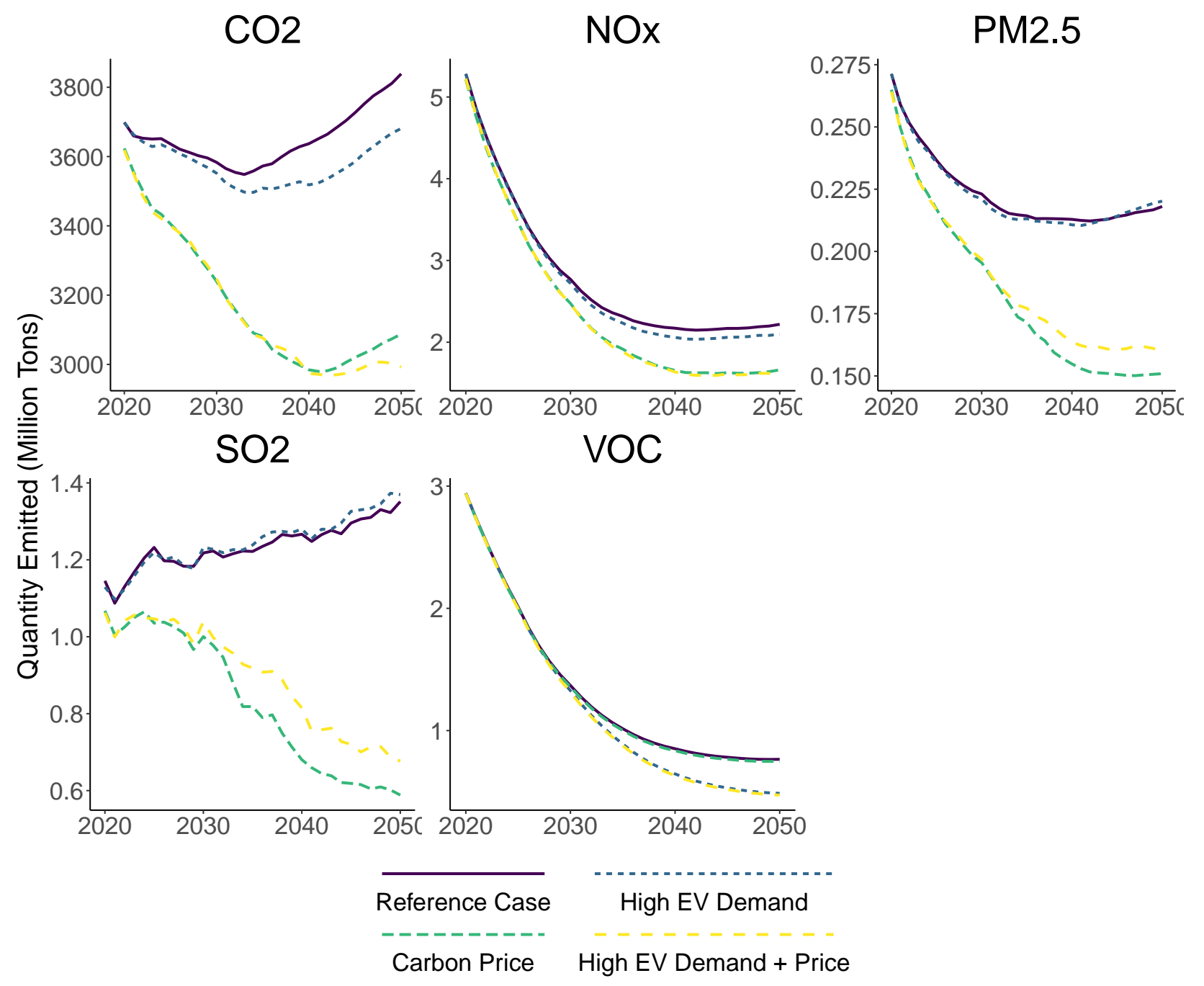

Figure 7: Aggregate emissions associated with passenger vehicles and the electricity generation sector. 


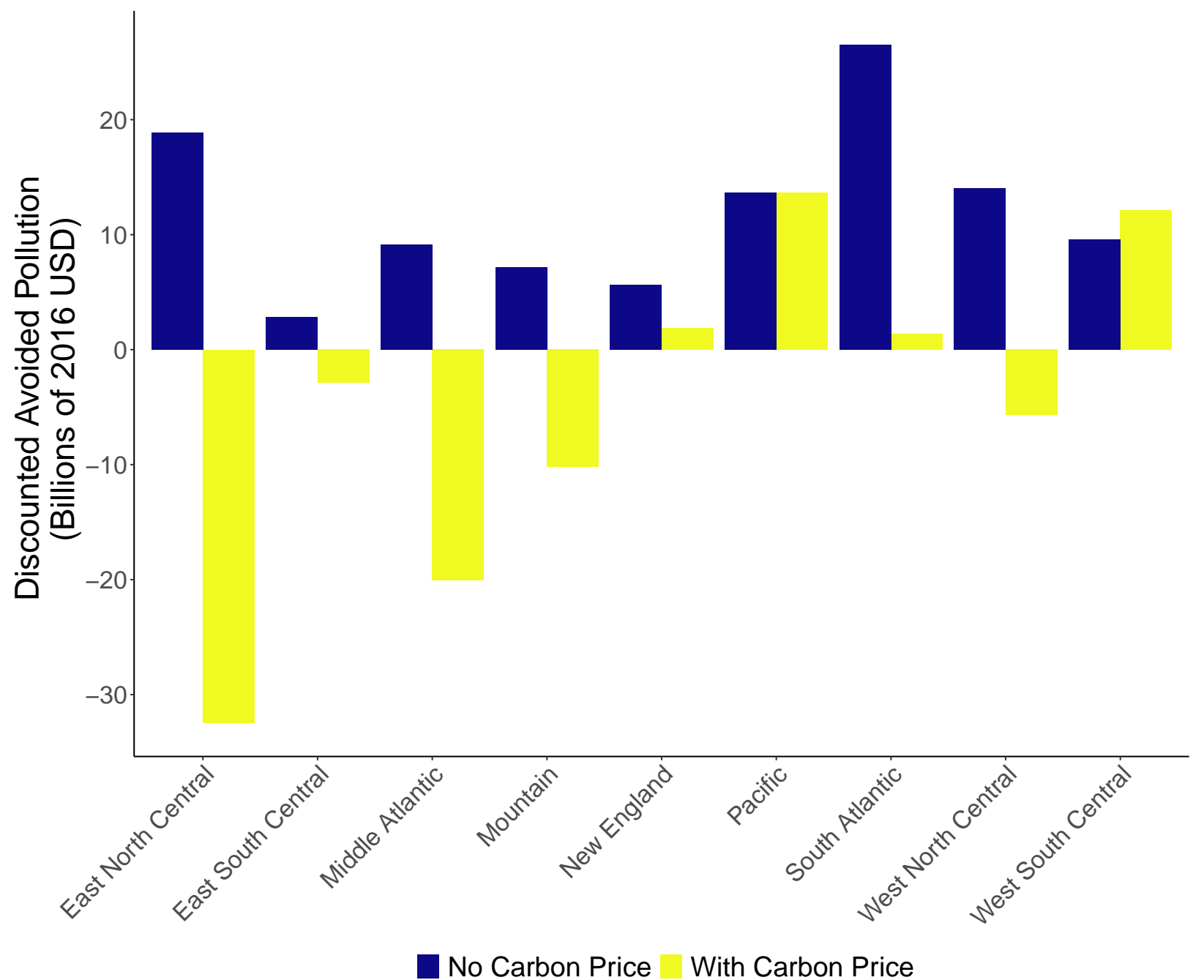

Figure 8: Change in discounted avoided pollution damages due to addition of electric vehicles (billions of $2016 \$$ ). 


\section{Appendix}

\section{A Analytical Model}

This Appendix section lays out a simple analytical theory model to provide further insight into the concepts discussed in Section 2. The purpose of this section is to highlight the main factors that influence when a carbon price is likely to be at a level that pushes coal generation to the margin and reduces the emission reduction benefits of electric vehicles.

The analytical model is explicitly a short-run model, but as discussed in Section 2, the implications carry over to power plant retirements in the long run. We make the same assumptions as in Section 2: inelastic electricity demand, a typical or average time period, heterogeneity in efficiencies or heat rates of different generation facilities, or differential efficiency investments as a response to carbon pricing. Again, we focus only on the wholesale market for electricity (i.e., the 'energy' market).

Let initial demand be denoted as $D_{0}$. This refers to the typical or average load on the electricity grid in a particular region at a particular time. For simplicity, we assume a competitive market for electricity. Power plants produce electricity with different fuels and technologies. As in Section 2, we consider must-take generation (nuclear and renewables, $R$ ), baseload natural gas combined cycle $(N G C C)$, coal $(C)$, and natural gas peakers $(N G)$. For illustrative purposes, we assume that each non-peaker technology faces a technologyspecific constant marginal cost and peaking plants face an increasing marginal cost. With the exception of the must-take generation, each technology produces when price reaches or exceeds marginal cost. The supply of must-take generation is constant at the capacity of the technology, and is given by $S_{R}(P)=\operatorname{Cap}_{R}$. We thus write the supply of electricity from power plants from each of the other fuels as follows:

$$
\begin{gathered}
S_{N G C C}(P)= \begin{cases}0 & P<M C_{N G C C} \\
{\left[0, \operatorname{Cap}_{N G C C}\right]} & P=M C_{N G C C} \\
\operatorname{Cap}_{N G C C} & \text { otherwise }\end{cases} \\
S_{C}(P)= \begin{cases}0 & P<M C_{C} \\
{\left[0, C_{C}\right]} & P=M C_{C} \\
\operatorname{Cap}_{C} & \text { otherwise }\end{cases} \\
S_{N G}(P)= \begin{cases}0 & P<M C_{N G}(0) \\
y(P) & \text { otherwise }\end{cases}
\end{gathered}
$$


where $M C_{N G C C}$ and $M C_{C}$ are the marginal costs of generation for natural gas combined cycle and coal plants. $M C_{N G}(0)$ refers to the minimum marginal cost of generation for natural gas peaker plants. $C a p_{N G C C}$ and $C a p_{C}$ represent the capacity of natural gas combined cycle and coal plants, respectively. $S_{N G}(P)$ is the upward-sloping supply curve of natural gas peakers once the price is sufficiently high that they are dispatched. The aggregate short-run supply curve is thus:

$$
S(P)=\operatorname{Cap}_{R}+S_{N G C C}(P)+S_{C}(P)+S_{N G}(P)
$$

Prices are determined by equating electricity demand with supply. That is, the equilibrium price $P^{*}$ is implicitly defined by the equilibrium condition that supply equal demand, $D_{0}=S\left(P^{*}\right)$.

\section{A.1 Imposition of a Carbon Price}

Now consider the introduction of a carbon price (e.g., a carbon tax or allowance price in a permit trading system). Let the carbon price (in terms of dollars per ton of $\mathrm{CO}_{2}$ ) be given by $\tau$. Let $\beta_{j}$ denote the emissions intensity of technology $j$, where $\beta_{N G C C}<\beta_{N G}<\beta_{C}$. For simplicity, we assume that $\beta_{N G}$ does not change along the supply curve, but we could easily allow for this without changing the insights from this framework. The carbon tax increases the marginal cost of production by $\tau \times \beta_{j}$. Under the simplifying assumption that each resource has a constant emissions intensity, $\widehat{S_{J}}(P, \tau)$ represents the supply function for resource $j$ under a carbon tax of $\tau$. Thus, for each fuel the post-tax supply function is given by:

$$
\begin{array}{r}
\widehat{S_{N G C C}}(P, \tau)=S_{N G C C}\left(P-\tau \beta_{N G C C}\right) \\
\widehat{S_{C}}(P, \tau)=S_{C}\left(P-\tau \beta_{C}\right) \\
\widehat{S_{N G}}(P, \tau)=S_{N G}\left(P-\tau \beta_{N G}\right) .
\end{array}
$$

Denote the equilibrium electricity price after a carbon price is added by $P^{* *} . P^{* *}$ is implicitly defined by the following equality:

$$
D_{0}=\operatorname{Cap}_{R}+S_{N G C C}\left(P^{* *}-\tau \beta_{N G C C}\right)+S_{C}\left(P^{* *}-\tau \beta_{C}\right)+S_{N G}\left(P^{* *}-\tau \beta_{N G}\right)
$$

Suppose that $P^{*}>M C_{N G}$, i.e., the natural gas peaker was initially the marginal generator. Then, there are three possible outcomes of the carbon price:

Case 1: The carbon price is low (recall Panel (b) in figure (1)). In this case, there is minimal 
reordering of the generation stack and the marginal generator is still the natural gas peaker.

This case occurs when $\tau \leq \frac{M C_{N G}\left(D_{0}-C a p_{R}-C a p_{N G C C}-C a p_{C}\right)-M C_{C}}{\beta_{C}-\beta_{N G}} .{ }^{41}$

Case 2: The carbon price is moderate (recall Panel (c) in figure (1)). In this case, there is more substantial reordering of the generation stack and coal generation is pushed to the margin. This case occurs when $\tau \in\left(\frac{M C_{N G}\left(D_{0}-C a p_{R}-C a p_{N G C C}\right)-M C_{C}}{\beta_{C}-\beta_{N G}}, \frac{M C_{N G}\left(D_{0}-C a p_{R}-C a p_{N G C C}-C a p_{C}\right)-M C_{C}}{\beta_{C}-\beta_{N G}}\right) .{ }^{42}$

Case 3: The carbon price is high (recall panel (d) in figure (1)). In this case, there is even more substantial reordering of the generation stack and coal generation is pushed to being supramarginal and uneconomic. This case occurs when $\tau \geq \frac{M C_{N G}\left(D_{0}-C_{a p}-C_{R} a p_{N G C}\right)-M C_{C}}{\beta_{C}-\beta_{N G}}$.

Note that at both moderate and high carbon prices, the total amount of coal generation will be reduced. But, under a moderate carbon price, the marginal generation can be coalfired.

\section{A.2 Adding Electric Vehicle Charging Demand}

Given the differences in emission factors between coal and natural gas, the intuition should already be clear about what would happen if we add load from electric vehicles charging. To be precise, we follow through by considering increased demand for electricity. Consider $D_{1}=D_{0}+D_{E V}$ where $D_{E V}>0$.

The additional electricity sector emissions from the electric vehicles charging is different depending on the level of the carbon price, in the following way:

Case 1 (Low Carbon Price): $\Delta$ Emissions $=D_{E V} \times \beta_{N G}$

Case 2 (Moderate Carbon Price): There are two possibilities depending on how much load is added by the electric vehicles. Let $\phi=\operatorname{Cap}_{C}-\left(D_{0}-\operatorname{Cap}_{R}-\operatorname{Cap}_{N G C C}-N G\left(P^{* *}-\right.\right.$ $\left.\left.\tau \beta_{N G}\right)\right)$.

Case 2a (New Load Covered By Coal Generation, $\left.D_{E V} \leq \phi\right)$ :

$\Delta$ Emissions $=D_{E V} \times \beta_{C}$

Case 2b (New Load Partly Covered By Coal Generation, $\left.D_{E V}>\phi\right)$ :

$$
\Delta \text { Emissions }=\phi \times \beta_{C}+\left(D_{E V}-\phi\right) \times \beta_{N G}
$$

\footnotetext{
${ }^{41}$ For no reordering at all to occur, $M C_{N G}(0)+\tau \beta_{N G}(0) \geq M C_{C}+\tau \beta_{C}$. This is a subset of case 1 . There is an additional case where a small amount of reordering occurs, but the marginal generator is still the natural gas peaker. This occurs when $\tau \in\left(\frac{M C_{N G}(0)-M C_{C}}{\beta_{C}-\beta_{N G}}, \frac{M C_{N G}\left(D_{0}-C a p_{R}-C_{a p_{N G C}}-C a p_{C}\right)-M C_{C}}{\beta_{C}-\beta_{N G}}\right)$. In terms of the emissions implications, this is identical to the case where no reordering occurs.

${ }^{42}$ In this case, $M C_{N G}\left(D_{0}-\operatorname{Cap}_{R}-\operatorname{Cap}_{N G C C}-\operatorname{Cap}_{C}\right)+\tau \beta_{N G} \leq M C_{C}+\tau \beta_{C}$ (the marginal cost of natural gas peakers that dispatch is less than or equal to the marginal cost of coal) as well as $M C_{N G}\left(D_{0}-\right.$ $\left.\operatorname{Cap}_{R}-\operatorname{Cap}_{N G C C}\right)+\tau \beta_{N G}>M C_{C}+\tau \beta_{C}$ (it is not cheaper to meet all remaining demand net of renewables and combined cycle electricity with natural gas).
} 


\section{Case 3 (High Carbon Tax): $\Delta$ Emissions $=D_{E V} \times \beta_{N G}$}

The key take-away here is that the change in emissions from the additional load from electric vehicles depends on the level of the carbon price. For moderate carbon prices (where moderate is determined by the marginal costs and emission factors of coal and natural gas), we can find that coal-fired generation is partly or entirely used to power electric vehicles. For a marginal increase in electric vehicle load, case $2 \mathrm{~b}$ does not apply and a moderate carbon price is covered by case $2 \mathrm{a}$. This is the case even though the moderate carbon pricing can reduce overall emissions itself. It just reduces the emission reductions from policies to promote electric vehicles.

\section{B Commodity prices}

This appendix provides additional information on the commodity prices used in the empirical analysis in our study.

Figure B.1 presents the price of natural gas and coal in ERCOT, MISO, PJM, and SPP for every month of our sample, expressed as $\$ / M M B t u$ and $\$ / M W h$. The latter is calculated as the plant-specific product of fuel price (in $\$ / M M B t u$ ) and heat rate (in MMBtu/MWh) in a given month. During 2014-2019, the EIA Form 923 data for ERCOT, MISO, PJM and SPP consists of 71,551 coal and natural gas transactions (plant, month, contract type, fuel type, fuel cost, etc.) with known positive fuel cost, for 276 plants. To calculate the variable fuel cost per MWh, the monthly fuel transactions are matched to monthly heat rates, which are calculated as the ratio of total fuel input for electricity generation and total net electricity generation per month. We can match 69,291 of these transactions for 273 plants $^{43}$, of which 26,247 are coal transactions and 43,044 are natural gas transactions. Of these, 58,599 transactions are spot or short-term contracts up to 12 months, of which 17,095 are coal transactions and 41,504 are natural gas transactions.

Figure B.2 presents the ratio of variable fuel cost (in $\$ / \mathrm{MWh}$ ) of coal-fired and gas-fired electricity generation in ERCOT, MISO, PJM, and SPP for every month in our sample, for different subsamples of the EIA Form 923 transaction data. Panel (a) is the standard case from Figure 3 that includes spot prices and contracts up to 12 months. Only focusing on spot prices (panel (b)) does not significantly change the ratio. Similarly, panel (c) shows that the ratios are not driven by outliers in the heat rate (above $50 \mathrm{MMBtu} / \mathrm{MWh}$ ) or fuel price (above 200 \$/MMBtu). For example, the peaks in gas prices around February 2015 and January 2018 are robust and arise because of cold spells and congestion in the gas

\footnotetext{
${ }^{43}$ Three plants generate no electricity in our sample: CCT Terminal in IL, BRSC shared storage in MI, and Silver Lake in MN.
} 


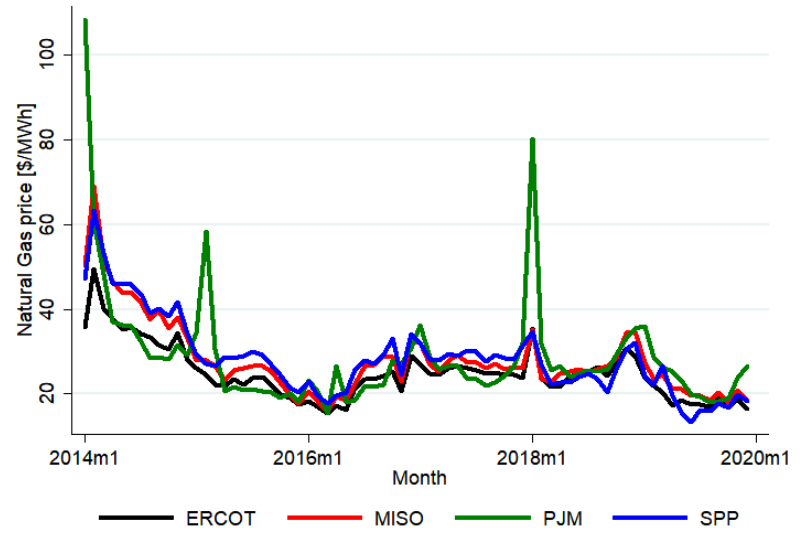

(a) Natural gas price $[\$ / \mathrm{MWh}]$

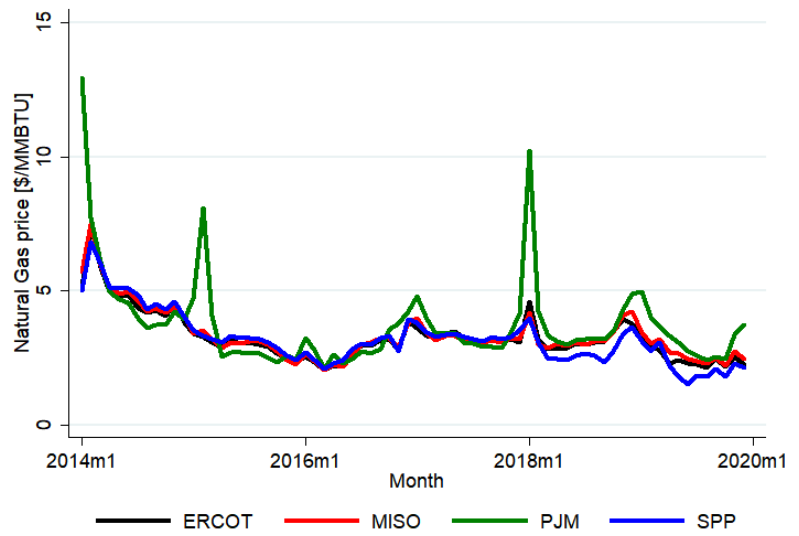

(c) Natural gas price $[\$ / \mathrm{MMBTU}]$

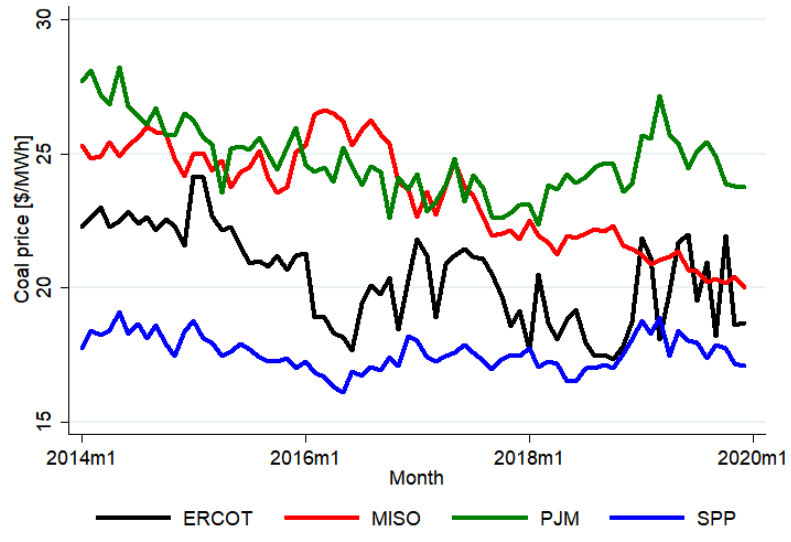

(b) Coal price $[\$ / \mathrm{MWh}]$

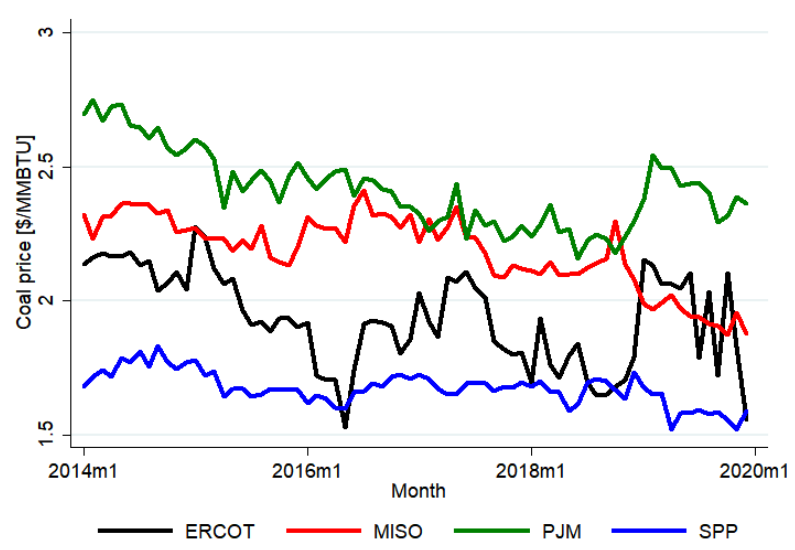

(d) Coal price $[\$ / M M B T U]$

Figure B.1: Price of natural gas and coal in ERCOT, MISO, PJM, and SPP during 2014-2019, using spot prices and long-term contract up to 12 months, in $\$ / \mathrm{MWh}$ and $\$ /$ MMBTU. 
network. Panel (d) shows the coal-gas ratio of the fuel cost in $\$ / M M B t u$, ignoring heat rate improvements that are affecting the ratio of the variable generation costs in $\$ / \mathrm{MWh}$. As a result, the level of the coal-gas ratio decreases, but not the general trend, because heat rate improvements happened continuously over the duration of our sample and mostly for gas-fired power plants.

All four panels in B.2 are extremely similar and any of these time series could be used for our empirical analysis to give comparable results.

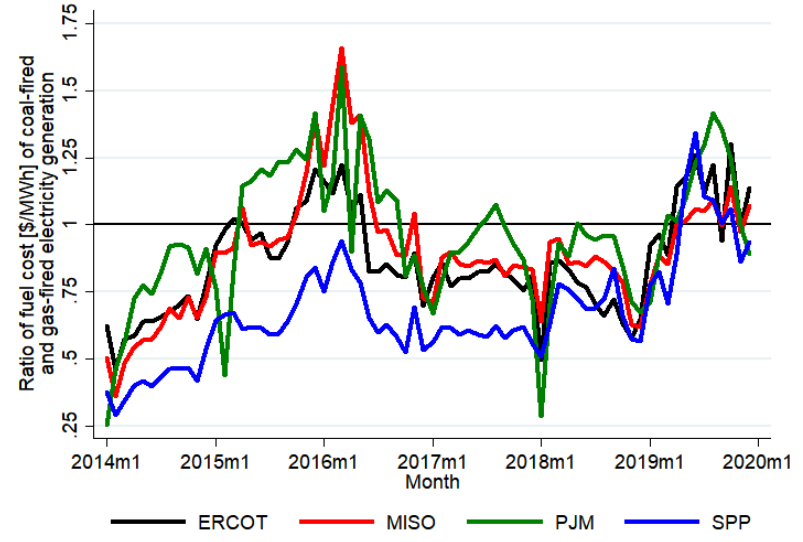

(a) Spot prices and contract up to 12 months

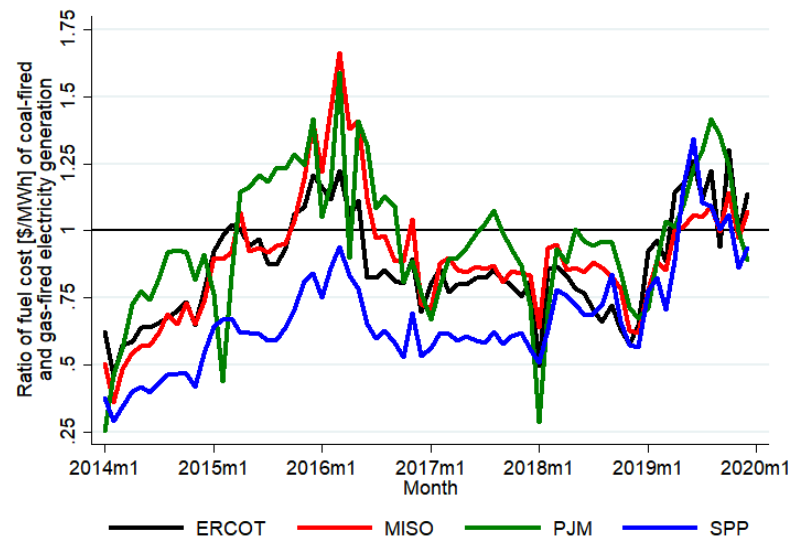

(c) Spot prices and contract up to 12 months, with outliers removed

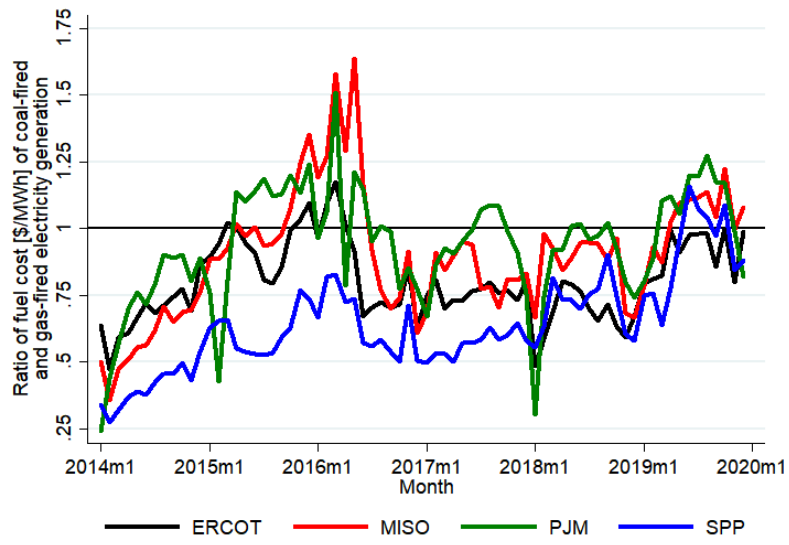

(b) Spot prices only

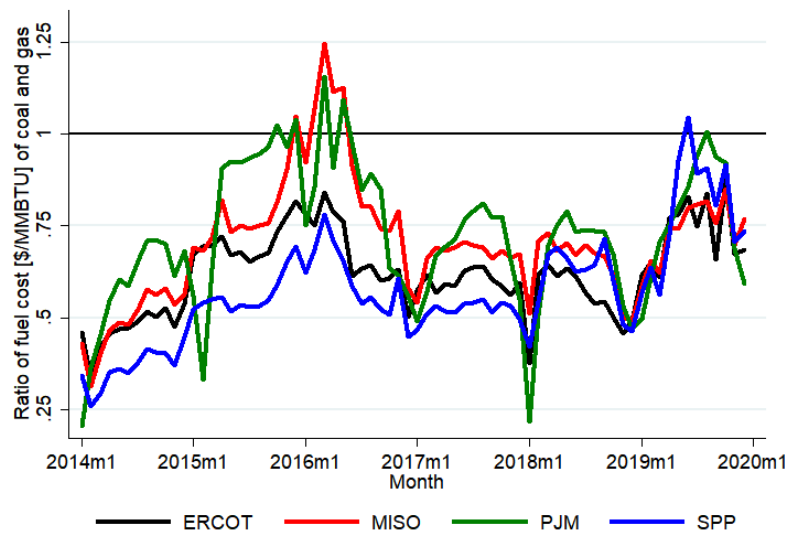

Figure B.2: Ratio of variable fuel cost of gas-fired and coal-fired electricity generation in ERCOT, MISO, PJM, and SPP during 2014-2019, for different subsamples of the EIA Form 923 transaction data. Outliers are defined as having a heat rate above $50 \mathrm{MMBtu} / \mathrm{MWh}$ or a fuel price above 200 $\$ /$ MMBtu. Panel (d) plots the ratio of the fuel cost in $\$ / M M B t u$, ignoring the heat rate. 


\section{Additional estimation results}

This appendix provides additional estimation results for our empirical analysis to provide further insight into the dynamics at play.

We begin by showing the share of marginal generation that is natural gas-fired over each quantile of the implicit carbon price (Figure C.1). This figure is the complement to Figure 4, and indeed we find that the relationship flips, with lower natural gas shares at higher implicit carbon prices for MISO, SPP, and ERCOT. PJM shows increasing natural gas shares at higher implicit carbon prices.

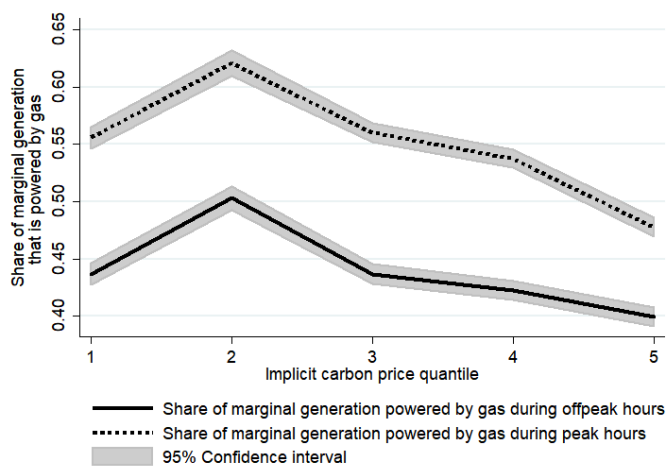

(a) MISO

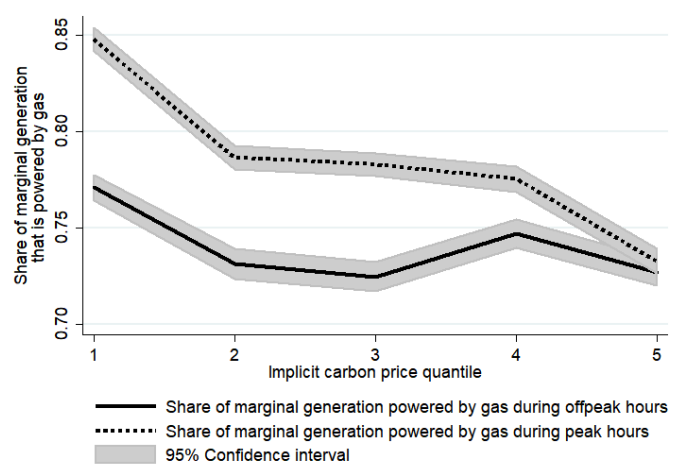

(c) ERCOT

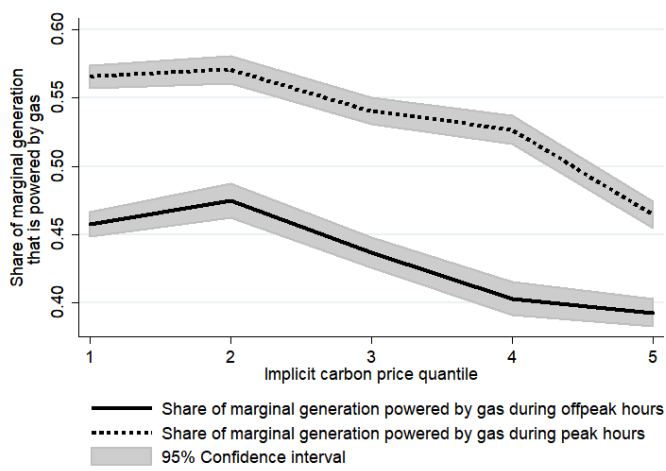

(b) SPP

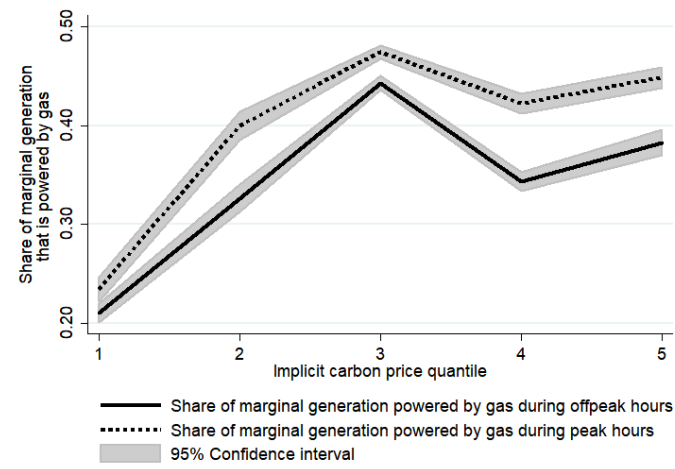

(d) PJM

Figure C.1: Share of marginal generation that is gas-fired generation for different levels of the carbon price in ERCOT, MISO, PJM, and SPP. Error bars represent the 95\% confidence interval.

We next show the details for the uncontrolled and maximum delay electric vehicle charging profiles from EPRI. As expected, the uncontrolled charging profiles are much higher in the evening hours and into the night, while the maximum delay charging profiles are much higher in the early morning just before households leave their home to go to work. These patterns are by design, but are based on some evidence from how consumers charge their electric vehicles that EPRI has collected. 

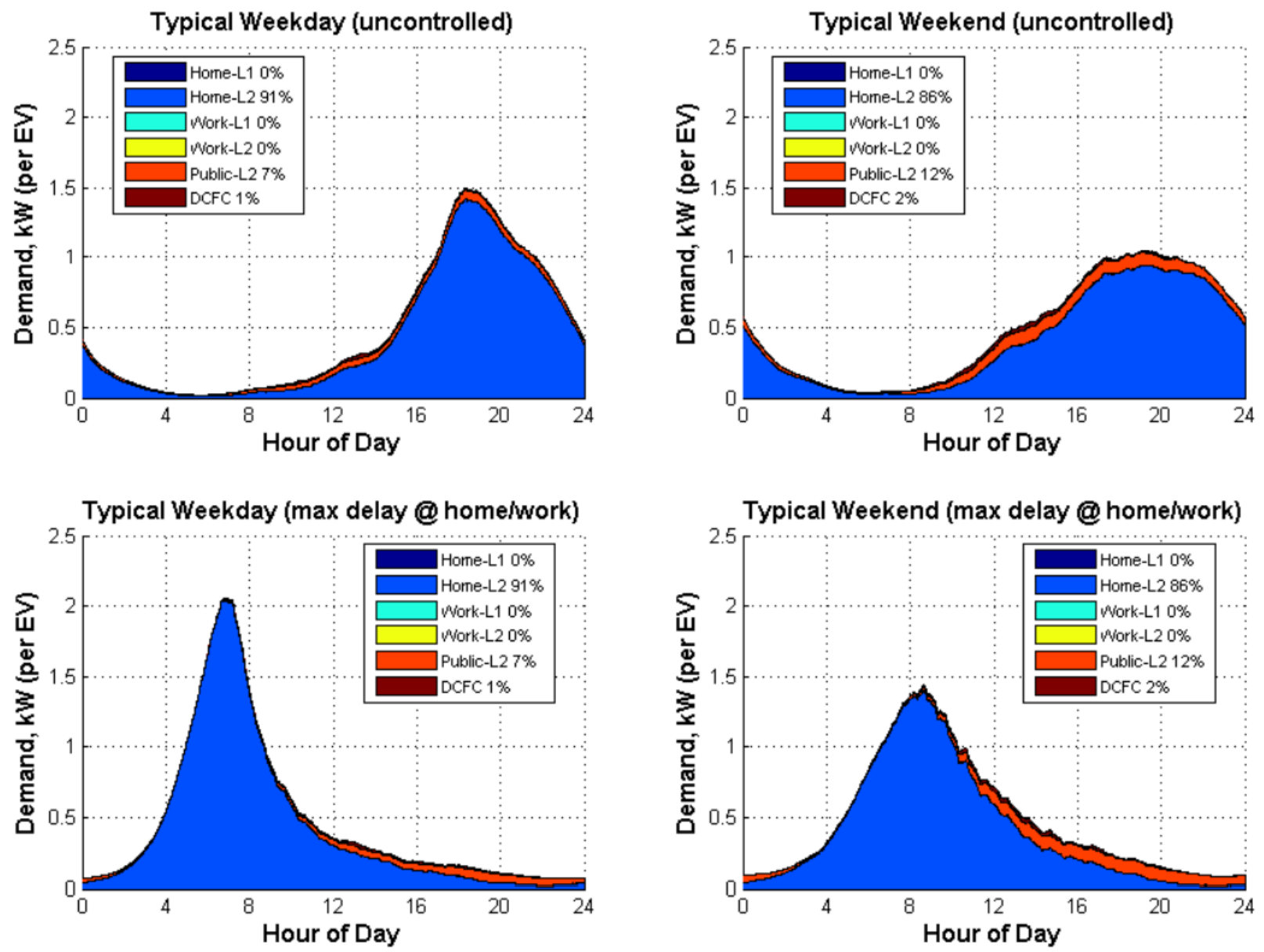

Figure C.2: Uncontrolled and maximum delay electric vehicle charging profiles from EVI-Pro (US Drive n.d.). 
To determine the marginal emissions from charging electric vehicles, we estimate for every ISO region how coal- and gas-fired electricity generation respond to changes in electricity consumption in peak and off-peak hours in our primary specification. Now we allow for a separate coefficient on load for each hour of the day because different charging profiles of electric vehicles would lead to more load at different hours of the day. This approach allows for insight into any given pattern of electric vehicle charging that the reader is interested in. The dependent variable in our analysis, $q_{f t}$ is generation technology $f$ hourly generation output at time $t$.

Similar to Holland et al. (2016) and Graff Zivin et al. (2014), we estimate the following empirical specification:

$$
q_{f t}=\sum_{h=1}^{24} \beta_{h} \text { hour }_{h} \text { load }_{t}+\gamma_{S} q_{\mathrm{solar}, t}+\gamma_{W} q_{\mathrm{wind}, t}+\delta_{h m y}+\epsilon_{f t} .
$$

where hour $_{h}$ is an indicator variable for hour of the day $h$ and $l_{\text {oad }}$ is electricity demand at time $t$. Because intermittent renewable generation can affect the need for conventional generation, we control for hourly solar output $q_{\text {solar, } t}$ and hourly wind output $q_{\text {wind, } t}$ (Fell \& Kaffine 2018). We also include fixed effects $\delta_{h m y}$ for each hour-of-the-day interacted with the month-of-the-sample to flexibly account for seasonality and daily patterns in load and fossil generation throughout our sample. $\epsilon_{f t}$ is the error term. The coefficients of interest are the marginal emissions factors $\beta_{h}$, which represent the change in coal- and gas-fired electricity generation in response to an increase in electricity consumption in hour of the day $h$.

To estimate how the marginal generation technologies depend on carbon prices, we run the above specification separately for different implicit carbon prices, just as in our primary specifications. For simplicity, in these specifications, we use a high, medium, and low implicit carbon price.

Figure C.3 presents the $\beta_{h}$ coefficients for the regression where the dependent variable is coal generation. These coefficients represent the share of marginal electricity demand that is met using coal-fired power generation for every hour of the day in ERCOT, MISO, PJM, and SPP for three implicit carbon prices. We see that the share of marginal generation that is coal-fired varies throughout the day and is generally higher at night. We find that a carbon price pushes coal to the margin in ERCOT, MISO and SPP, especially during peak hours. This means that at higher carbon prices, a larger share of marginal electricity demand is met by coal-fired power generation. However, in ERCOT we also find that at a high carbon price, this share decreases significantly during nighttime hours. The opposite happens in PJM, where coal is pushed off the margin in almost all hours when the carbon 


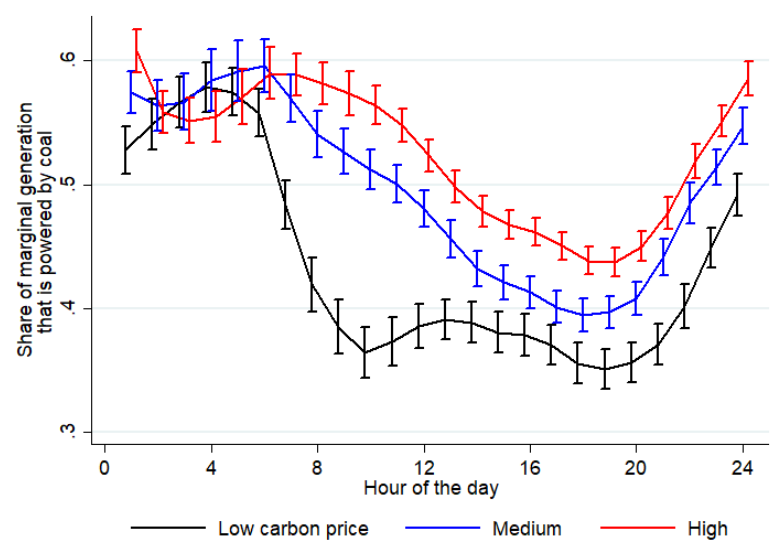

(a) MISO

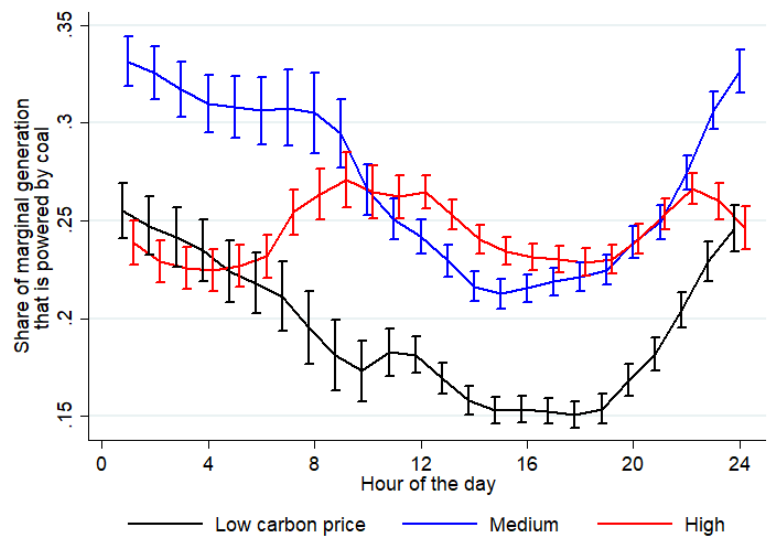

(c) ERCOT

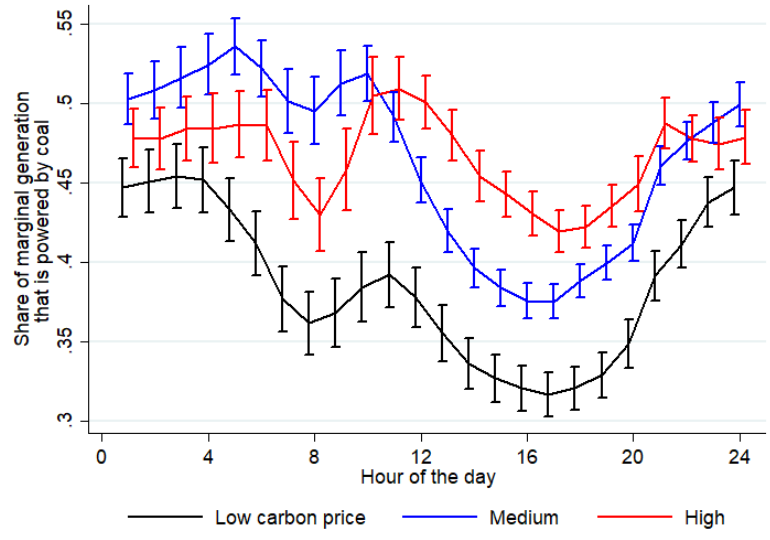

(b) SPP

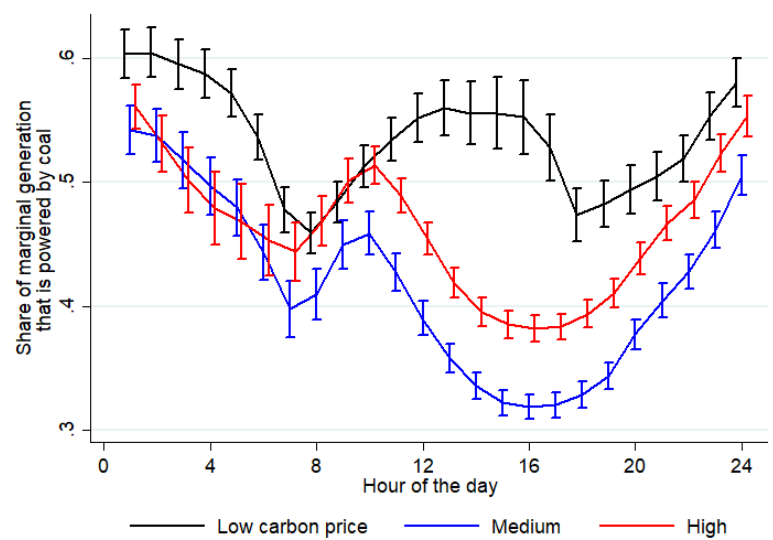

(d) PJM

Figure C.3: Share of marginal generation that is coal-fired generation for every hour of the day in ERCOT, MISO, PJM, and SPP. Error bars represent the $95 \%$ confidence interval. 
price increases.

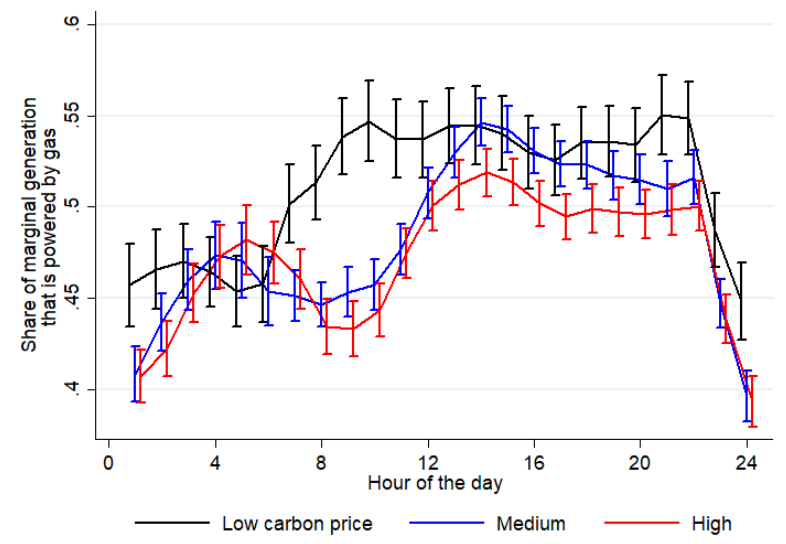

(a) MISO

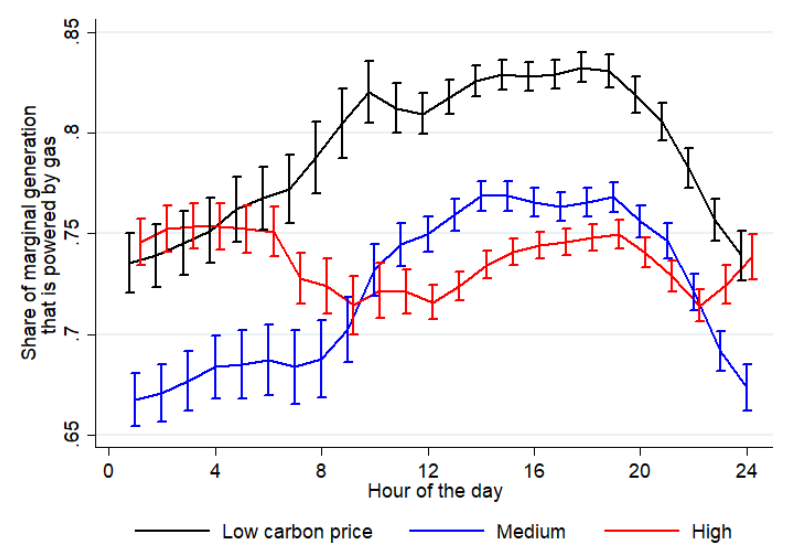

(c) ERCOT

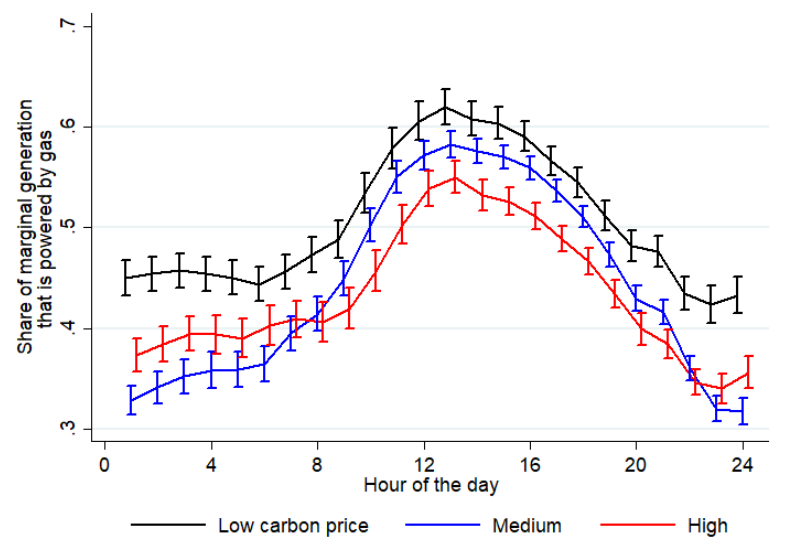

(b) SPP

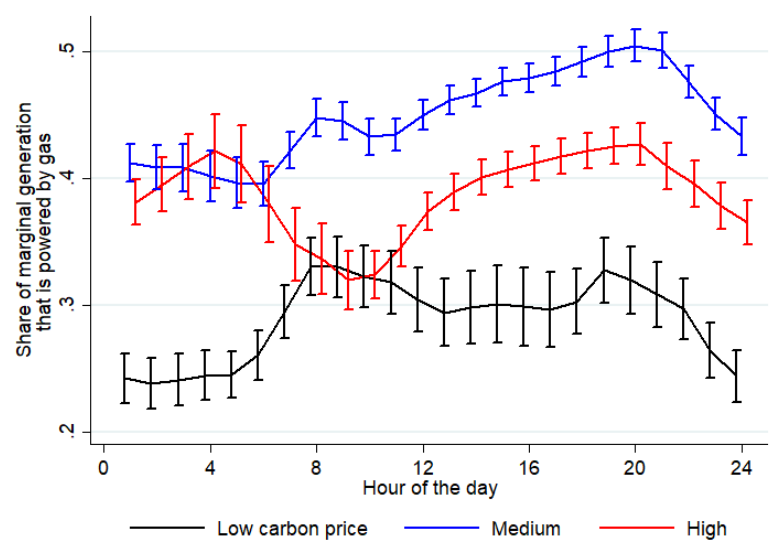

(d) PJM

Figure C.4: Share of marginal generation that is gas-fired generation for every hour of the day in ERCOT, MISO, PJM, and SPP. Error bars represent the $95 \%$ confidence interval.

Figure C.4 presents the share of marginal electricity demand that is met using natural gas-fired power generation for every hour of the day in ERCOT, MISO, PJM, and SPP. In this case, we find the opposite result: in ERCOT and SPP a carbon price pushes gas off the margin and on the margin in PJM. This is the case because in all ISO regions, except PJM, coal and gas comprise almost $100 \%$ of marginal generation. In PJM, the share of marginal demand met by imports, dual-fuel and oil is respectively $5 \%, 3 \%$ and $2 \%$.

Finally, Figure C.5 presents the combined effect of coal and gas-fired electricity generation on marginal carbon emissions for every hour of the day. Marginal carbon emissions are generally lower in the afternoon peak hours, because of a higher share of gas plants on the margin, but they are increasing with carbon prices, as coal is pushed to the margin. This effect is statistically significant in SPP and MISO. In PJM, marginal carbon emissions are 
lower at low carbon prices, while in ERCOT they are highest at medium carbon prices.

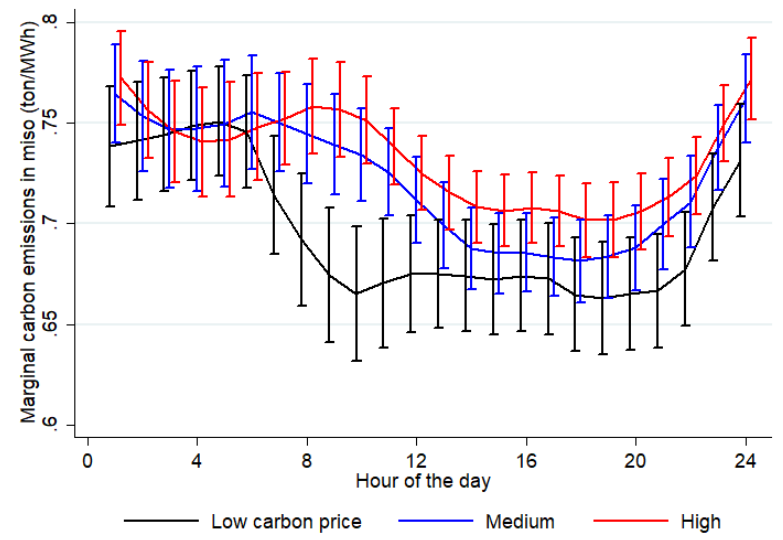

(a) MISO

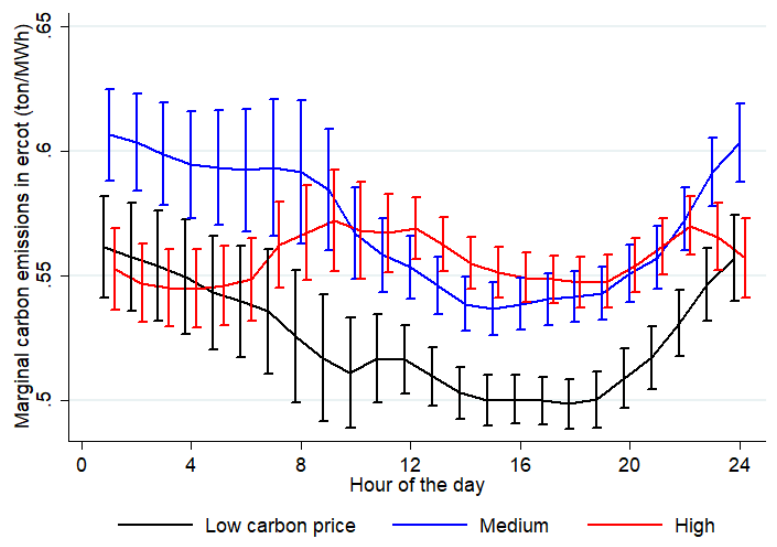

(c) ERCOT

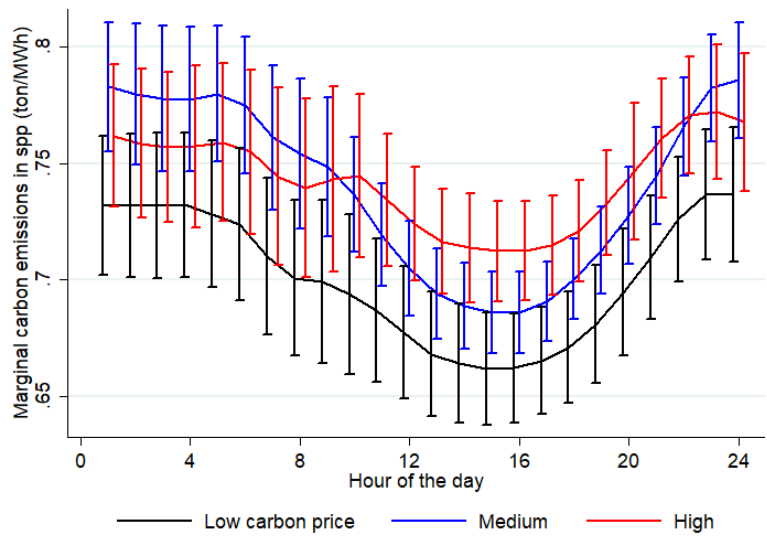

(b) SPP

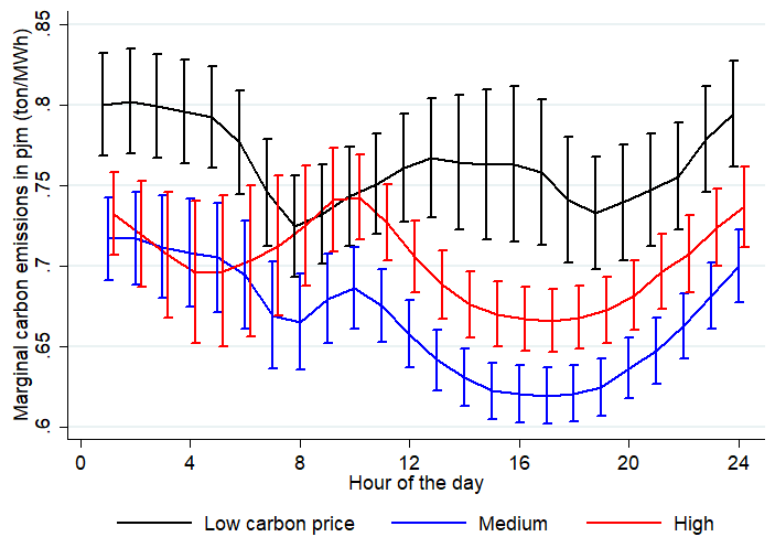

(d) PJM

Figure C.5: Marginal carbon emissions (ton/MWh) for every hour of the day in ERCOT, MISO, PJM, and SPP. Error bars represent the $95 \%$ confidence interval.

For reference and to provide further context, we also estimate the average share of coal generation at different levels of the carbon price in the four regions over the implicit carbon price quantiles (Figure C.6). We observe that in all four regions, the average share of coal generation is declining with higher implicit carbon prices.

Next, we examine the capacity factors for coal generation for each of the four regions (Figure C.7). We observe that in general, the capacity factors decline with higher implicit carbon prices, although the pattern in PJM is not nearly as clear or steady as in the other three regions, as in PJM there is a quick decrease followed by an increase and then another decrease.

In Figures C.8 and C.9, we show the net new natural gas-fired capacity over time and the total installed coal capacity over time. These are shown for each of the four regions and 


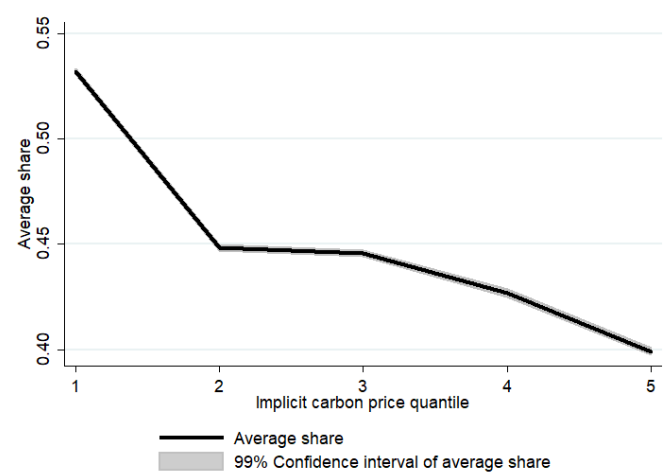

(a) MISO

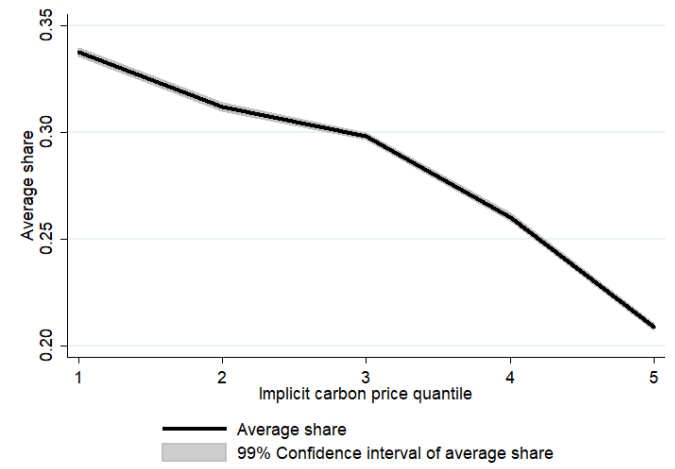

(c) ERCOT

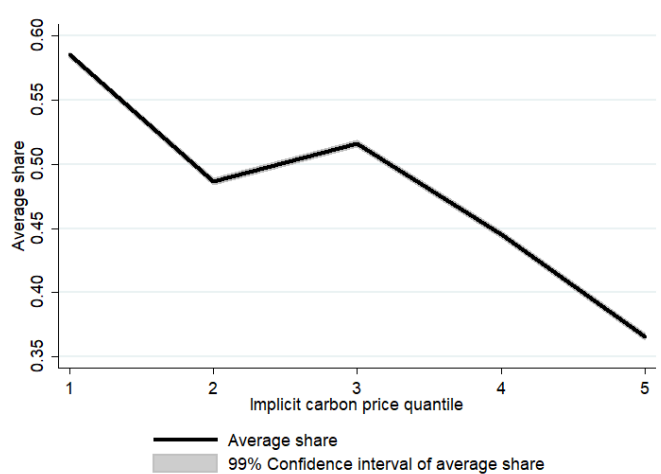

(b) SPP

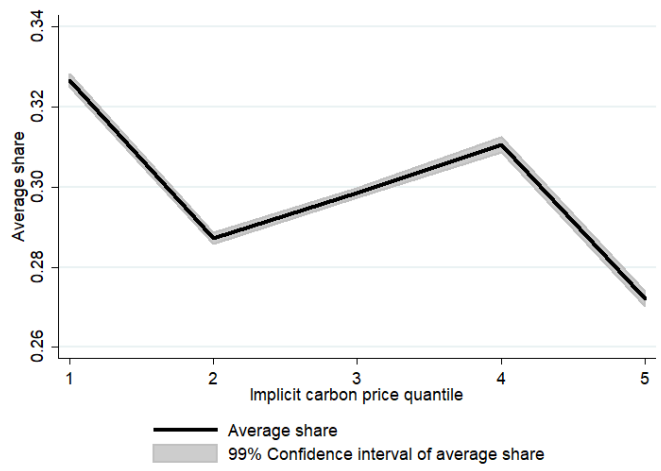

(d) PJM

Figure C.6: Average share of coal generation at different levels of the carbon price in ERCOT, MISO, PJM, and SPP. 


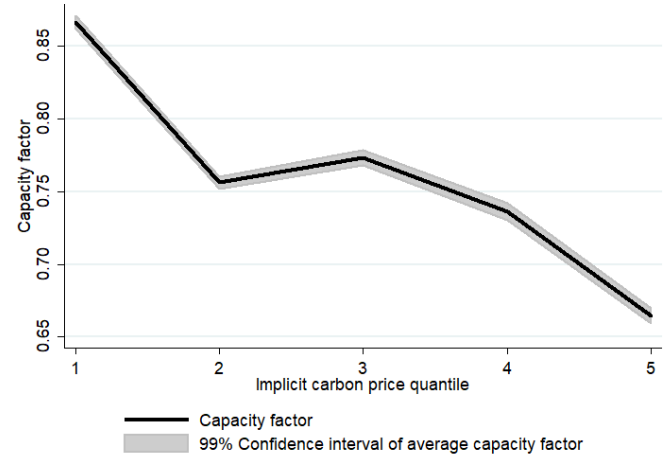

(a) MISO

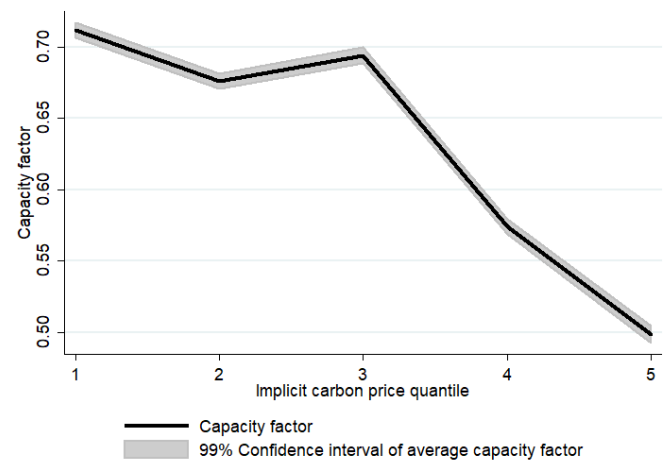

(c) ERCOT

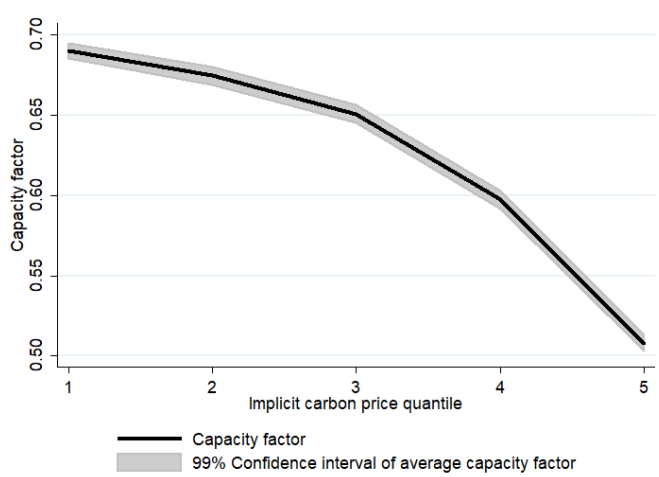

(b) SPP

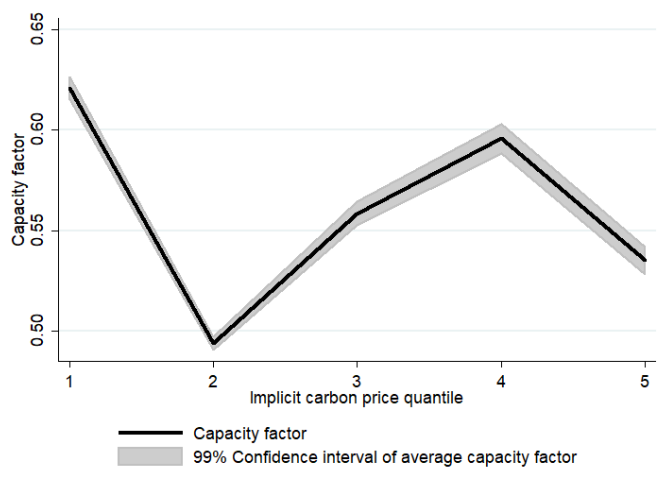

(d) PJM

Figure C.7: Capacity factor of coal generation at different levels of the carbon price in ERCOT, MISO, PJM, and SPP. 
highlight that PJM had much more new natural gas-fired capacity come online and many more coal plant retirements than the other three regions.

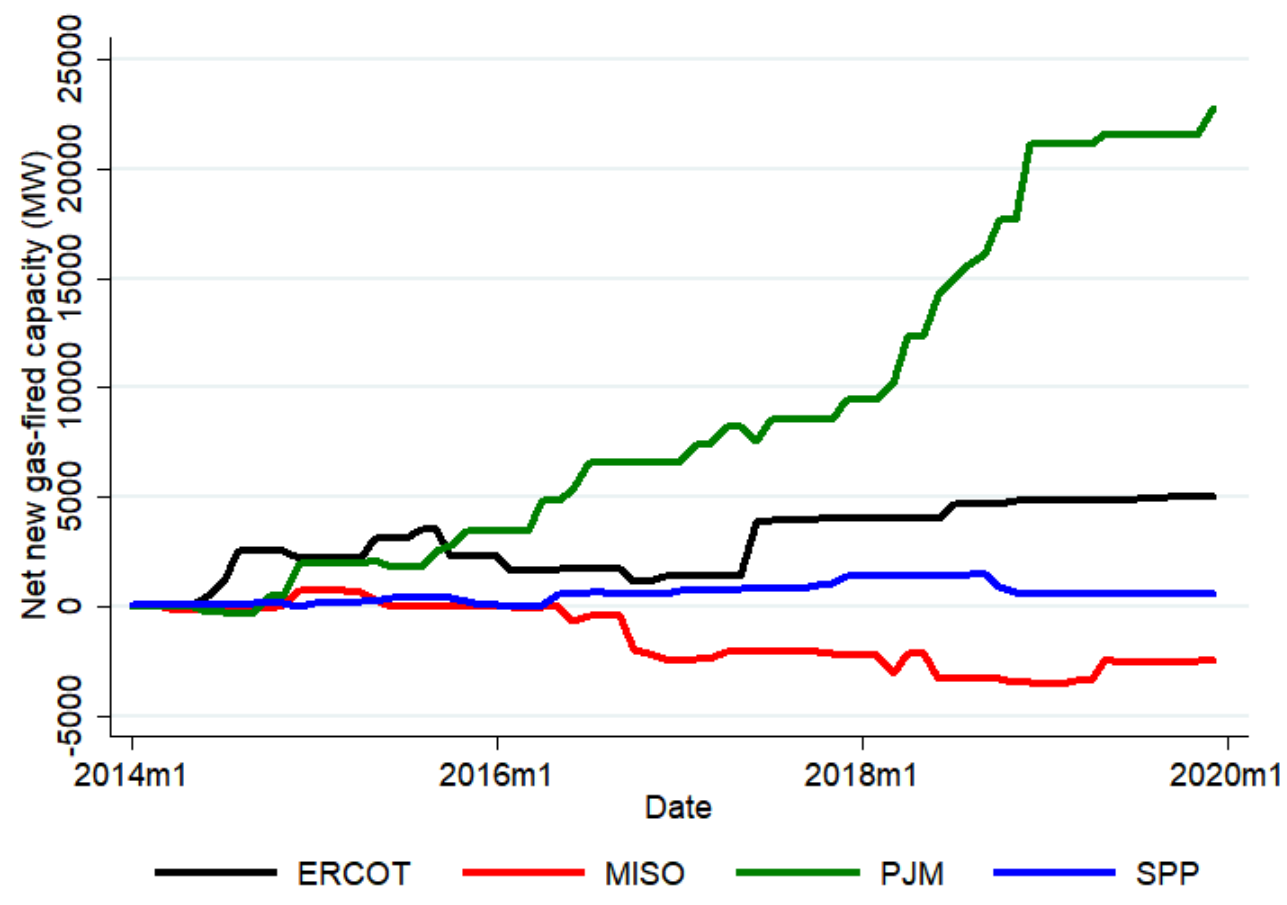

Figure C.8: Net new gas-fired capacity over time in ERCOT, MISO, PJM, and SPP. 


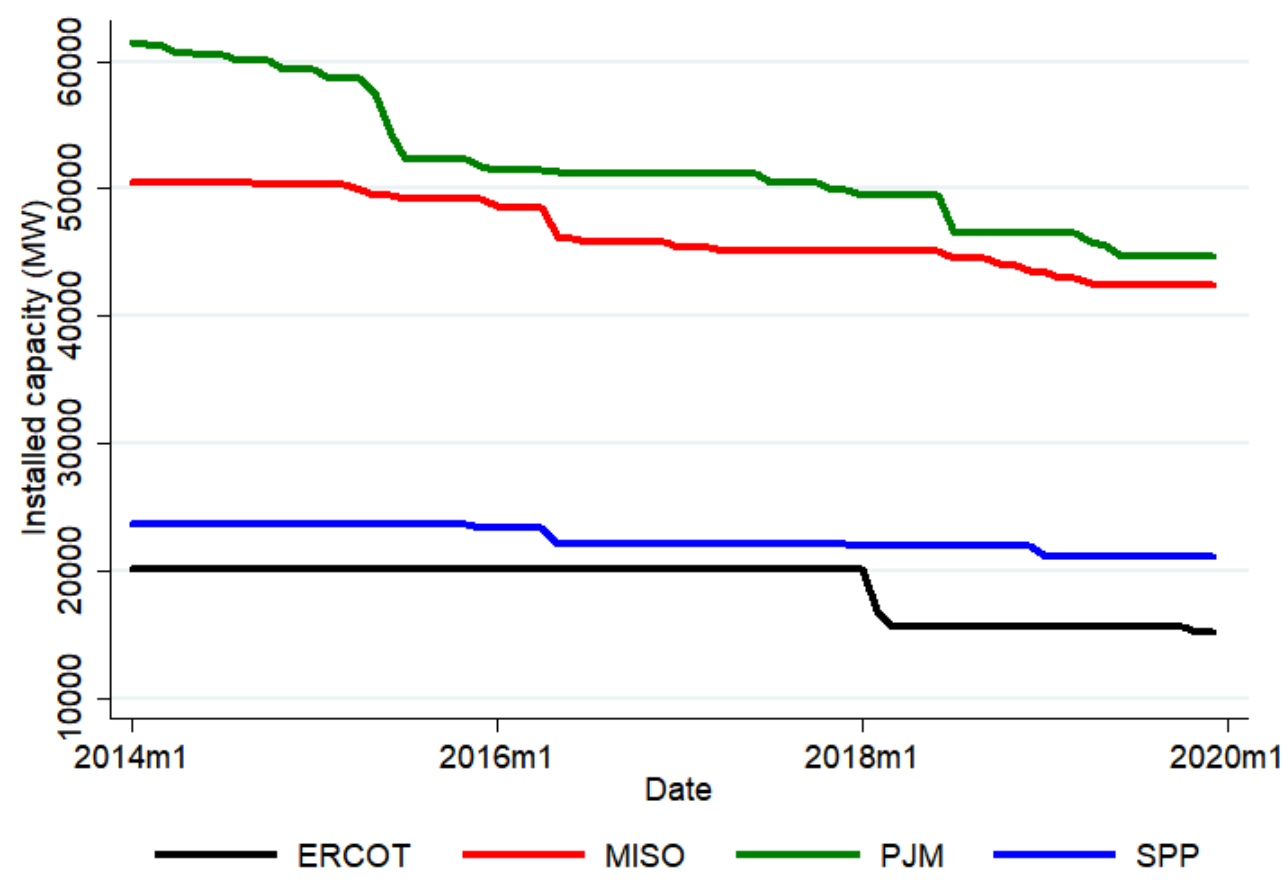

Figure C.9: Installed coal capacity over time in ERCOT, MISO, PJM, and SPP.

\section{Dynamic simulation}

\section{D.1 Literature Using the National Energy Modeling System}

To be more inclusive than there is space to be in the main text, here we discuss several more of the papers and reports that use the same modeling framework we do. Researchers have used versions of the National Energy Modeling System to examine a range of policy-relevant questions: to model proposed federal energy policies such as the Clean Power Plan (EIA 2015, Houser et al. 2015, Larsen et al. 2016) and others (Cullenward et al. 2016), to assess the capacity of broad policy portfolios to reduce emissions (Brown et al. 2001, Bernow \& Duckworth 1998, Geller et al. 1999, Palmer et al. 2010), to examine the efficacy of energy efficiency policies (Koomey et al. 2001, Scott et al. 2007, Auffhammer \& Sanstad 2011, Brown et al. 2011, Houser \& Mohan 2013), to explore dynamics of the natural gas markets (Brown et al. 2009, Brown \& Krupnick 2010, Mignone et al. 2017, Bordoff \& Houser 2014, Gillingham \& Huang 2019), to evaluate transportation policies alone and in combination (Gallagher \& Collantes 2008, Morrow et al. 2010, Small 2010, Chandel et al. 2011, Small 2012, Gillingham 2013, Gillingham \& Huang 2020), and to consider other changes to residential (Wilkerson et al. 2013), commercial, or industrial emissions (Brown et al. 2013). 


\section{D.2 Changes to Create Yale-NEMS}

In this study, we take a recent version of the National Energy Modeling System, and run it on a server at Yale. We call this "Yale-NEMS" at EIA's request as it may have small differences from the model run at EIA. Our modifications are quite minor and relate simply to outputting additional results and developing scenarios of our own. We can replicate EIA's own Annual Energy Outlook baseline (to a rounding error). In this Appendix section, we discuss the changes we made for this study to the modeling framework.

\section{D.2.1 Electric Vehicle Demand}

As discussed in the main text, vehicle adoption is modeled using a nested logit framework. The first stage is a choice of five fuel groups (conventional, hybrid electric, dedicated alternative fuel vehicle, fuel cell vehicles, and electric vehicles); the second stage involves choices between sub-technologies (e.g., 100- and 200-mile electric vehicles within the 'EV' category). Utility in the first stage depends on estimated utility for the sub-technologies in the second stage. Utility in the second stage is a function of vehicle characteristics including fuel economy, price, vehicle range, fuel availability, battery replacement cost, performance, home refueling capability, maintenance costs, luggage space, and make and model diversity within vehicle class. Increasing electric vehicle adoption in Yale-NEMS involves a combination of changes to the characteristics that contribute to this estimated utility: to battery prices (which in turn affect vehicle sales prices), to make and model diversity, and to preferences for different technology types.

Attributes of alternative fuel vehicles, including electric vehicles, are determined endogenously in the model. In particular, electric vehicle prices are based on the cost of comparable conventional vehicles with an additional battery system cost. Lithium ion costs (in dollars per $\mathrm{kWh}$ ) are modeled as a function of production scale and a learning rate that changes over four production stages. The $\$ / \mathrm{kWh}$ price is scaled by battery size and combined with an additional non-battery system cost before being added back to the base vehicle cost. Yale-NEMS' baseline treatment of battery prices is arguably conservative on a number of fronts. First, the starting price in 2017 is higher than many estimates-100 mile and 200 mile range electric vehicle batteries are assumed to cost $\$ 340$ and $\$ 290$ per $\mathrm{kWh}$, respectively, while industry estimates are much lower (note that the newest AEO has lower battery costs). Additionally, the learning curve is rather flat. Under the default assumptions, the price levels off by 2040 at around $\$ 190 / \mathrm{kWh}$ and $\$ 165 / \mathrm{kWh}$ for the two types of electric vehicles, which is above more recent estimates (e.g., around $\$ 156 / \mathrm{kWh}$ in 2019 and even lower today). ${ }^{44}$

\footnotetext{
${ }^{44}$ See https : //www. theverge.com/2021/3/15/22325813/vw-volkswagen-power-day-battery-electric-car-announc
} 
Several of our scenarios involve directly modifying the price trajectory for batteries to be consistent with much more optimistic industry projections (as low as $\$ 20 / \mathrm{kWh}$ in 2040 in both the main high EV demand scenario and the high electric vehicle demand scenario with preferences for electric vehicles increased earlier).

Make and model diversity is a straightforward parameter that captures the diversity of offerings of a given technology relative to gasoline vehicles. We gradually increase this parameter to equal gasoline vehicle offerings through the 2020s, but it has only a modest effect on vehicle adoption.

For each technology in the calibrated logit model, there is a constant added to the utility from specific characteristics that captures unobserved preference for different types of vehicles. As electric vehicles become more widespread, people may become more comfortable with the idea of purchasing them and utility from an electric vehicle may change, even controlling for observable improvements in characteristics. To incorporate this dynamic and to match BNEF's electric vehicle adoption trajectory, we increase the constant for all plugin electric vehicles. This preference adder increases over time, following the logistic shape typical of the adoption of new technologies. Exact details on this trajectory are available from the authors upon request.

\section{D.3 Additional Figures and Tables from Dynamic Simulation}

In this Appendix section, we present a set of additional figures and tables to further highlight different aspects of the results and better explain our scenarios. We begin by showing a map of the electricity market module and transportation module regions used in this study (Figure D.1). We then present the path of prices over time of 100-mile and 200-mile range compact electric vehicles in both the high electric vehicle demand and reference case (Figure D.2). The path of prices over time for conventional vehicles is also shown for reference. This figure shows that the price is declining faster in the high electric vehicle demand case than in the reference case. Figure D.3 shows the share of new light duty vehicles that are electric vehicles or plug-in hybrid electric vehicles across our scenarios, showing the ambition in our high electric vehicle scenario.

For additional context, in Table D.1 we show the number of electric vehicle sales in two example years, 2030 and 2040, along with the number of total light-duty vehicles for reference. This table shows the dramatic increase in electric vehicle sales in the high electric vehicle scenario relative to the reference case, which amounts to an additional 2.47 million sales in 2030 and an additional 8.84 million sales in 2040.

mc_cid=982fee4e91\&mc_eid=b1fa5041a3. 
Table D.1: Sales of electric vehicles and total vehicles by region and scenario

\begin{tabular}{clllll}
\hline \multirow{2}{*}{ East North Central } & \multicolumn{3}{c}{ Reference Case } & \multicolumn{2}{c}{ High EV Demand } \\
& & EV Sales & Total LDV Sales & EV Sales & Total LDV Sales \\
\hline \multirow{2}{*}{ East South Central } & 2040 & 0.17 & 2.58 & 0.57 & 2.59 \\
& 2030 & 0.06 & 0.61 & 1.56 & 2.63 \\
Middle Atlantic & 2030 & 0.07 & 0.81 & 0.18 & 0.79 \\
& 2040 & 0.19 & 2.25 & 0.46 & 0.81 \\
Mountain & 2030 & 0.09 & 1.23 & 0.52 & 2.25 \\
\multirow{3}{*}{ New England } & 2040 & 0.12 & 1.39 & 1.37 & 2.27 \\
& 2030 & 0.06 & 0.71 & 0.27 & 1.24 \\
Pacific & 2040 & 0.06 & 0.72 & 0.80 & 1.40 \\
South Atlantic & 2030 & 0.46 & 2.38 & 0.15 & 0.72 \\
& 2040 & 0.46 & 2.51 & 0.40 & 0.72 \\
West North Central & 2030 & 0.25 & 3.36 & 1.56 & 2.37 \\
West South Central & 2040 & 0.33 & 3.63 & 0.83 & 3.35 \\
& 2030 & 0.06 & 1.04 & 2.17 & 3.61 \\
United States & 2030 & 0.17 & 1.08 & 0.20 & 1.04 \\
& 2040 & 0.23 & 2.45 & 0.62 & 1.10 \\
\hline
\end{tabular}

Notes: Sales are in millions of vehicles. The 'Reference Case' and 'High EV Demand' columns contain sales of electric vehicles ('EV Sales') and of all light-duty vehicles ('LDV Sales') in those scenarios in both 2030 and 2040 .

On the left side of Figure D.4, we show the capacity factor for coal-fired power plants in each of our scenarios. On the right side of Figure D.4, we present the total capacity of coalfired power plants. These figures show that the dominant force in the Yale-NEMS results is the retirement of coal plants (and delayed retirements due to electric vehicles when there is carbon pricing that would have been retiring the coal plants anyway). Figure D.5 shows the total net installed capacity of renewable energy in each of the scenarios. The high electric vehicle demand combined with carbon pricing leads to the most renewables installed, and this is followed by the carbon pricing scenario, the high electric vehicle demand scenario, and the reference case.

Figure D.6 shows the net present value of avoided pollution damages by pollutant for each of the scenarios relative to the reference case. Again a 3\% discount rate is used. The greatest avoided pollution damages are from avoided $\mathrm{CO}_{2}$, followed by $\mathrm{SO}_{2}, \mathrm{NO}_{\mathrm{x}}, \mathrm{PM} 2.5$, and VOCs. Figure D.7 presents a map of the United States, with lighter colors showing higher net avoided damages (summed over all sectors and all pollutants) relative to the reference case by Census region. The greatest benefits accrue to the Southeast in the high electric vehicle scenario and to the upper Midwest in the other scenarios. These results are a function of the existing vehicle stock, existing electricity generation mix, and what generation will be used to charge the electric vehicles. Figure D.8 shows a breakdown of 
Panel (a) of Figure 6 by region. The top panel (Panel (a)) shows two regions where electric vehicles reduce more emissions under a carbon price than in a world without the carbon price: Pacific and West South Central. The bottom panel (Panel (b)) shows that in five regions there is an increase in emissions due to added electric vehicles under a carbon price policy.

Figure D.9 shows that the interaction between electric vehicles and carbon pricing can still occur when the model is adjusted to run an reference case similar to AEO2020. Our last figure, Figure D.10, shows the capacity factor for coal and the total capacity under the sensitivity run with low-cost renewables and the sensitivity run with earlier electric vehicle adoption. We see that our main finding-that higher electric vehicle demand can slow coal retirements-can still hold under lower-cost renewables and are even stronger with faster adoption of electric vehicles. Of course, we should caution that low-enough costs of renewables would eventually push coal supramarginal and would flip our main finding. 


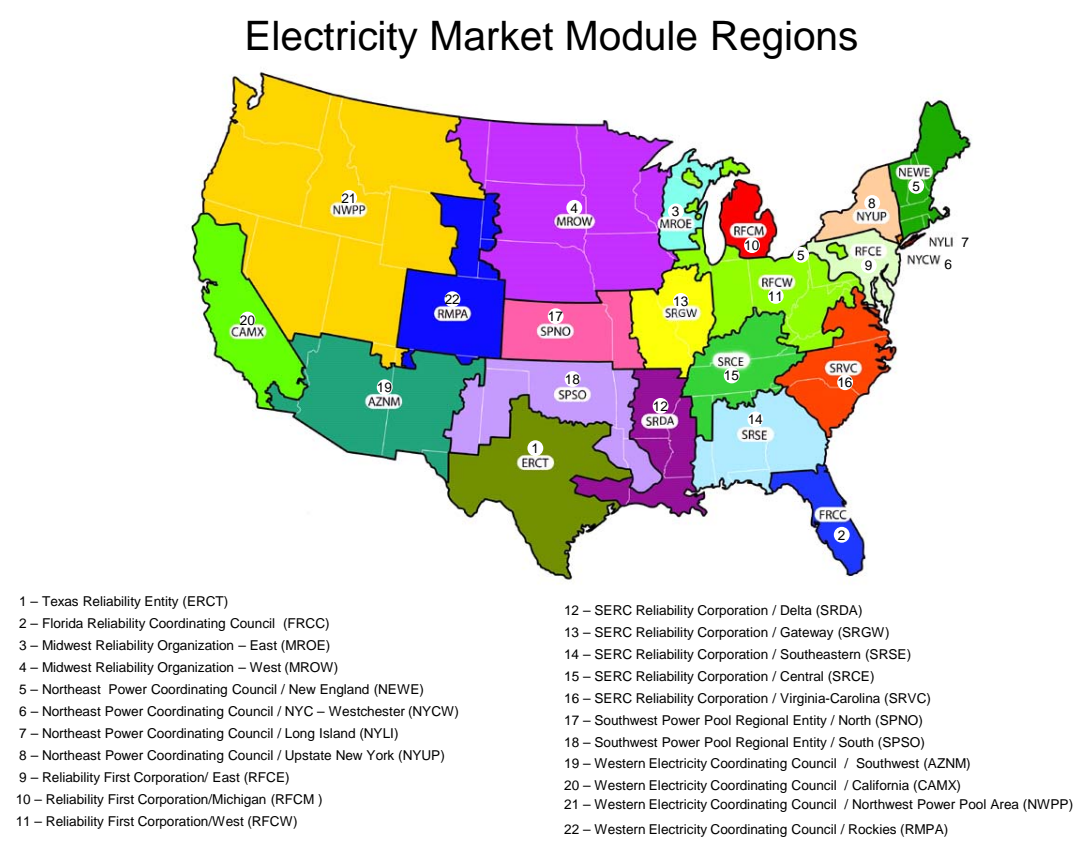

(a) Yale-NEMS electricity market module calculations are done at the NERC region level. Source: EIA

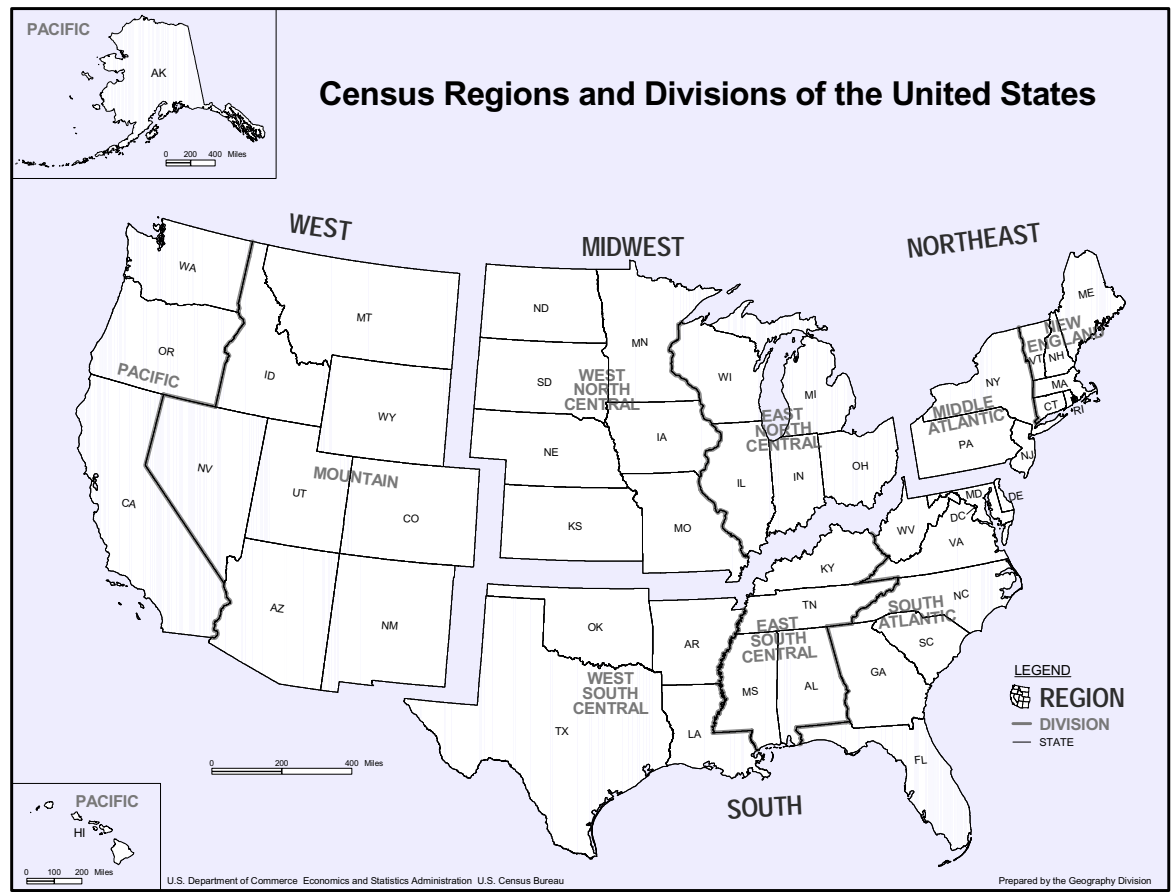

(b) Many submodule calculations are done at the census region level, including the transportation calculations. Source: US Census Bureau

Figure D.1: Regions used in different parts of Yale-NEMS. 


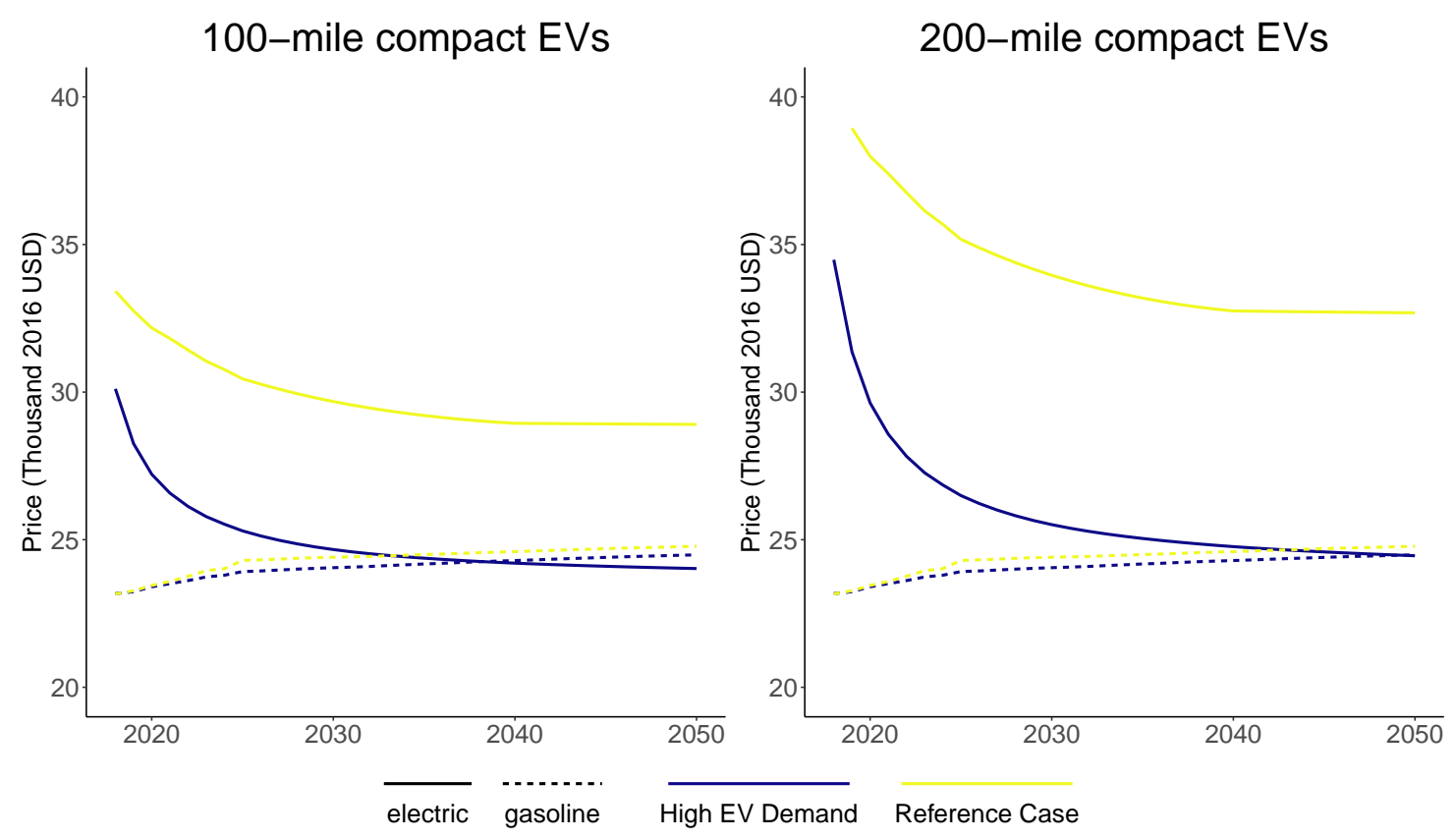

Figure D.2: Price of 100-mile and 200-mile compact EVs for the reference scenario and the high EV demand scenario compared to gasoline vehicle prices.

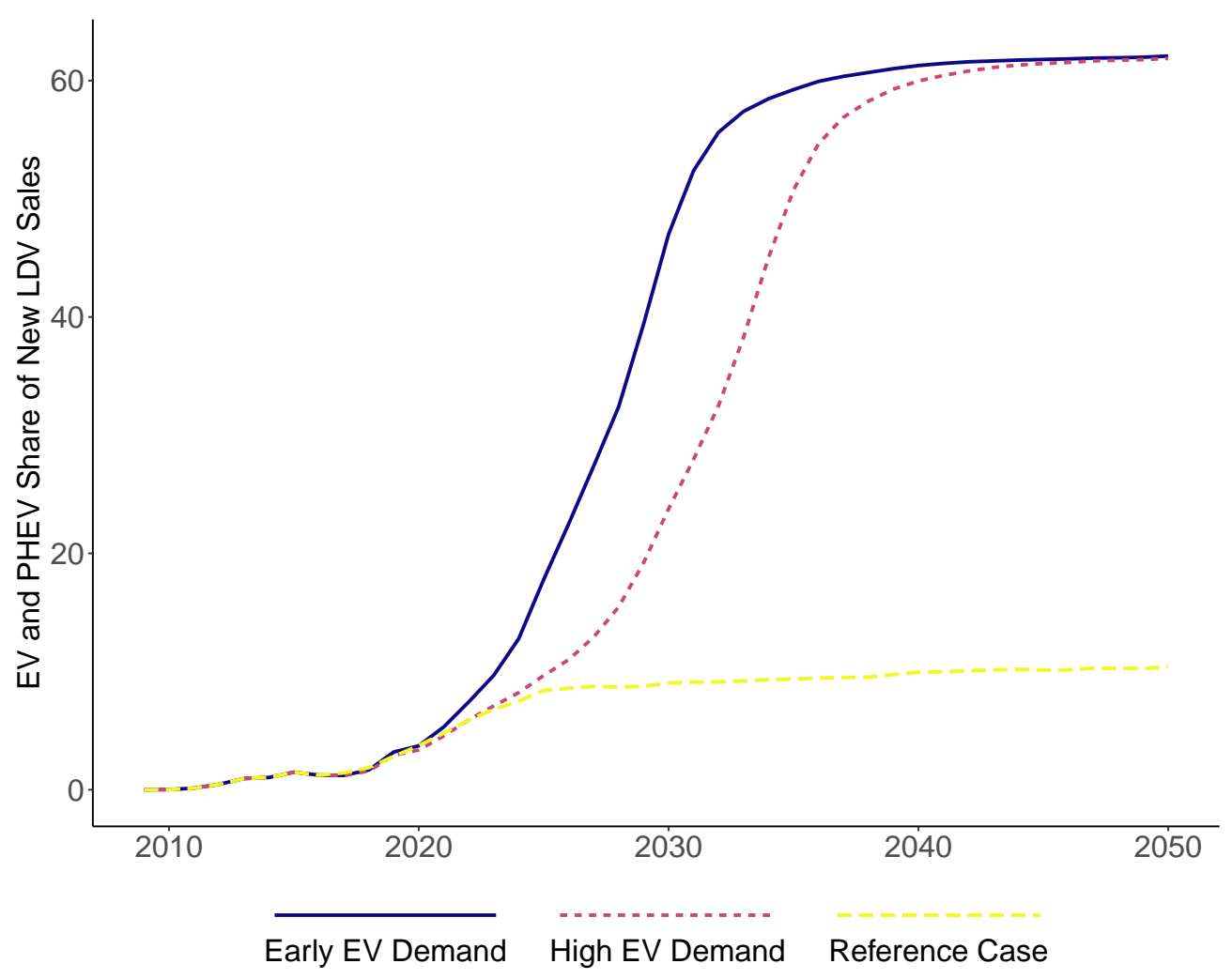

Figure D.3: Share of new light-duty vehicle sales that are EVs or plug-in hybrid EVs (PHEVs) in the high EV demand case compared to the reference case and a sensitivity case. 


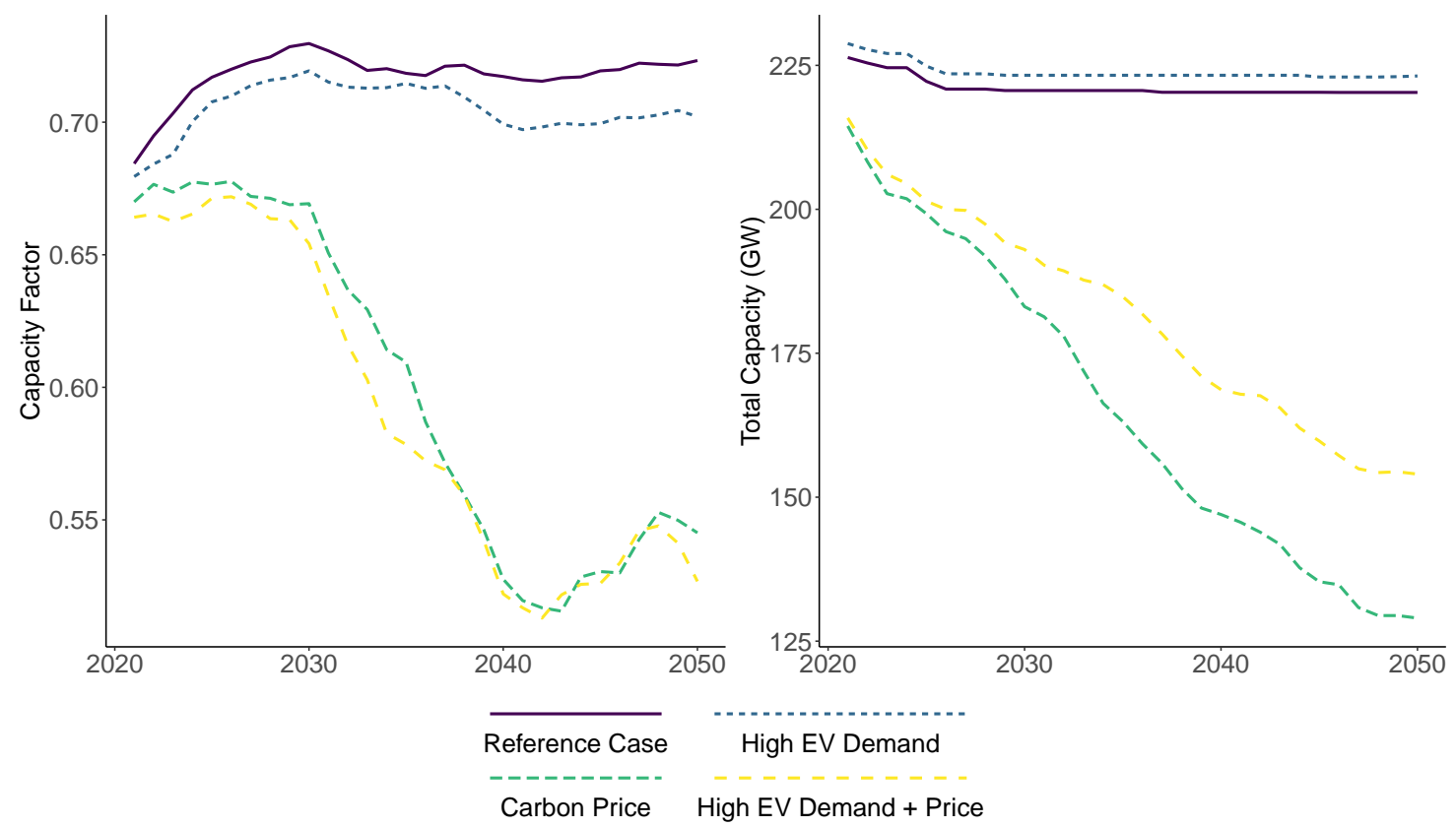

Figure D.4: Coal capacity factor (left) and total capacity (right) under the central four scenarios.

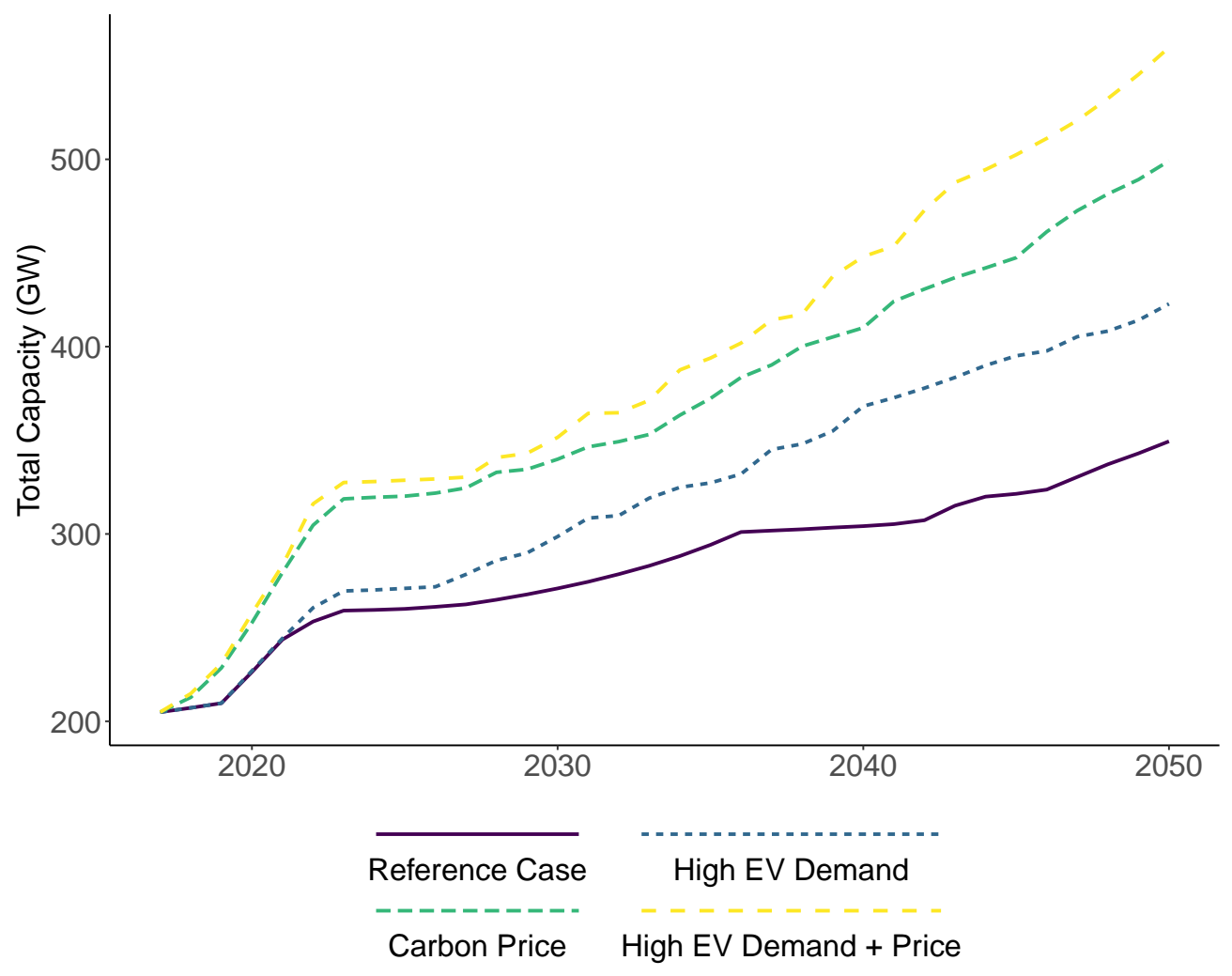

Figure D.5: Capacity of renewables facilities for the central four scenarios. 


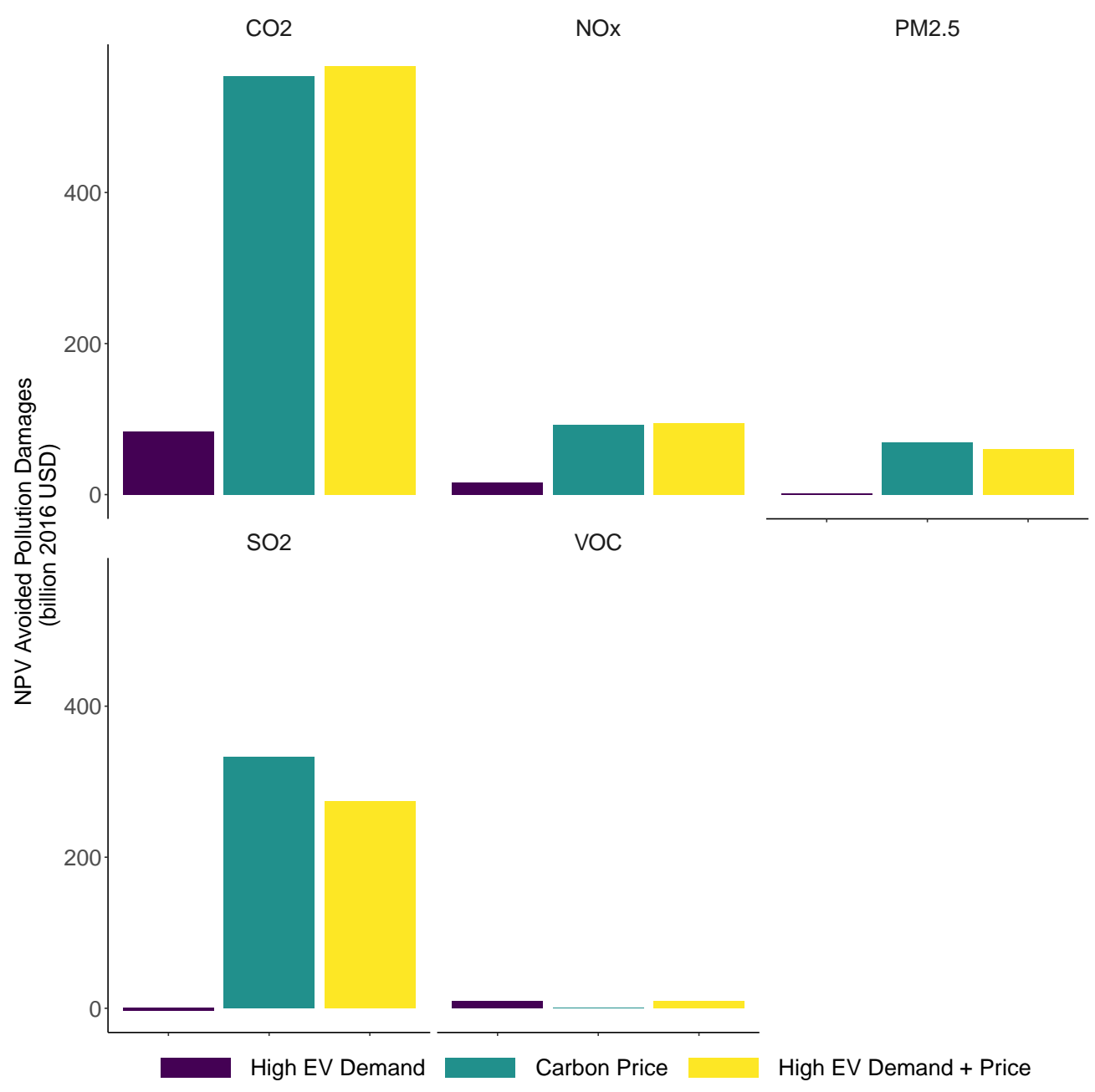

Figure D.6: Total avoided damages by pollutant relative to the reference case. 


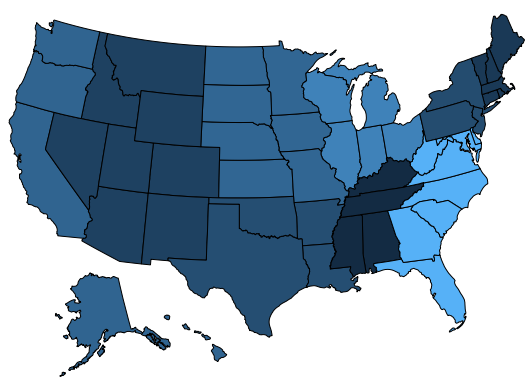

Avoided Damage Per Year (Billions)

$\begin{array}{lll}0.2 & 0.4 & 0.6\end{array}$

(a) Avoided damages (billions) per year in the high EV scenario.

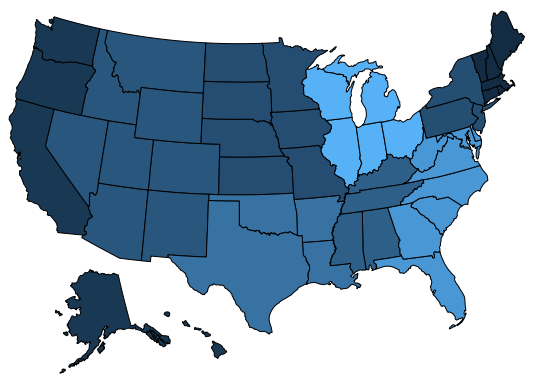

Avoided Damage Per Year (Billions) $\quad 2 \quad 4 \quad 6$

(b) Avoided damages (billions) per year in the combined high $\mathrm{EV}+$ carbon price scenario.

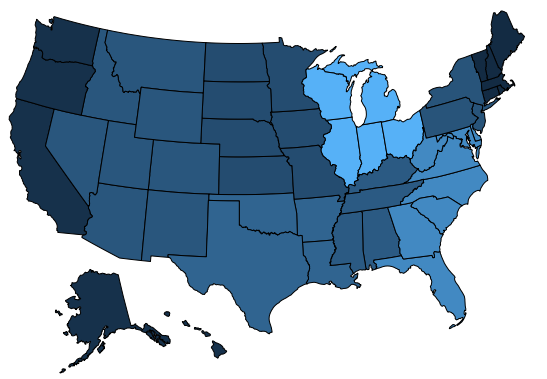

$\begin{array}{lllll}\text { Avoided Damage Per Year (Billions) } & 2 & 4 & 6 & 8\end{array}$

(c) Avoided damages (billions) per year in the pricing-only scenario.

Figure D.7: Scenarios involving a carbon price. 


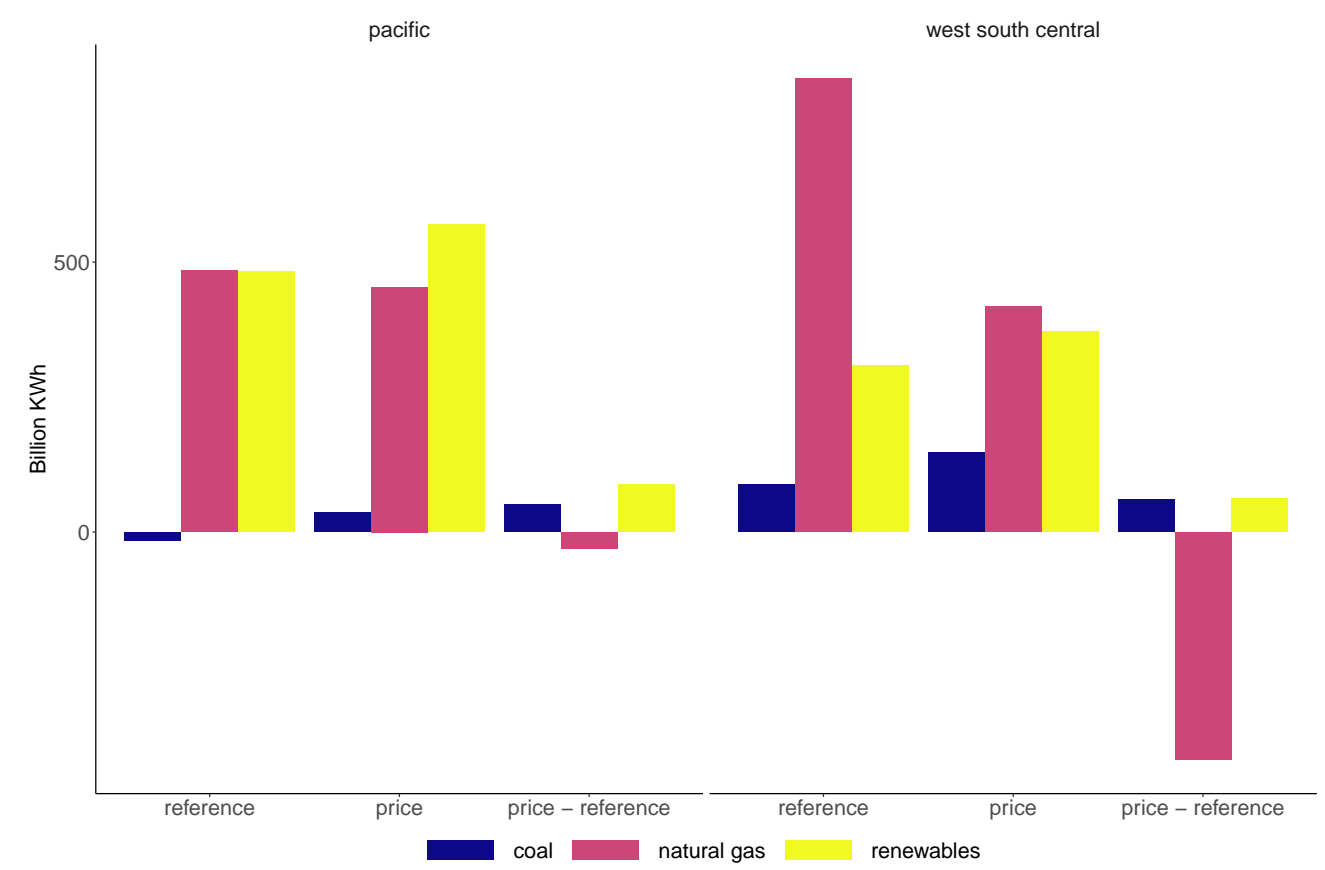

(a) In two regions, EVs are more emissions reducing under a carbon price than in a world without it.

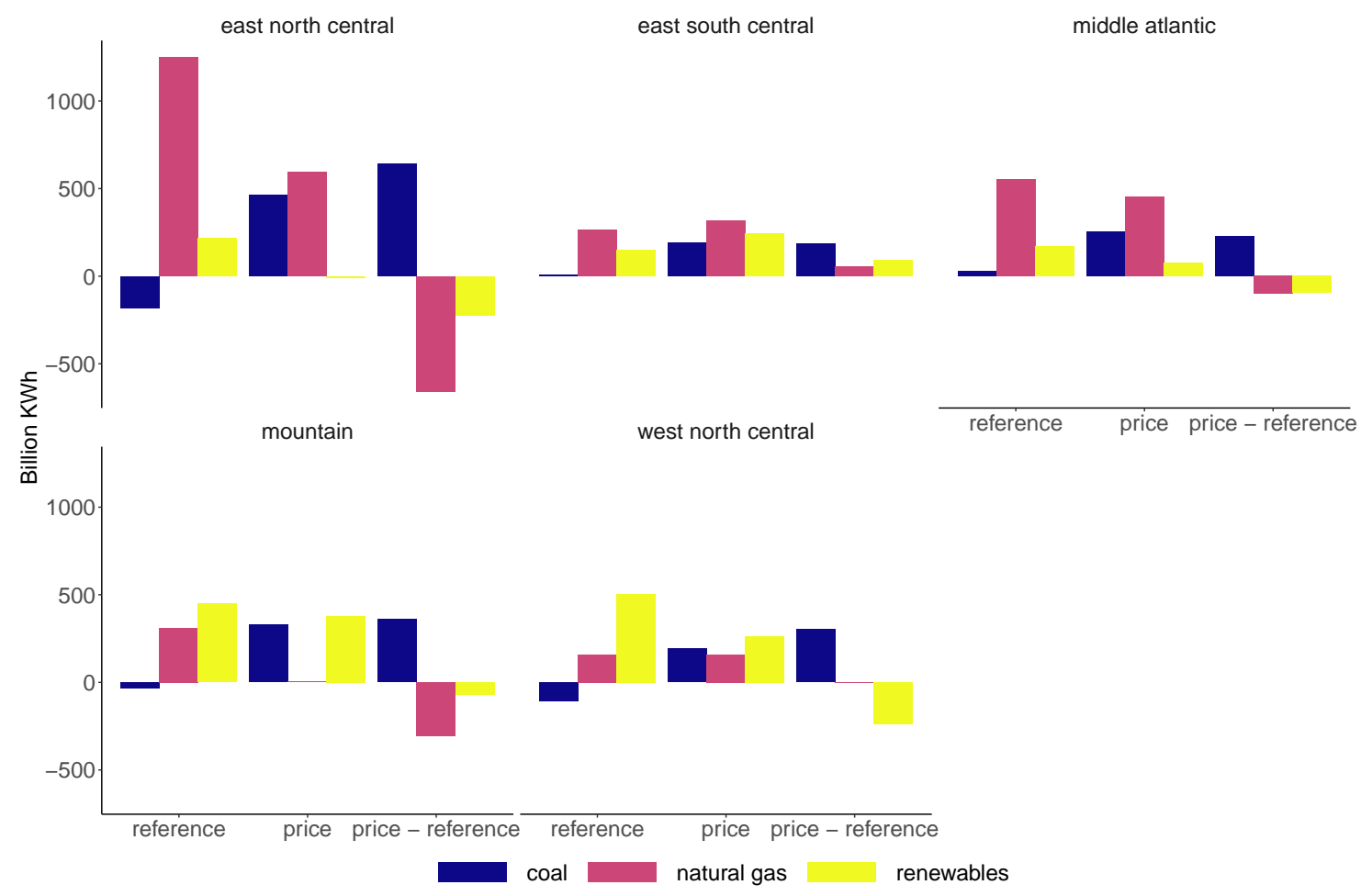

(b) Five regions see an increase in emissions associated with EVs under a carbon price.

Figure D.8: Regional changes in generation from coal, natural gas, and renewables associated with adding EVs in the presence and absence of a carbon price. Part (a) shows regions where EVs reduce emissions more in the presence of a carbon price (i.e., regions where EVs and carbon pricing policy are complementary), and part (b) shows regions where EVs increase pollution damages in the presence of a carbon price. 


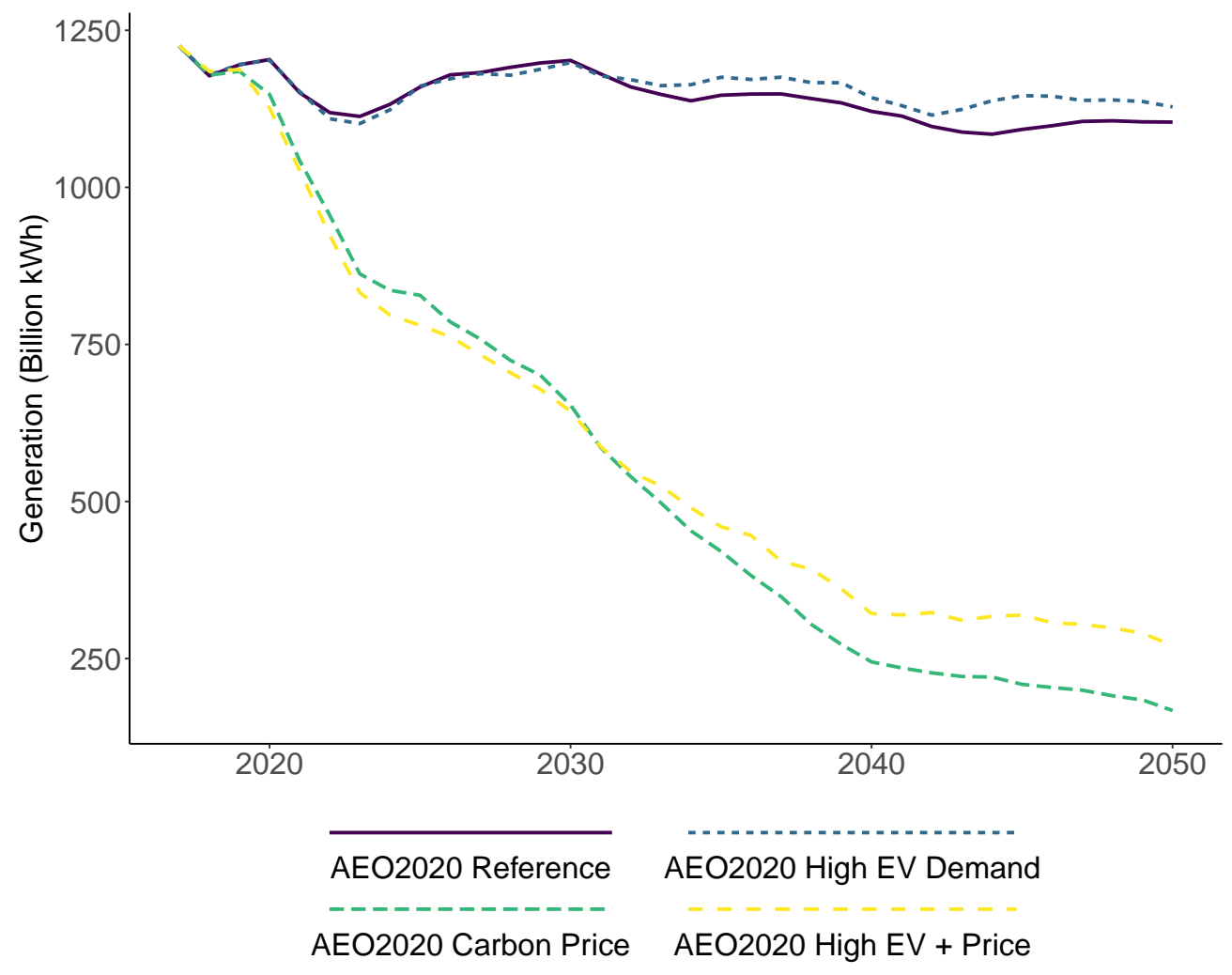

Figure D.9: Coal-fired generation over time under scenarios that replicate AEO 2020 natural gas and renewable assumptions. 


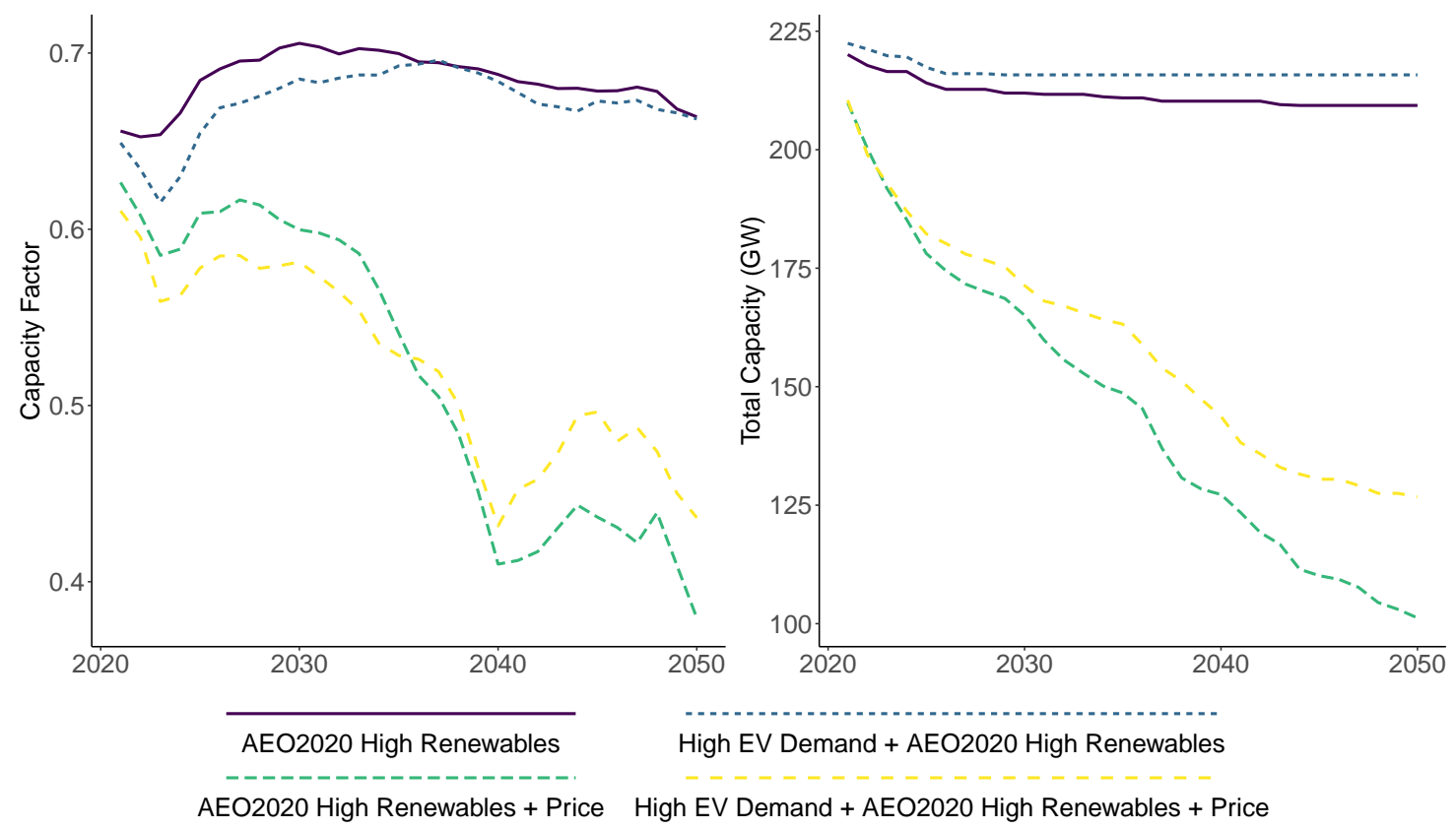

(a) Coal capacity factor (left) and total capacity (right) under the low-cost renewables assumption.

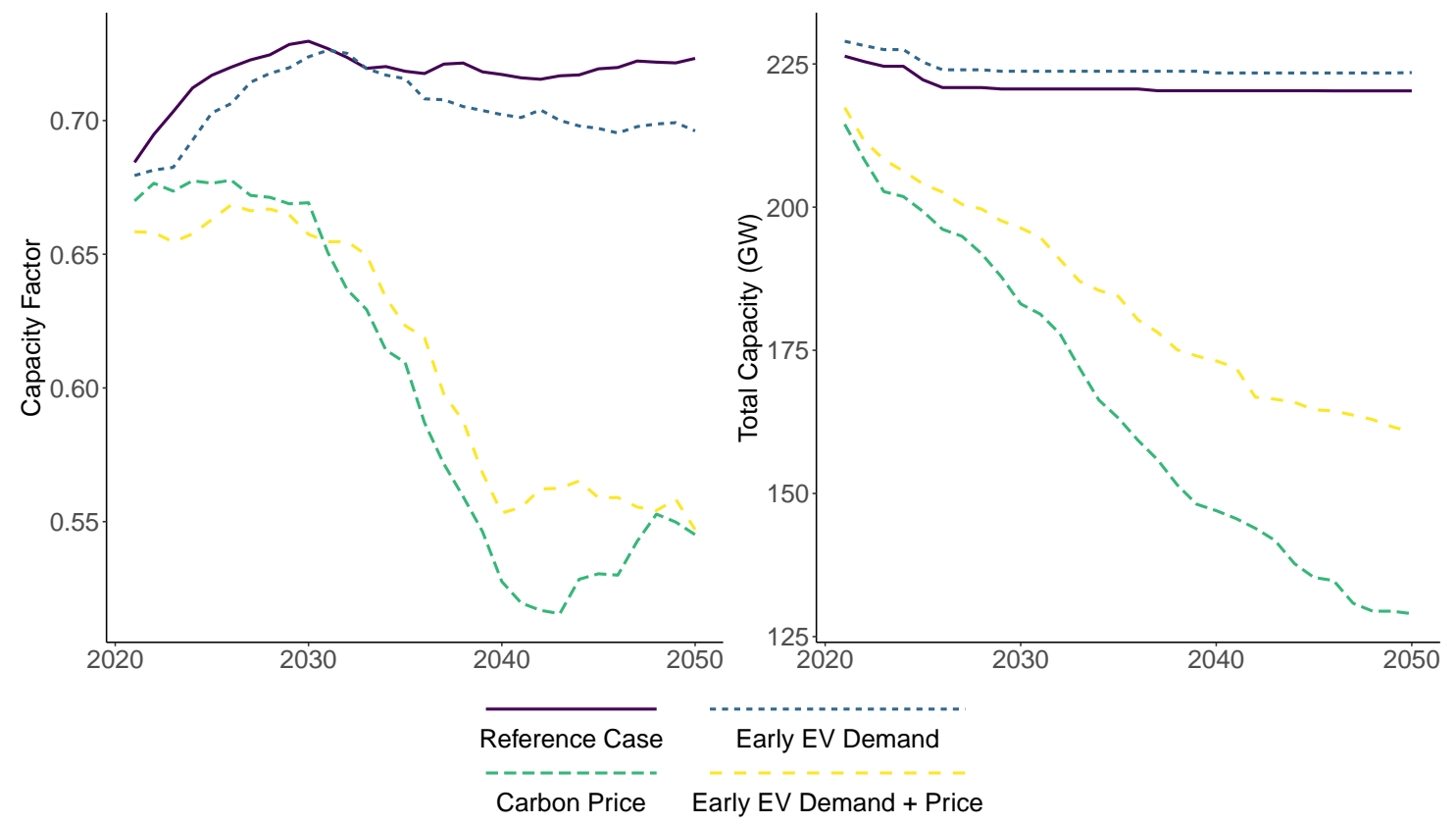

(b) Coal capacity factor (left) and total capacity (right) under the early EV adoption trajectory.

Figure D.10: Coal capacity factor and total capacity for sensitivity cases. 